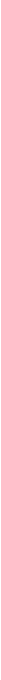

\title{
DEMETRIOS PRIZE 2019! Optimizing T-Cell Culture in Microfluidic Devices
}

Authors: Julia Pinter

Submitted: $\quad$ 16. July 2019

Published: $\quad$ 17. July 2019

Volume: 6

Issue: 7

Affiliation: Hochschule Furtwagen University (HFU), Universitätsklinikum Freiburg, Germany.

Languages: English

Keywords: $\quad$ Demetrios Prize 2019, Winner, CAR T-Cell Therapy, Microfluidics, Machine Learning , International Engineering.

Categories: Demetrios Project, Life Sciences

DOI: $\quad 10.17160 /$ josha.6.7.587

Abstract:

One of the winners, german Julia Pinter, focused his research on the subject of Cancer. Cancer is the disease with the highest mortality worldwide, treated with the same standard approaches for decades. This conventional therapy strategies do not take the evolutionary development of cancer into consideration nor the role of the immune system in this process. Cancer has been shown to hide from the immune surveillance by establishing an immunosuppressive microenvironment. Furthermore, tumor cells are rarely recognized as pathogens by immune cells since they originate from self-material. As a result, there is a recent trend in cancer treatment to redirect the immune system to cancer specificity. In the broad range of immunotherapies, especially the CAR T-cell therapy stands out due to its several advantages of precisely detecting tumor antigens since in this approach autologous $T$ lymphocytes are genetically engineered ex vivo to express chimeric antigen receptors (CARs) which specifically bind to the antigen expressed on cancer cells.

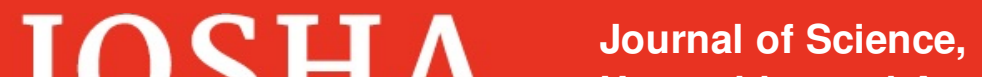 Humanities and Arts}




\title{
Bachelor Thesis
}

in

\author{
International Engineering
}

\section{Optimizing T-Cell Culture in Microfluidic Devices}

\author{
Referent: Prof. Dr. rer. nat. habil. Hans- \\ Peter Deigner \\ Discussant: Prof. em. Dr. Drs. h. c. Roland \\ Mertelsmann \\ Submitted on: $\quad 29.01 .2019$ \\ Submitted by: Julia Pinter \\ Matriculation Number: 251295 \\ Ernst-Ziegler-Weg 16 \\ 74889 Sinsheim \\ julia.pinter@hs-furtwangen.de
}





\section{Abstract}

\section{Thema der Bachelor-Thesis:}

Optimizing T-Cell Culture in Microfluidic Devices

Verfasser: Julia Pinter

1. Betreuer: $\quad$ Prof. Dr. rer. nat. habil. Hans-Peter Deigner

2. Betreuer: Prof. em. Dr. Drs. h. c. Roland Mertelsmann

Semester/Studiengang: 7/International Engineering

Kurzfassung: Krebs ist die Krankheit mit der weltweit höchsten Mortalitätsrate, die seit Jahrzehnten mit den gleichen Therapiekonzepten behandelt wird. Diese konventionellen Ansätze, Chirurgie, Strahlentherapie und zytostatische Medikamente, betrachten weder die evolutionäre Entwicklung von Krebs noch die Rolle des Immunsystems in diesem Prozess. Krebszellen zeichnen sich durch eine immunsuppressive Mikroumgebung aus. Außerdem werden sie von Immunzellen selten als Pathogen erkannt werden, da sie ursprünglich von körpereigenem Material abstammen und sich dadurch vor der Immunüberwachung verbergen. Ein neuer Ansatz, dem Immunsystem von Krebspatienten wieder Tumorspezifizität zu verleihen, ist derzeit ein Schwerpunkt der Krebsforschung. Unter den zahlreichen Ansätzen der Immuntherapie rangt besonders die CAR-T-Zell-Therapie heraus aufgrund ihrer vielfältigen Vorteile wie der genauen Erkennung von Tumorantigenen. Bei diesem Therapieansatz werden autologe T-Lymphozyten ex vivo genetisch verändert werden, sodass sich chimerische Antigenrezeptoren (CARs) auf ihrer Zelloberfläche zeigen, die ein spezifisches Krebsantigen binden. Um die Faktoren, die diese vielversprechende Therapiestrategie noch einschränken wie beispielsweise exorbitant hohe Kosten, zu überwinden, werden mikrofluidische Zellkulturplatformen verwendet, da sie eine drastische Reduzierung der benötigten Reagenzienvolumina und eine physiologische Mikroumgebung, die in Echtzeit präzise 
kontrolliert werden kann, ermöglichen. Um dieses System noch weiter zu automatisieren Fläche, die von in einem selbst hergestellten Mikrochip kultivierten Zellen eingenommen wird, bestimmt und analysiert. Dieser numerische Wert dient als ein Richtwert für die Wachstumsfaktorkonzentration, mit der die Zellen versorgt werden. Da die Anzahl der benötigten Experimente zu hoch ist, um von Menschen durchgeführt zu werden, soll die T-Zell-Kultivierung von Machine-Learning-Algorithmen übernommen werden

Schlüsselwörter: CAR-T-Zell-Therapie, Mikrofluidik, Machine Learning 


\section{Title of Bachelor Thesis:}

Optimizing T-Cell Culture in Microfluidic Devices

Author:

1. Examiner:

2. Examiner:

Semester/Course:
Julia Pinter

Prof. Dr. rer. nat. habil. Hans-Peter Deigner

Prof. em. Dr. Drs. h. c. Roland Mertelsmann

Abstract: Cancer is the disease with the highest mortality worldwide, treated with the same standard approaches since decades. This conventional therapy strategies do not take the evolutionary development of cancer into consideration nor the role of the immune system in this process. Cancer has been shown to hide from the immune surveillance by establishing an immunosuppressive microenvironment. Furthermore, tumor cells are rarely recognized as pathogens by immune cells since they originate from self-material. As a result, there is a recent trend in cancer treatment to redirect the immune system to cancer specificity. In the broad range of immunotherapies, especially the CAR T-cell therapy stands out due to its several advantages of precisely detecting tumor antigens since in this approach autologous $\mathrm{T}$ lymphocytes are genetically engineered ex vivo to express chimeric antigen receptors (CARs) which specifically bind to the antigen expressed on cancer cells. In order to overcome the factors that are still limiting this promising treatment strategy such as exorbitant costs, microfluidic cell culture platforms will be evaluated since they offer a drastic reduction of reagent volumes needed and also a physiologic microenvironment that can be precisely controlled in real-time. In order to further automatize the culture system, the area occupied by the $T$ cells cultured in a self-fabricated microchip is determined and analyzed. This numeric value serves as a guide value for the growth factor concentration the cells are administered with. Since the amount of required experiments is too high to be carried out by human beings, the studies presented here will allow the $T$ cell culture optimization to be taken over by machine learning algorithms in the future.

Keywords: CAR T-Cell Therapy, Microfluidics, Machine Learning 


\section{Table of Contents}

Abstract 3

Statutory Declaration Fehler! Textmarke nicht definiert.

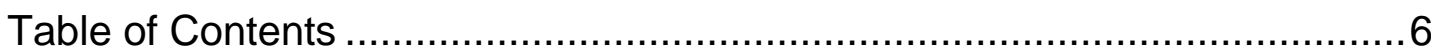

Table of Symbols and Formulas ........................................................ 7

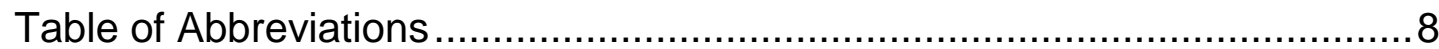

List of Tables ................................................................................. 11

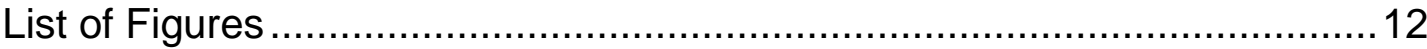

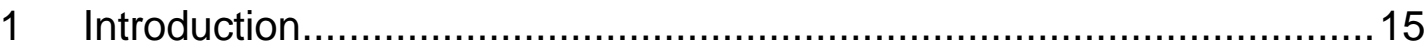

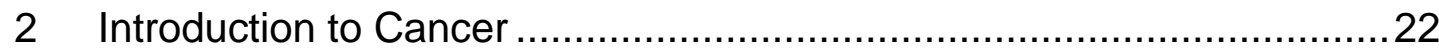

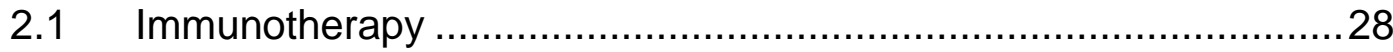

2.1.1 CAR T-Cell Therapy .............................................. 32

3 Introduction to Human T-Cell Culture ............................................. 38

4 Introduction to Microfluidics ........................................................ 46

4.1 Microfluidic Devices for Cell Culture .......................................... 49

4.1.1 Microfluidic Devices for the Cancer Treatment......................51

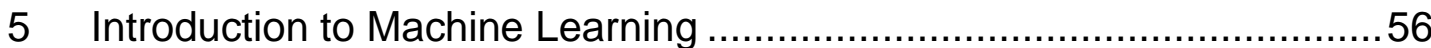

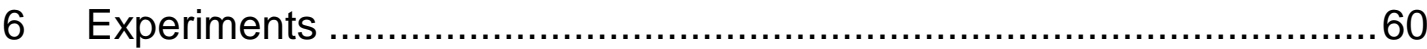

6.1 Materials and Methods ........................................................62 62

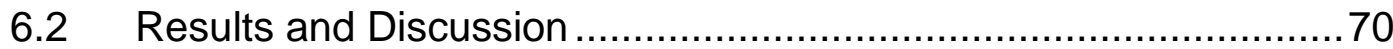

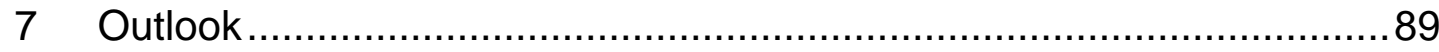

7.1.1 Industrial Interest for Microfluidic Devices ............................91

7.1.2 Industrial Interest for CAR T-Cell Therapy ........................93

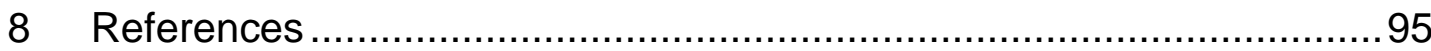




\section{Table of Symbols and Formulas}

$\begin{array}{ll}\varnothing & \text { Diameter } \\ g & \text { G-Force (Relative centrifugal Force (RCF)) } \\ \mathrm{H} & \text { Height } \\ \mathrm{L} & \text { Length } \\ \text { W } & \text { Width }\end{array}$




\section{Table of Abbreviations}

$\begin{array}{ll}\text { ACT } & \text { Adoptive Cell Therapy } \\ \text { ALL } & \text { Acute Lymphoblastic Leukemia } \\ \text { APC } & \text { Antigen Presenting Cell } \\ \text { ASCT } & \text { Autologous Stem Cell Transplant } \\ \text { Ca }^{2+} & \text { Calcium } \\ \text { CAR } & \text { Chimeric Antigen Receptor } \\ \text { CD } & \text { Cluster of Differentiation } \\ \text { CO2 } & \text { Carbon Dioxide } \\ \text { Con A } & \text { Concanavalin A } \\ \text { CRISPR } & \text { Clustered Regularly Interspaced Short Palindromic Repeats } \\ \text { CRS } & \text { Cytokine Release Syndrome } \\ \text { CTLA-5 } & \text { Cytotoxic T-Lymphocyte-Associated Protein 4 } \\ \text { DC } & \text { Dendritic Cell } \\ \text { DLBCL } & \text { Diffuse Large B-Cell Lymphoma } \\ \text { DNA } & \text { Deoxyribonucleic Acid } \\ \text { ECM } & \text { Extracellular Matrix } \\ \text { EFGR } & \text { Epidermal Growth Factor Receptor } \\ \text { e.g. } & \text { exempli gratia (for example) } \\ \text { EMA } & \text { European Medicines Agency } \\ \text { et al. } & \text { et alii/et aliae (and others) } \\ \text { F-actin } & \text { Filamentous Actin } \\ \text { FBS } & \text { Fetal Bovine Serum } \\ \text { FDA } & \text { Food and Drug Administration } \\ \text { GPCR } & \text { G Protein-Coupled Receptor } \\ \text { Her2 } & \text { Human Epidermal Growth Factor Receptor 2 } \\ \text { Hz } & \text { Hertz } \\ \text { i.e. } & \text { id est (that is) } \\ \text { IL-2 } & \text { Interleukin 2 } \\ \text { IL-2R } & \text { Interleukin 2 Receptor } \\ \text { IS } & \text { Immunological Synapse } \\ \end{array}$




$\begin{array}{ll}\text { IT } & \text { Information Technology } \\ \text { JM } & \text { Jurkat cell line } \\ \text { M } & \text { Molar } \\ \text { MACS } & \text { Magnetic-Activated Cell Sorting } \\ \text { MHC } & \text { Major Histocompatibility Complex } \\ \text { ML } & \text { Machine Learning } \\ \text { mRNA } & \text { Messenger RNA } \\ \text { min } & \text { Minutes } \\ \text { Ml } & \text { Microliter } \\ \text { ml } & \text { Milliliter } \\ \text { mm }{ }^{2} & \text { Square Millimeter } \\ \text { NaOH } & \text { Sodium Hydroxide } \\ \text { NCD } & \text { Non-Communicable Disease } \\ \text { NK Cell } & \text { Natural Killer Cell } \\ \text { nl } & \text { Nanoliter } \\ \text { PBMC } & \text { Peripheral Blood Mononuclear Cell } \\ \text { PD-1 } & \text { Programmed Cell Death Protein 1 } \\ \text { PDMS } & \text { Polydimethylsiloxane } \\ \text { PenStrep } & \text { Penicillin-Streptomycin } \\ \text { PHA } & \text { Phytohemagglutinin } \\ \text { PMA } & \text { Phorbol 12-Myristate 13-Acetate } \\ \text { PS } & \text { Polystyrene } \\ \text { RNA } & \text { Ribonucleic Acid } \\ \text { RPMI } & \text { Roswell Park Memorial Institute } \\ \text { scFv } & \text { Single-Chain Variable Fragment } \\ \text { SiO } 2 & \text { Silicon Dioxide } \\ \text { TCR } & \text { T-Cell Receptor } \\ \text { TIL } & \text { Tumor-Infiltrating Lymphocyte } \\ \text { WHO } & \text { World Health Organization } \\ \text { X } & \text { Magnification of Microscope } \\ & \end{array}$





\section{List of Tables}

Table 1: Comparison of different approaches of cancer immunotherapy (adapted based on

Houot et al. 2015: 1118). 


\section{List of Figures}

Figure 1: Correlation of socioeconomic condition and incidences of specific cancer types (Source: Bray et al. 2018: p. 10)

Figure 2: Cancer Hallmarks described by Hanahan et al. (Source: Hanahan et al. 2011: 647)

Figure 3: Cancer-Immunity Cycle described by Chen and Mellman (Source: Chen and

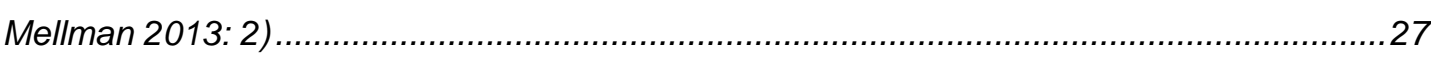

Figure 4: Phylogenetic tree visualizing carcinogenesis (Source: Willyard 2016: 168)..........28

Figure 5: Structure of chimeric antigen receptors (CARs) (Adapted based on June and Sadelain 2018: 66)

Figure 6: Conventional manufacturing process of CAR T-cells (Adapted based on Levine et al. 2017: 93f.)

Figure 7: Effect of repetitive PHA-stimulation (Arrows: PHA-stimulation; black circles:

restimulated T cells; white circles: unstimulated controls) (Source: Cantrell and Smith 1983: 1905)

Figure 8: IL-2 induces the expression of its own expression using purified Jurkat IL-2 (rectangles) or recombinant IL-2 (circles) which can be seen in the rise in $T$ cell proliferation determined by the incorporation increase of IL-2 receptor numbers measured by ${ }_{3}^{3}[H]$ thymidine after 36 hours $(A)$ and in the increase of IL-2 receptor numbers measured by ${ }^{3} \mathrm{H}$-labeled anti-Tac binding after 12 hours (B) (Source: Depper et al. 1985: 4233)

Figure 9: Production of II-2 by Jurkat-JMN cell line $(A)$ and normal PBMCs $(B)$, previously stimulated by PHA (C) and cultured in different medium compositions (white circle: PHA and TPA; black circle: HS and FCS; black triangle: TPA; starlet and diamond: additional cultures using 50\% CM) (Source: Pawelec, Krammer and Wernet 1982: 389). 44

Figure 10: Microfluidic manufacturing process via photolithography (Source: Sommer et al. 2009: 20).

Figure 11: Microfluidic manufacturing process via flexographic printing (Source: Bourguignon et al. 2018: 2)

Figure 12: Microfluidic non-adherent cell culture device developed by Dixon et al. (Adapted based on Dixon et al. 2014: 8) 50

Figure 13: Comparison of conventional 2D and microfluidic 3D approach for in vivo testing of immunotherapies (Source: Adriani et al. 2016: 1477) .52

Figure 14: Microfluidic device for the assessment of the efficacy of engineered $T$ cells developed by Pavesi et al. (Adapted based on Pavesi et al. 2017: 3)

Figure 15: Single-cell interactions between DCs and T cells encapsulated in a microdroplet (Adapted based on Sakar et al. 2015 3)..... 
Figure 16: Basic concept of the system for predicting individual tumor aggressiveness developed by Manak et al. (Adapted based on Manak et al. 2018: 2) 57 Figure 17: Intracellular signaling circuits that control cancer cell function presented by Hanahan and Weinberg (Source: Hanahan and Weinberg 2011: 657)..... 58

Figure 18: Surface of the carcinogenesis simulation model developed by Groten et al. (Source: Groten et al. 2016b: 19) 59

Figure 19: Changes in total tumor blood flow during different treatment regimens (AT-1: decreasing dose of drugs as the tumor responds; ST: conventional method of maximum dose; Ctr: control) (Source: Enriquez-Navas et al. 2016: 5). 60

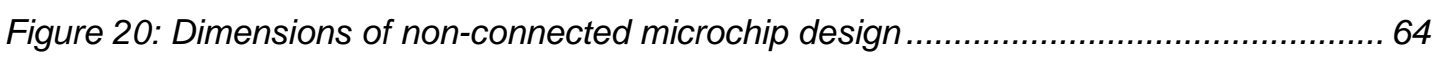

Figure 21: Dimensions of connected microchip design .....

Figure 22: Dimensions of 3D Cell Culture Chip offered by AIM Biotech Pte. Ltd. (a: Length of channels: $10.50 \mathrm{~mm}$; $b$ : Width of gel channel: $1.30 \mathrm{~mm}$; : Width of media channels: 0.50 $\mathrm{mm}$; d: Gap between posts: $0.25 \mathrm{~mm}$; Height of channels: $0.25 \mathrm{~mm}$ ) (Source:

https://www.aimbiotech.com/chips.html) 66

Figure 23: Dimensions of the $\mu$-Slide VI0,4 offered by Ibidi $\circledast \mathrm{GmbH}$.....

Figure 24: a) Jurkat in microdevice after seeding (10X); b) Accumulation of Jurkat cells in the center of a microchamber at the second day of culture (2.5X); c) Jurkat cells at the second day of culture in the microdevice (10X).....

Figure 25: Longitudinal section of the microdevice explaining the cell trapping mechanism 71 Figure 26: Change in area occupied by Jurkat cells treated with two different concentrations of PHA during five days of culture in a commercial microdevice.

Figure 27: a) $10 \times 10^{6}$ Jurkat cells/microchannel after three days of culture (10X); b) $1 \times 10^{7}$ Jurkat cells/microchannels after three days of culture (10X). 73

Figure 28: Different Jurkat cell concentrations after three days of culture in the microdevice (2.5X): a) $1 \times 10^{6} \mathrm{cell} / \mathrm{s} / \mathrm{ml}$; b) $5 \times 10^{5} \mathrm{cell} / \mathrm{s} / \mathrm{ml}$; c) $2.5 \times 10^{5} \mathrm{cell} / \mathrm{s} / \mathrm{ml}$ 73

Figure 29: $5.05 \times 105$ Jurkat cells/ml imaged with $10 X(a))$ and $20 X$ (b)) magnification ....... 74 Figure 30: a) Human T Lymphocytes after seeding (10X); b) Human T Lymphocytes after three days of culture (10X)... 75

Figure 31: a) Jurkat cells in RPMI 1640 containing phenol red stained with a CellTracker ${ }^{\text {TM }}$ concentration of $5 \mu \mathrm{M}(20 X) ; b)$ Jurkat cells in RPMI 1640 without phenol red stained with a CellTracker ${ }^{T M}$ concentration of $5 \mu M$ (20X); c) Jurkat cells in RPMI 1640 medium without phenol red stained with a CellTracker ${ }^{T M}$ Concentration of $2.5 \mu \mathrm{M}(20 \mathrm{X})$.............................. 76 Figure 32: Jurkat cells stained with CellTracker ${ }^{T M}$ concentration of $25 \mu M(40 X)$.................. 76 Figure 33: $5 \times 10^{5} \mathrm{~T}$ cells/m/ stained with $2.5 \mu \mathrm{M}$ CellTracker ${ }^{T M}$ Red CMTPX (40X)........... 77 Figure 34: Magnetic beads used for $T$ cell activation seeded in a self-fabricated microchip and focused using the $10 X(a))$ and the $20 X(b))$ magnification 77 Figure 35: $8 \times 10^{4}$ freshly isolated human Tlymphocytes $/ \mathrm{ml}$ activated with $C D 3 / C D 28$ beads in AIM Biotech microdevice on day 1 of culture (a): 10X; b): 40X) 79 
Figure 36: $8 \times 10^{4}$ human T lymphocytes $/ \mathrm{ml}$ activated with $C D 3 / C D 28$ beads on day 2 of culture in AIM Biotech microdevice (10X) 79

Figure 37: Development of activate $T$ cells in a 24-well plate for nine days receiving different growth factor exposure. .80

Figure 38: Changes in area occupied by human T lymphocytes directly seeded in microfluidic devices and, moreover, activated by magnetic beads and stimulated with 20 $n g / m I I L-2$

Figure 39: Changes in growth rate of human $T$ lymphocytes directly seeded in microfluidic devices and, moreover, activated by magnetic beads and stimulated with $20 \mathrm{ng} / \mathrm{ml} \mathrm{IL}-2 \ldots . .82$ Figure 40: Human T lymphocyte proliferation measured in the area occupied by the cells with different IL-2 concentrations as a second stimulus ..... 83

Figure 41: Human T lymphocyte proliferation measured in the growth rate with different IL-2 concentrations as a second stimulus

Figure 42: Absolute numbers of human T lymphocytes stimulated with different IL-2 concentrations measured with an automatic cell counter after removing the cells from the microdevice

Figure 43: Clear correlation between cell area measured by software and cell number measured by automatic cell counter.

Figure 44: Evaluation matrix considering the microfluidic cell culture platforms used in the course of this thesis project

Figure 45: Closed-loop system for automated and portable T-cell culture 


\section{Introduction}

In the $21^{\text {st }}$ century, the expected life span of the global population is restricted by noncommunicable diseases (NCDs). Among those, cancer contributes most to that massive barrier to ageing with 9.6 million of caused deaths (cf. Bray et al. 2018: 1). The term cancer is being used as a general designation for "diseases caused by uncontrolled cell proliferation and migration" (Smith, E. et al. 2018: 1) capable of spreading aggressively via the blood and lymphatic systems to diverse tissue types found in the human body (cf. Smith, E. et al. 2018: 1). The World Health Organization (WHO) estimates that, in 2018, there will be approximately 18 million new cases of persons diagnosed with cancer worldwide, among whom 3 million will die in the end because of the malignant disease. In general, it can be observed that the number of people newly diagnosed with cancer is increasing continuously. This is principally due to longer general life expectancy. The effects of changes in life style and exposure to novel environmental determinants are presumed to add to the cancer burden. Simultaneously, the numbers of deaths caused by cancer show a negative slope throughout the last five decades. An explanation for this can be found in improvements in diagnosis and therapy as a result of incrementing efforts in cancer research (cf. Bray et al. 2018: 1f.).

These augmented ambitions in improving cancer treatment strategies need to take into account that many basic aspects of this mortal diseases cannot be controlled or battled by pharmaceuticals. This is because their rise is often provoked by certain genome parts, randomly modifying their composition during the process of natural ageing (cf. Smith, E. et al. 2018: 2). Furthermore, the distribution of cancer types is connected to the socioeconomic situation of the respective countries (Fig. 1). It clearly can be claimed that those forms associated with modern life style like lung cancer caused by smoking are "westernized" while viral-caused carcinogenesis is more frequent in emerging countries. Consequently, there also exist inequalities in the availability of 
knowledge and funding for innovation of cancer treatment strategies (cf. Bray et al. 2018: 2).

A

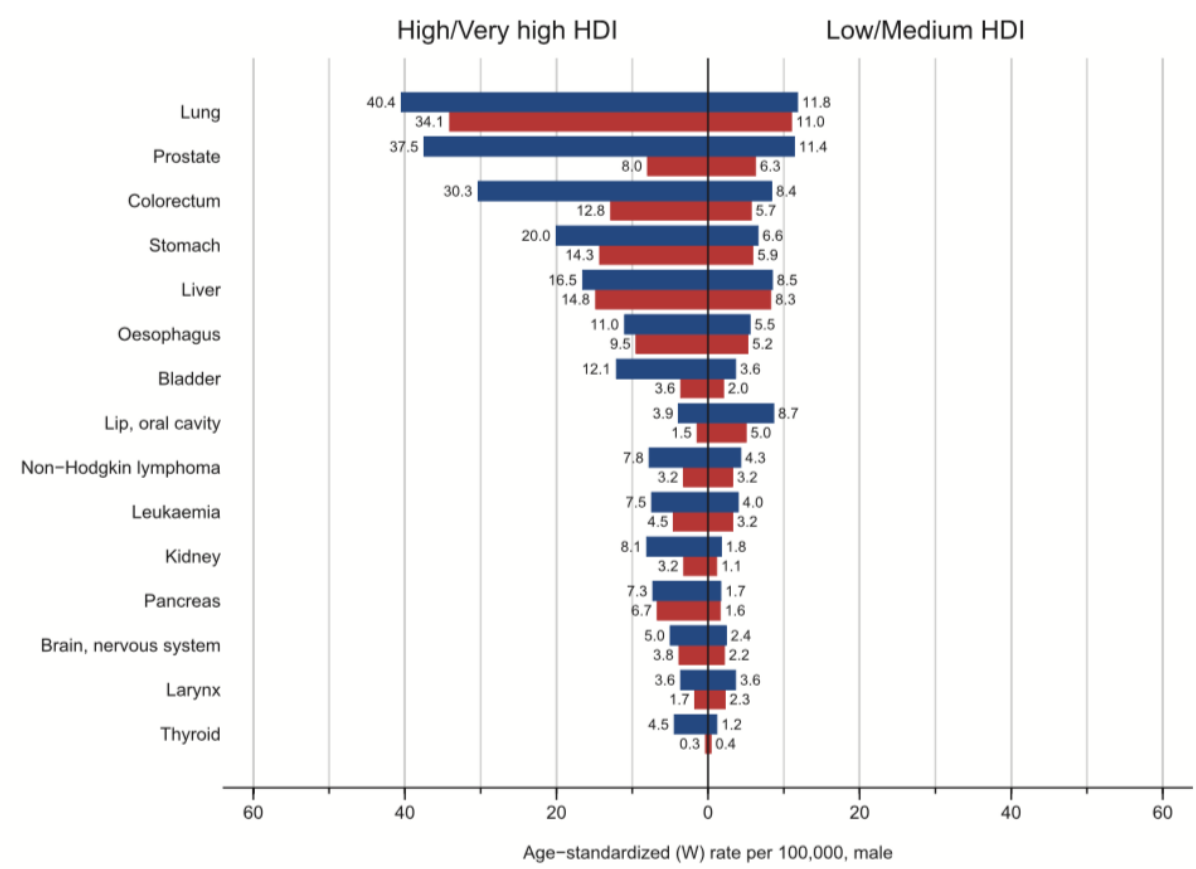

B

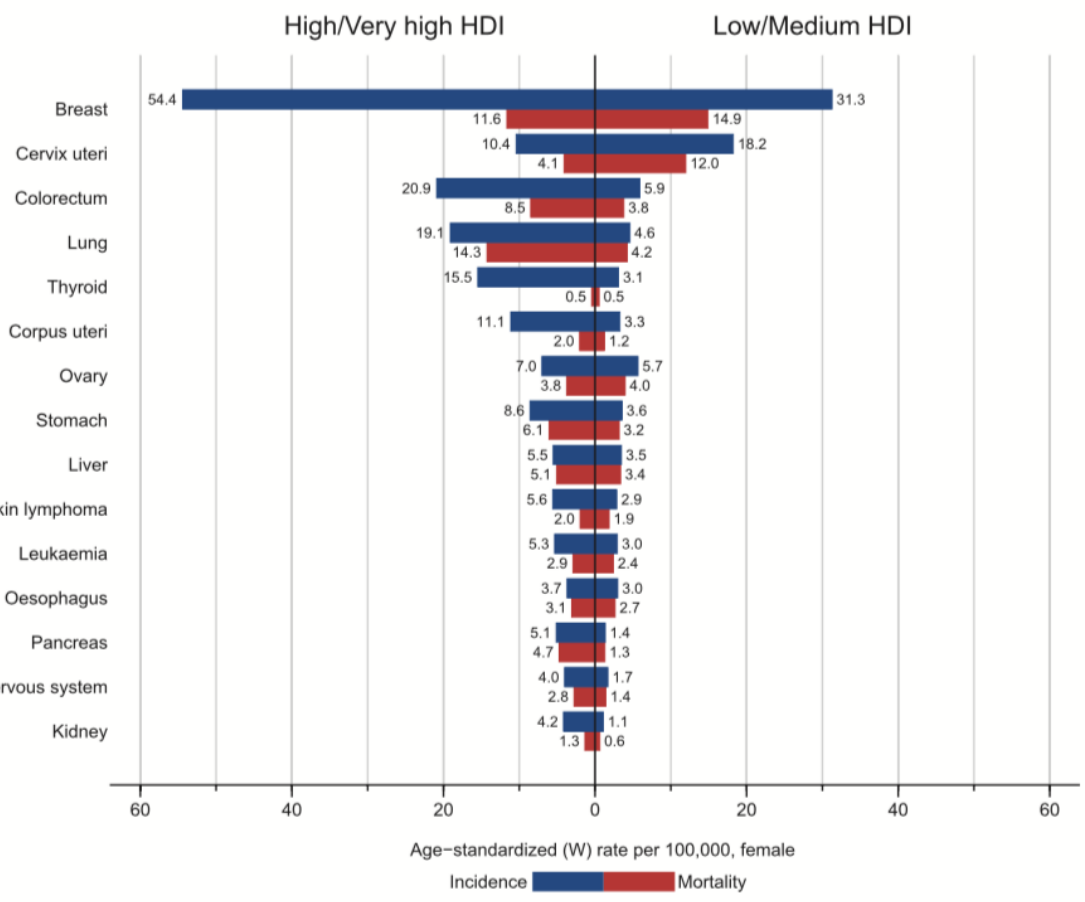

Figure 1: Correlation of socioeconomic condition and incidences of specific cancer types (Source: Bray et al. 2018: p. 10) 
As described above, a basic property of cancer is the development of a population of cells, frequently as solid tumors but also as so-called liquid cancers like leukemia, which are always composed of diverse cell types. This heterogeneity has to be assessed by novel diagnostic as well as therapeutic approaches to be able to eliminate all cancerous cells, at least those which are proliferating.

The classical treatments, cytotoxic chemotherapy, hormonal therapy or radiation therapy, while extending life span and quality of life, are rarely curing cancer (cf. Willyard 2016: 1f.; Hinrichs and Rosenberg 2014: 56).

A novel strategy for treating cancer is based on targeting the therapy to the diversity of cancerous cells. The immune system of the patient is capable of detecting and eradicating pathologic micro-organisms. Since cancer mutations frequently lead to neoantigens, the immune system should be able to recognize them Consequently, adoptive cell therapy (ACT) with cells capable of recognizing and killing cancer cells could become a new pillar in cancer treatment in addition to surgery, chemotherapy and radiation as the immune system of a given patient with cancer apparently is not able to eliminate this malignant disease. This therapeutic approach is based on the administration of autologous $T$ lymphocytes which have been modified in vitro for the detection of specific cancerous cells by genetical engineering introducing tumorspecific receptors on their surface (cf. Hinrichs and Rosenberg 2014: 56f.). This strategy offers several advantages since it does not depend on the administration of cytotoxic drugs as in the case of chemotherapy or on the injection of non-self tissue, thus functioning as a "living drug" dynamically interacting with cancer cells. Another benefit of ACT can be found in its property of taking advantage of the immune system's memory capacity to guarantee long-term protection from carcinogenesis (cf. Houot et al. 2015: 1115).

There are two main methods of manipulating the immune system to redirect it towards eradicating cancer cells: an ex vivo approach using the principles of adoptive cell therapy and an in vivo method based on the administration of antibodies specialized to block receptors involved in T-cell activation. After ex 
vivo expansion, tumor-infiltrating lymphocytes (TILs) have been used with some clinical success (cf. Rosenberg et al. 1988: 1679). However, the collection and generation of TILs requires surgical intervention and tedious as well as expensive laboratory procedures. Another approach studied has been the cloning of autologous (or donated) $\mathrm{T}$ lymphocytes which already express $\mathrm{T}$ cell receptors (TCRs) specialized in the detection of specific cancer cells. More recently, autologous $\mathrm{T}$ lymphocytes have been genetically engineered, specifically redirecting them to detect and bin to antigens expressed by tumor tissue. Autologous $T$ cells can be artificially redirected by genetically engineering them to express chimeric antigen receptors (CARs). An antibody fragment able to bind to molecules particularly expressed by tumor cells is being attached to the intracellular domains of the T-cell receptor. Currently, the most frequently used strategy of in vivo manipulation of the immune sys- 
tem's function is muting the inhibitory signals emitted by activated $T$ cells through the application of monoclonal antibodies.

In order to hinder the tumor-induced inhibition of T cell activation, antibodies capable of binding to the specific surface receptors found on immune cells that control the negative signaling loop between $\mathrm{T}$ lymphocytes are injected to shut down these signals. Due to its functional principle, this immunotherapy approach is called checkpoint inhibition. The main limitation of this therapy method is its unspecificity regarding tumor antigens and frequently the induc-

Table 1: Comparison of different approaches of cancer immunotherapy (adapted based on Houot et al. 2015: 1118)

\begin{tabular}{lll}
\hline & TILS & TCRs \\
\hline Type of therapy & ACT & ACT \\
Drug & Unmodified (naturally & T cells genetically \\
& occurring) T cells & engineered ex vivo \\
isolated form tumors & from peripheral T cells \\
& and expanded ex vivo & to express \\
& recombinant TCR \\
& against a tumor Ag
\end{tabular}

\begin{tabular}{|c|c|c|}
\hline $\begin{array}{l}\text { Requirement for tumor } \\
\text { Ag identification }\end{array}$ & No & Yes \\
\hline $\begin{array}{l}\text { Specificity against } \\
\text { tumor cells }\end{array}$ & Polyclonal & Monoclonal \\
\hline Origin of $\mathrm{Ag}$ targeted & $\begin{array}{c}\text { Intracellular and } \\
\text { extracellular }\end{array}$ & $\begin{array}{l}\text { Intracellular (MHC-I- } \\
\text { restricted T cells) }\end{array}$ \\
\hline MHC-restricted & $Y_{e s}^{a}$ & $Y_{e s}^{a}$ \\
\hline Long-lasting protection & Yes & Yes \\
\hline Off-the-shelf & No & No \\
\hline Personalized therapy & $++++^{b}$ & +++ \\
\hline Main limitations & $\begin{array}{l}\text { Feasibility } \\
\text { Mostly restricted to } \\
\text { melanoma }\end{array}$ & $\begin{array}{l}\text { On-target/off-tumor } \\
\text { toxicity }\end{array}$ \\
\hline
\end{tabular}

tion of sometimes lethal autoimmune syndromes (cf. Houot et al. 2015: $1115 \mathrm{ff})$. Because of the relative ease of use by injection, numerous clinical 


\begin{tabular}{|c|c|c|}
\hline & CARs & Checkpoint inhibitors \\
\hline Type of therapy & ACT & Antibody \\
\hline Drug & $\begin{array}{l}\text { T cells genetically } \\
\text { engineered ex vivo } \\
\text { from peripheral } \\
\text { T cells to express a } \\
\text { CAR (scFv with TCR } \\
\text { signaling molecules) } \\
\text { against a tumor } \\
\text { surface Ag }\end{array}$ & $\begin{array}{l}\text { Antibodies blocking } \\
\text { inhibitory molecules } \\
\text { on T cells to enhance } \\
\text { their function }\end{array}$ \\
\hline $\begin{array}{l}\text { Requirement for tumor } \\
\text { Ag identification }\end{array}$ & Yes & No \\
\hline $\begin{array}{l}\text { Specificity against } \\
\text { tumor cells }\end{array}$ & Monoclonal & Polyclonal \\
\hline Origin of $\mathrm{Ag}$ targeted & Surface & $\begin{array}{c}\text { Intracellular and } \\
\text { extracellular }\end{array}$ \\
\hline MHC-restricted & No & No \\
\hline Long-lasting protection & Yes & Yes \\
\hline Off-the-shelf & No & Yes \\
\hline Personalized therapy & ++ & None \\
\hline Main limitations & $\begin{array}{l}\text { On-target/off-tumor } \\
\text { toxicity } \\
\text { CRS } \\
\text { Tumor escape (loss of } \\
\text { surface } \mathrm{Ag} \text { ) }\end{array}$ & $\begin{array}{l}\text { Autoimmune } \\
\text { manifestations }\end{array}$ \\
\hline
\end{tabular}

trials have been performed

showing tumor regressions and extended disease-free survival. However, overall survival benefits have only been observed in a very limited number of studies (Tab. 1).

The need for a shift in cancer treatment strategies from static towards dynamic targeted therapies focusing on the heterogenous nature of tumors is also supported by the Nobel Price Committee. Consequently, this year's Nobel Prize in Medicine was awarded to James P. Allison and Tasuku Honjo for their contribution to the development of targeted cancer therapy by identifying the specific surface molecules responsible for attenuating the $T$ cell activation process, the checkpoints (cf. Smith, E. et al. 2018: 1).

Since the potential of exploring the immune system to control and possibly eradicate cancer has been convincingly demonstrated, researchers are still confronted with plenty of challenges to realize the proposed ideas on a larger scale. Firstly, T cell physiology is not fully understood. As a result, experi- 
mental progress is hindered for example by the lack of dynamic control of the environment in which $\mathrm{T}$ cells perform their diverse functions. This is why there is an immense need for a new platform which enables investigators to precisely control and visualize the $\mathrm{T}$ cell microenvironment (cf. Dura et al. 2015: 2).

The issue of lacking control of the cellular microenvironment can be assessed by down-scaling the assays utilizing microfluidic devices. This microscale chips composed of minuscule channels with diverse geometrical characteristics offer, among their several advantages, a closer approximation to the in vivo situation (cf. Zhang and Van Noort 2011: 297f.).

The most efficient approach among the different strategies of adaptive cell therapy seems to be the treatment with CAR T cells. This is because their specificity towards detecting cancer cells can be exactly controlled through genetic engineering which often is limited in other approaches. Another challenge in improving the efficiency of adoptive cell therapies against cancer consists in developing the therapeutic approach in view of the multitude of parameters to be taken into account for all ex vivo processes. Possibly, this problem of multiparameter complexity is one of the reasons for the reproducibility crisis (cf. Baker 2016: 454). We hypothesize that the biological and technical approaches can be optimized by controlling the process through the introduction of an autonomous system and machine learning (ML). IT techniques can e.g. "outperform humans at tasks such as image recognition" (Kording et al. 2018: 62) by imitating the memory and learning capacity of the human brain, i.e. Machine Learning (ML) (cf. Chen and Asch 2017: 25072508).

In order to create a flexible cancer treatment approach based on CAR T-cell therapy, the heterogeneity as a basic cancer characteristic has to be taken into account. The challenge of generating in vivo-like conditions to be able to study $T$ cell function and the need for down-scaling experiments with the possibility of augmenting the dimensions will be considered in the course of this thesis. Therefore, it is aspired to develop a microfluidic device for T cell 
activation and proliferation in an automated manner based on Machine Learning. Hence, a self-learning algorithm controls the growth factor administration (and later the gene transduction process) based on computerassisted analysis of changes of cell morphology and the growth of the area occupied by the cells to optimally stimulate $T$ cells. The main objective of the development of this system is to increase the knowledge of $T$ cell function of individual patients to be able to optimally adjust therapeutic parameters to the targeted tumor antigen. The long-term objective of this strategy is to facilitate a personalized medicine as well as cost reduction of this promising but at the present extremely expensive treatment approach.

\section{Introduction to Cancer}

The potentially mortal noncommunicable disease (NCD) of cancer is "characterized by the accumulation of a variable number of genetic alteration and the loss of normal cellular regulatory processes" (Chen and Mellman 2013: 1). This heterogeneity of tumor composition imposes the exposure of novel surface receptors (neo-antigens). Theoretically, these molecules can be detected by the immune system through recruiting $T$ cells specialized in identifying cancer cells by binding to the antigens expressed on pathogenic cells' surfaces. Cancerous tissue is able to circumvent immune surveillance by, for example, hampering the activation and proliferation of $T$ cells resulting in an immunosuppressive tumor microenvironment which guarantees further tumor growth (cf. Chen and Mellman 2013: 1).

Before assessing the interaction between the immune system and cancerous cells in detail, the mechanisms of tumor development and progress have to be clarified. These complex processes seem to follow the fundamental principles of biological evolution defined by Darwin: accumulations of genetic mutations generate cell populations with novel genetic properties as a result of selective forces compelling the cells to continuous adaption to their environment. The basis of applying evolutionary theories to cancer development is the cancer cells' inherent property of genetic instability. The origin of this 
unique feature can be found in the increased number of mitosis causing more frequent genome alterations (cf. Groten, Borner and Mertelsmann 2016a: 36f.).

Another hypothesis in the context of evolutionary cancer progress is the common progenitor clone which divides into numerous subclones that are selected on the basis of their adaption capabilities determined by mutations (cf. Groten, Borner and Mertelsmann 2016a: 37). These sublines can cause cancer relapse but cannot be tackled by chemotherapies since they are not the actual origin of cancer but their progenitor cells. The identification of these cells is crucial to be able to develop cancer therapies specifically adapted to their functionalities (cf. Ding et al. 2012: 509). Since cellular genetic heterogeneity augments with each mutation, it can be claimed that cancer progress is also driven by entropy which is characterized by an increasing molecular disorder (cf. Groten, Borner and Mertelsmann 2016a: 43f.).

Among all the described knowledge on cancer progress given by evolution to determine a therapy targeted to prevent cancer from proliferating, especially the tumor heterogeneity is of importance. As a result, there is a need for a radical change in current cancer treatment approaches since their majority still leaves out the dynamic cancer cell transformation (cf. Groten, Borner and Mertelsmann 2016a: 41).

In 2000, the research group of Hanahan provided a basis for understanding cancer pathophysiology describing general properties of malignant cells during their development involving genetic instability and diversity (Fig. 2). This can be observed in the investigators' statement that 'tumors are more than insular masses of proliferating cells" (Hanahan and Weinberg 2011: 646) but are characterized by high complexity of tissue composition and their surrounding microenvironment. First of all, Hanahan et al. claim that biological mutations lead to the disruption and circumvention of negative proliferative signals needed for maintaining normal structural and functional aspects of cells. According to this research group, this behavior impedes the human body's natural "firewall" of apoptosis that gets applied in case of too high mi- 
tosis rates. Furthermore, cancer cells need to break the barrier of senescence to overcome the limitation in number of cell cycles. In order to guarantee their supply with oxygen and nutrients, cancer cells are capable of inducing the creation of new blood vessels. Probably the most mortal tumor capability described by Hanahan et al. is the potential of metastasis which is a slowly progressing process utilizing the distribution potential of the blood and lymphatic systems. In the 11 years that passed by between the two publications treating with Cancer Hallmarks written by Hanahan et al., the research group identified two novel cancer properties that can be integrated into the original concept of 2000: the dramatic alteration in metabolism negatively influencing cell proliferation and the circumvention of the immune control (cf. Hanahan and Weinberg 2011: 646-654, 657-661).

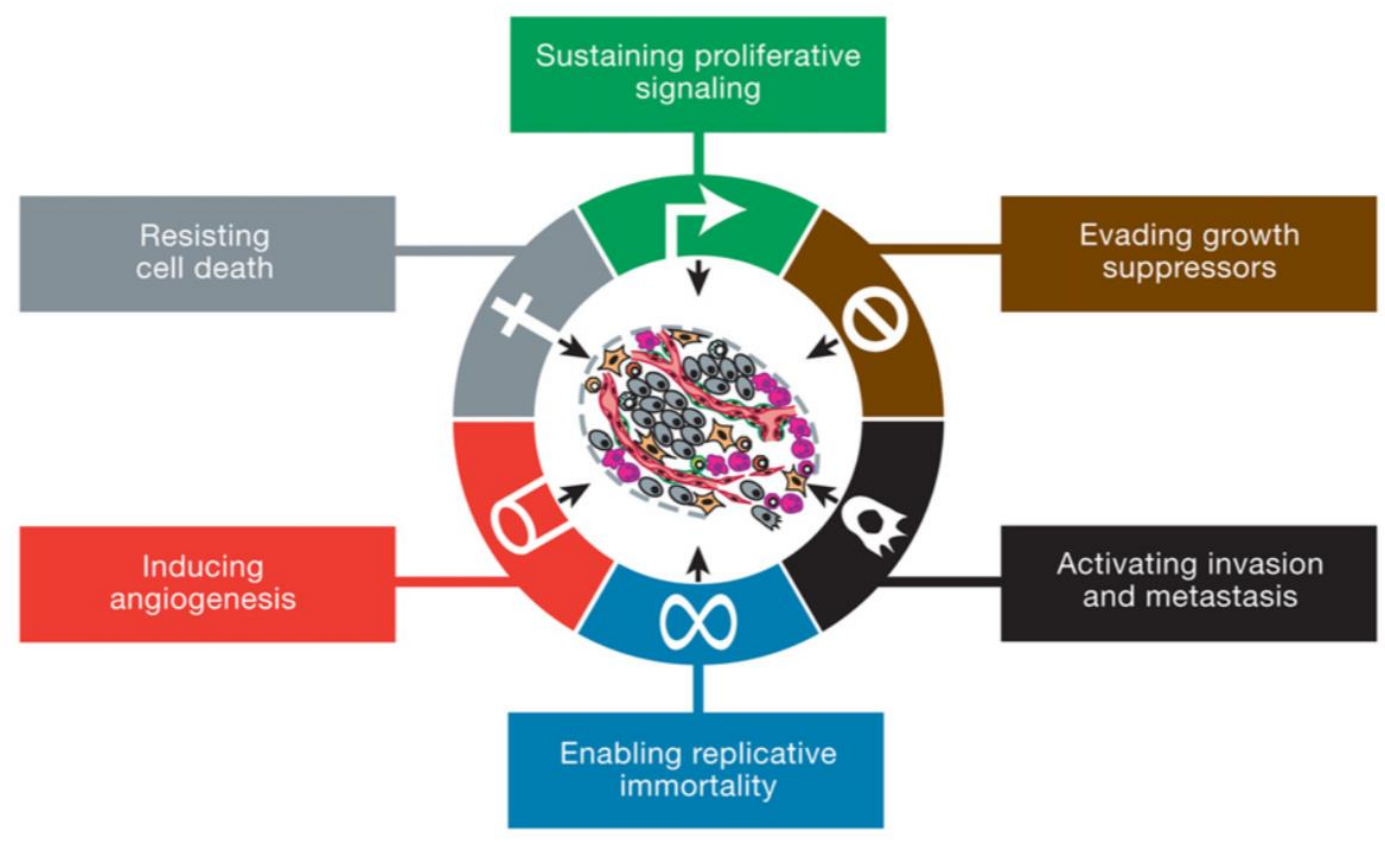

Figure 2: Cancer Hallmarks described by Hanahan et al. (Source: Hanahan et al. 2011: 647)

The immune system seems to play an ambivalent role in treating cancer. On the one hand, it has the capacity to eradicate malignant cells but can be directed by the tumor to support its progression on the other hand. To initiate an effective immune response, direct contact between the immune cells and the malignant cells is required (cf. Dura et al. 2016: E3599). This process can be controlled by two major systems: innate immunity and adaptive immunity. 
The former immunity is highly specific with an extreme multitude of T-cell receptors and immunoglobulin molecules. Moreover, adaptive immunity is responsible for host protection from pathogens that are not eliminated by the innate immune system. Furthermore, it establishes the immune system's memory function which improves its capability of recognizing pathologic intruders. (cf. Smith, A. et al. 2016: 60; Goldman and Schafer 2012: 214).

The basic components for the interaction with cancer of both major systems are $\mathrm{T}$ lymphocytes and antigen presenting cells (APCs). T lymphocytes have the capability of recognizing and killing malignant cells. The first step of this eradication process is getting $T$ cells activated via the interaction with an APC. The, their purpose is changed from resting to effector or memory function. Antigen presenting cells (APCs) are responsible for the control of the two major cellular as well as humoral immune systems. Thus, they guarantee immunity by recognizing pathologic antigens and presenting them to naïve $T$ cells. (cf. Zhao et al. 2018: 540; Guo et al. 2012: 597f.; Boulougouris et al. 1999: 1809; Goldman and Schafer 2012: 214).

To establish an antitumor immunity, the responses of both innate and adaptive systems are required. The innate immune system is able to "recognize and destroy virally infected cells and a range of tumor cells [without being restricted] by the major histocompatibility complex" (June and Sadelain 2018: 66). As a result of its activation, natural killer cells (NKs) are recruited in order to eliminate pathogens. The adaptive immune system, on the other hand, is dependent on antigen presenting cells like dendritic cells. This cell type exposes specific antigens to lymphatic cells in order to initiate their activation and to sensitize them to new malignant intruders (cf. June and Sadelain 2018: 66).

The main challenge of establishing antitumor immunity is that most tumor antigens are detected by the MHC as self-material since they descend from normal cells. As a consequence, they are not attacked by $T$ cells thus avoiding autoimmune reactions (cf. June and Sadelain 2018: 66). Another challenge cancer imposes on the immune system is the exploitation of its nega- 
tive feedback protecting cancer cells from immune surveillance. Upon activation, $T$ cells develop specific cell-surface receptors called checkpoints (e.g. CTLA-4, PD-1) designed to limit proliferative signaling. This is done by blocking the co-stimulation via inhibiting the B7 ligand meant to bind to the CD28 co-receptor on $T$ cells. This mechanism assures that $T$ cells only bind to foreign antigens for a limited time period to avoid autoimmunity and excessive immune responses. Cancer cells exploit this mechanism by binding to these checkpoint receptors. Thereby, the expansion of $\mathrm{T}$ cells targeted to specific tumor antigens is limited (cf. Alberts et al. 2008: 1591f.)

The process of developing a successful antitumor immune response is described by Chen and Mellman suggesting a Cancer-Immunity Cycle composed of seven steps (Fig. 3). Firstly, tumor antigens are bound by dendritic cells in order to present them to T cells using MHC surface molecules. Consequently, $\mathrm{T}$ lymphocytes are activated by the signaling of the presence of non-self-material within the body. As a result, tumor infiltration and the killing of specific target cancer cells is initiated. This being the case, antigens are released from killed tumor cells, returning to the beginning of the cycle. As described above, in the case of cancer the affected cells might be able to avoid their detection due to a variety of mechanisms such as being recognized as self-material or the immunosuppressive effects of the tumor microenvironment (cf. Chen and Mellman 2013: 1f.). 


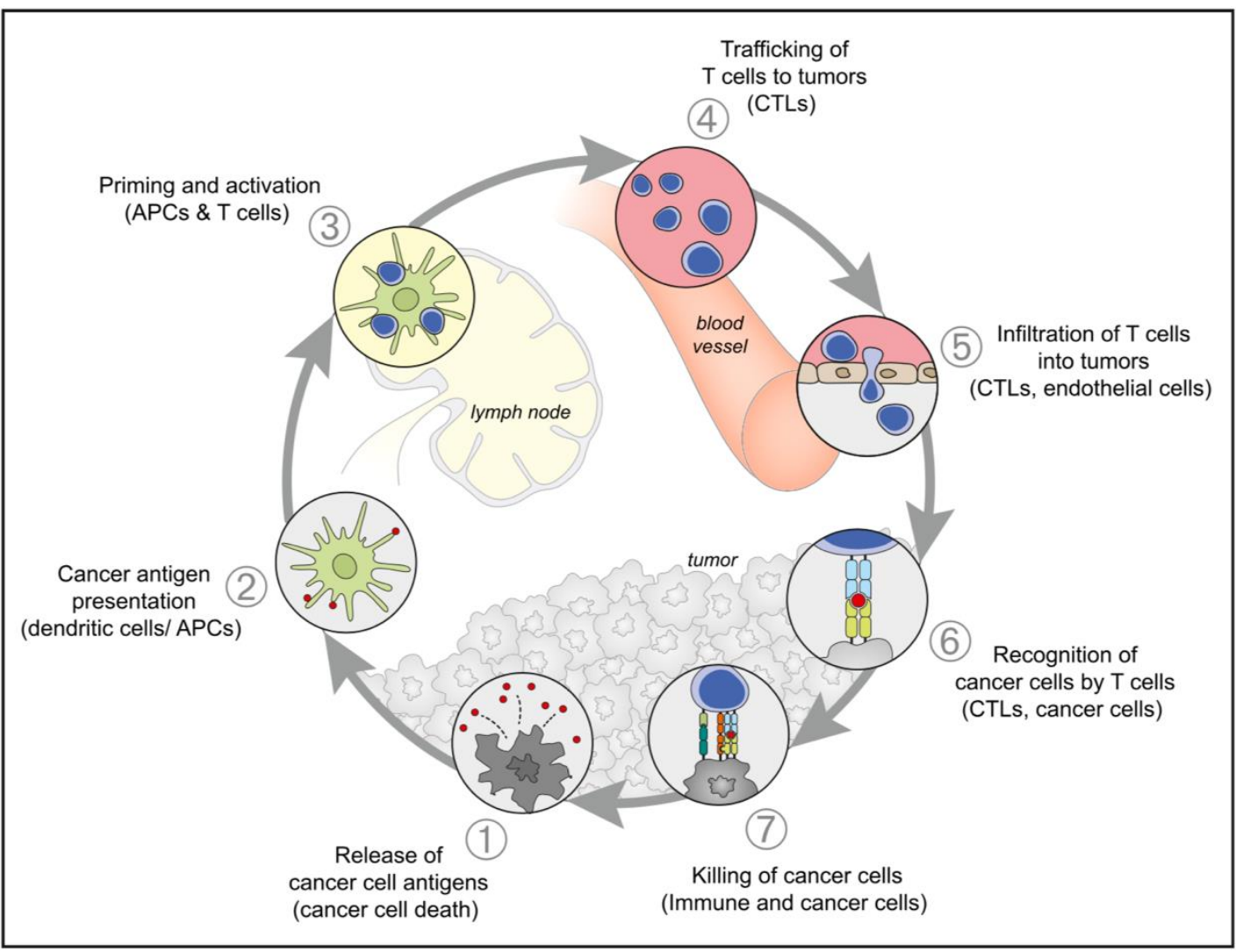

\section{Figure 3: Cancer-Immunity Cycle described by Chen and Mellman (Source: Chen and Mellman 2013: 2)}

To summarize the interaction between cancer cells and the immune system, the outcomes of this process can be divided in three categories: elimination, equilibrium and escape. The former describes the recognition and elimination of cancer cells by the immune system. The next step in cancer development, equilibrium, represents cancer eradication and growth at same velocities maintaining tumor size at the same level. Finally, cancer cells can potentially escape from immune surveillance which happens in most cases of cancer, thus accounting for the most lethal outcome of many malignancies (cf. Smith, A. et al. 2016: 60f.).

Based on extensive preclinical research, immunotherapies are currently experiencing an enormous upsurge in translational research and clinical application in the presence. 


\subsection{Immunotherapy}

Since decades, the mainstay in cancer therapy has not shifted away from its static focus on surgery, radiation and chemotherapy (cf. Gomes-Silva and Ramos 2018: 1). These approaches particularly concentrate on the functional behavior of single cancer cells and on the genetic background of cancer de-

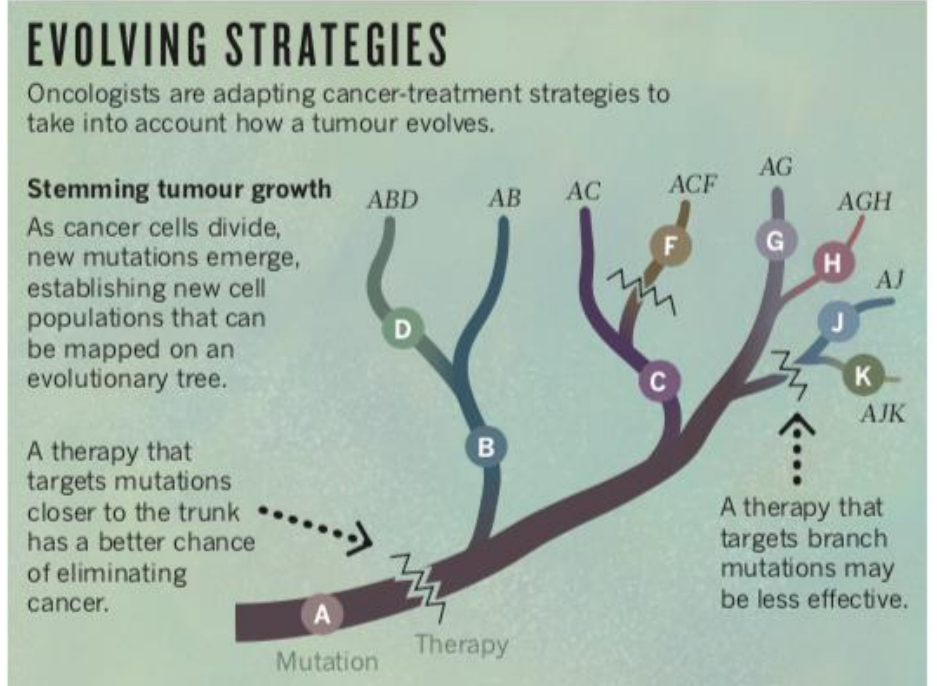

Adapting for balance

Cancer-cell populations compete, so completely killing cells that are sensitive to a particular drug lets resistant cells grow unfettered. Adjusting dosage according to tumour response could maintain balance in the populations.

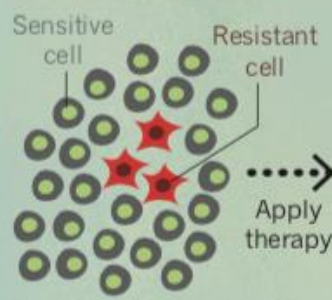

Only some cells are resistant.

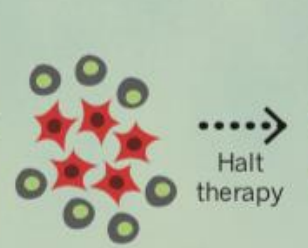

Some sensitive cells remain.

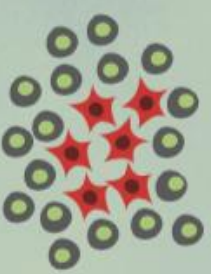

The tumour remains treatable.

The double bind

Developing resistance to one treatment can leave tumours vulnerable to others. Evolutionary modelling can suggest the best way to apply multiple therapies to almost eradicate resistant cells.

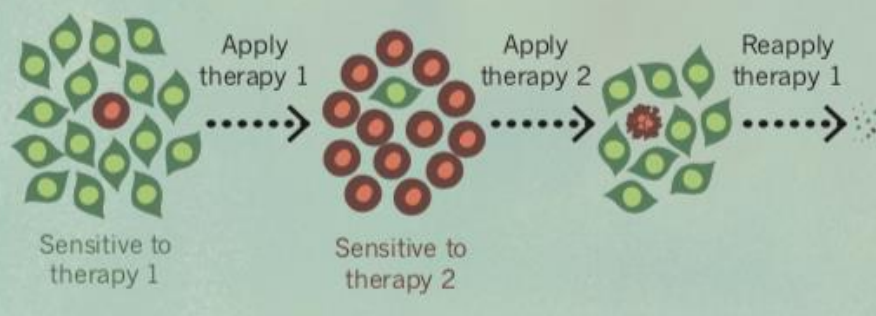
Figure 4: Phylogenetic tree visualizing carcino- mune system's inherent genesis (Source: Willyard 2016: 168)

velopment. The dynamics of tumors can especially be seen in creating a highly heterogenous microenvironment and spreading aggressively to various tissue types in the host's body (cf. Finn 2012: viii7). The complex heterogenous nature of cancer, among its several dynamic features, is getting increasingly revealed by research. Consequently, it is observed that more personalized treatment strategies have to be developed in terms of targeted therapies such as immunotherapies (cf. Gomes-Silva and Ramos 2018: 1).

Immunotherapies take advantage of the im- 
capability to recognize and eliminate pathologic intruders. The reinforcement of that intrinsic property is required in case of cancer eradication from the patient's body since tumors develop ways to circumvent the immune control. Since the immune system provides a memory function storing all pathologic organisms ever detected, it "holds promise of a life-long cure" (Finn 2012: viii7). As the concept of immunotherapies provides leeway allowing for individual therapy targets, it meets the newly arisen need for cancer treatment strategies to be dynamic. This needs to be taken into consideration since the tumor also is due to its continuous adaption to new circumstances evolving in a Darwinian manner. Because of the applicability of the basic principles of biological evolution to tumor development, its progress can be plotted as a phylogenetic tree. Following the basic rules of evolutionary genetics, it visualizes the first cancerous cells in the tree's trunk and the latest mutations in its branches (Fig. 4). To be able to completely eliminate cancer from the patient's body, "drugs tailored to the mutations that drive the growth of [the] tumor" (Willyard 2016: 166) have to be selected and administered. In summary, adaptive therapeutic approaches need to be applied which include immunotherapies in order to perform personalized medicine and exploit its several advantages (cf. Willyard 2016: 166ff).

At the present day, there exist two main approaches to manipulate the immune system's function: ex vivo by adaptive cell transfer (ACT) or in vivo by the administration of T-cell-specific antibodies. The former strategy was fundamentally influenced by the cellular theory of immunity published by Elie Metchnikoff in 1883. This conception states that the host's cells principally guide and control immune responses. The aim of this therapeutic approach consists in programming the immune system against cancer. To reach it, the highly immunosuppressive of cancer which inhibits its recognition by immune cells has to be vanquished (cf. Shukla and Steinmetz 2016: 1116; Finn 2012: viii6). This is why adaptive cell therapy is based on the ex vivo development of a "living drug" consisting of powerful tumor antigen-specific $T$ cells which later proliferate within the patient's body. Consequently, this guarantees a life-long capability of tumor detection preventing relapses of cancer (cf. 
Gomes-Silva and Ramos 2018: 1). One approach in ACT is the administration of autologous lymphocytes extracted from resected tumor tissue which is why this $T$ cells are able to detect cancer cells proceeding from this specific tumor. Due to this ability, they are called tumor-infiltrating lymphocytes (TIL) which are reinfused to the patient after ex vivo expansion. The main limitation of this adaptive treatment approach is the need for a major surgery the patients have to go through to resect tumor tissue. To avoid this burden, the second adaptive cell therapy strategy is based on the genetic modification of autologous $\mathrm{T}$ lymphocytes in order to give them the ability to detect tumor cells expressing specific antigens inside the patient's body. The two most common approaches are, first of all, the cloning of $T$ cells exposing $T$-cell receptors (TCRs) capable of detecting specific tumor antigens in a MHCdependent way. Hence, they rely on the storage of this antigens in the immune system's "memory" through a previous detection of this cancer cells. Avoiding the therapy-limiting MHC-dependence is desirable since cancer cells often suppress their detection by the immune system. To reach this, autologous $T$ cells can be genetically engineered to express chimeric antigen receptors (CARs) which are able to recognize specific tumor antigens without depending on the immune system's memory function (cf. Houot et al. 2015: 1115-1119).

The second immunotherapy approach is based on directly stimulating the immune system in vivo. To retain effector $T$ cells from unopposed activation, there exist many inhibitory signaling pathways. For example, blocking of specific surface receptors responsible for lymphocyte recruitment called checkpoint inhibitors can restrict $T$ cell proliferation. Those signals are often mimicked by cancer cells to circumvent immune detection and consequent elimination. To prevent the exploitation of this mechanism crucial for an effective immune response, antibodies specific for those checkpoint inhibitors are administered. The enormous advantage of this cancer treatment approach is the possibility of universal application independent from the type of antigen that determined as tumor-specific. On the other hand, these characteristic limits the desired specificity of novel therapy approaches at the same time. 
Continuing the list of benefits, it does not require any major manipulations of autologous cells nor a major surgical intervention. The main problem of this therapy is its risk of strong autoimmune reactions. In order to increase the positive therapeutic effect of checkpoint inhibition, it can be applied in combination with adoptive cell therapy strategies increasing the overall treatment efficacy. This is reached by generating a tumor-specific immune response being supported by the removal of diverse signals attenuating $T$ cell activation (cf. Houot et al. 2015: 1119f.).

Since the focus in cancer therapy has been fixated on surgery, chemotherapy and radiation for decades, there has not been realized much research in the field of immunotherapies which is why there still exist several limitations which have to be overcome in the future. Due to this static focus in cancer therapy, most patients finally treated with immune modulation have already run through chemotherapies strongly affect or even destroy a significant part of the lymphocytes due their enormous cytotoxic side effects. Consequently, there cannot be extracted sufficient viable $T$ cells for adaptive cell therapies. The main reason why conventional treatment approaches still are applied before trying immunotherapies is the low throughput and the static character of the current methods for this treatment approach which limits the therapeutic efficiency. Thus, more dynamic procedures are needed to meet the heterogeneity of cancer cells and the individuality of the disease in each patient (cf. Smith, A. et al. 2016: 64; Dura et al. 2015: 2).

Despite these challenges limiting the efficiency of immunotherapies, the adaptive cell transfer approach of genetically engineered autologous $T$ cells expressing chimeric antigen receptors (CARs) shows success rates comparable with conventional cancer treatments, only requiring a manufacturing method with an increased throughput in order to outperform common therapy approaches (cf. Smith, A. et al. 2016: 61). 


\subsubsection{CAR T-Cell Therapy}

CAR T-cell therapy is a promising therapy approach especially for treating hematologic cancers like lymphoblastic leukemia. It offers several advantages but also challenges compared to the conventional cancer treatment strategies of surgery, chemotherapy and radiation (cf. Wang and Rivère 2016: 1).

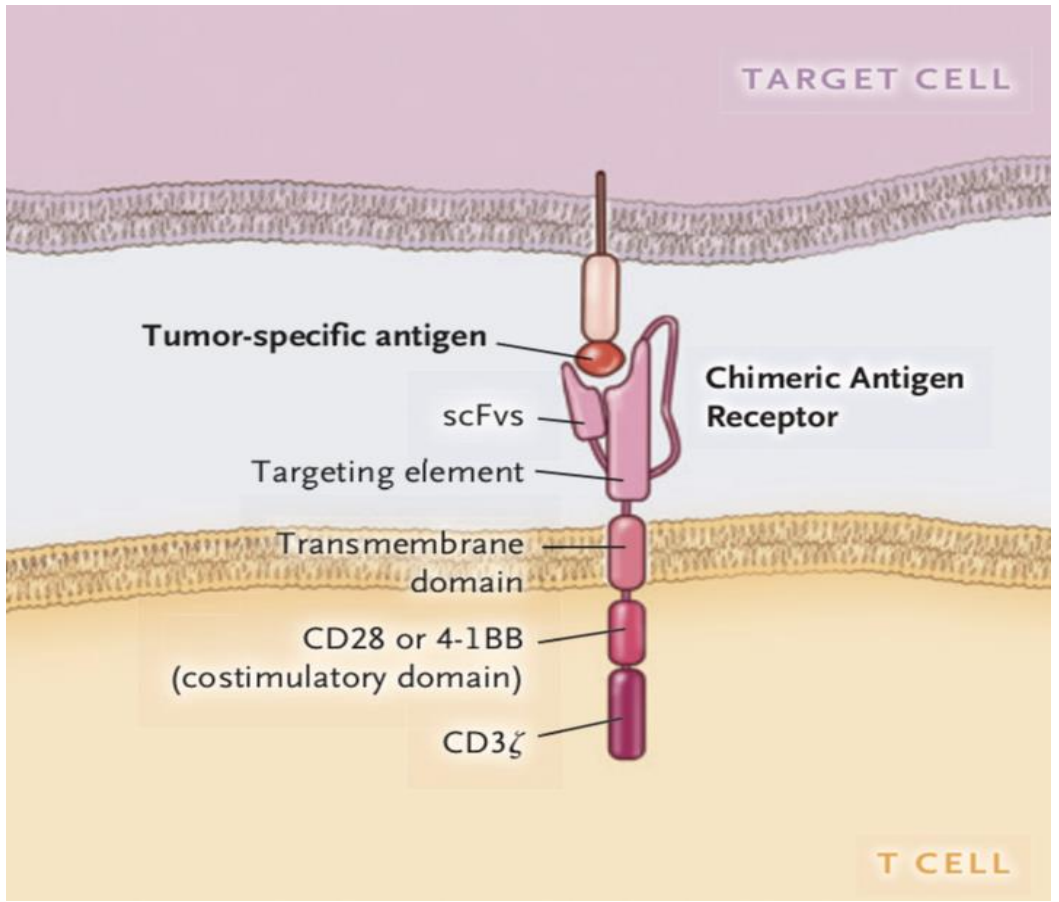

Figure 5: Structure of chimeric antigen receptors (CARs) (Adapted based on June and Sadelain 2018: 66)

The main functional component of genetically engineered $T$ cells used for this therapy is the chimeric antigen receptor (CAR). This Tcell surface receptor can be described as "a synthetic molecule [...] redirecting $T$ cell activity toward an antigen" (cf.

Gomes-Silva and Ramos 2018: 1) capable of binding tumor antigens in a manner similar to antibodies attach to antigens. To fulfill this recognition, a CAR is normally composed of two domains (Fig. 5): an extracellular domain and an intracellular domain. The former consists of a single-chain fragment (scFv) proceeding from a monoclonal antibody with the capability to detect a specific antigen. The latter incorporates signaling sites and originates from a T cell receptor (TCR) (cf. Zhao et al. 2018: 540). Since the firstly generated CARs were lacking selection control of the immune response target, costimulatory domains were aggregated. The associated aim of improving directed $T$ cell proliferation was reached by the expression of a receptor capable of pre- 
cise detection of a specific antigen presented by cancer cells (second generation $\mathrm{CAR}$ ) on the T-cell surface.
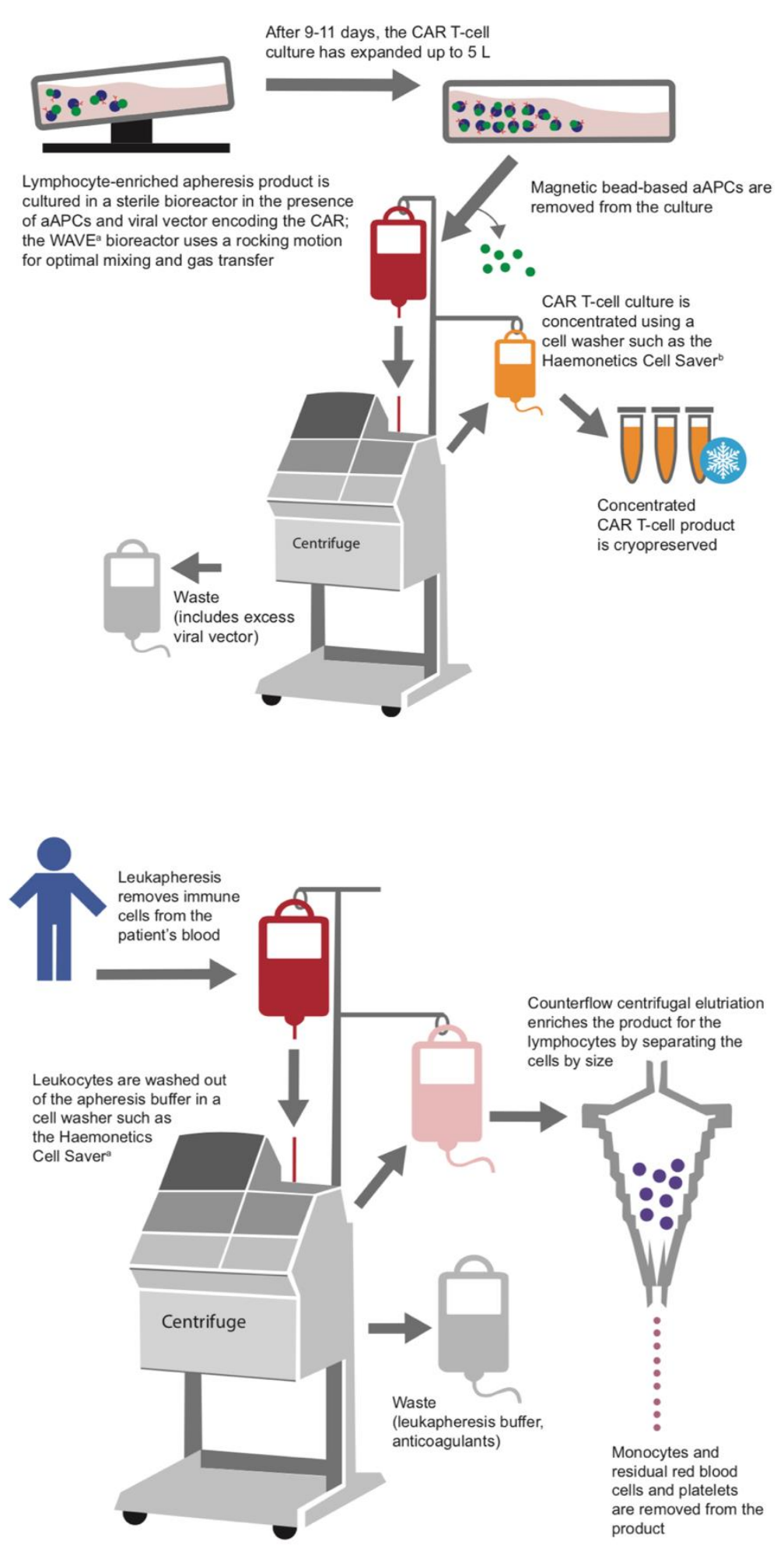

In the course of time, several alterations in costimulatory pathways of CAR T-cells were added. As a result, several generations of CARs differing in their treatment efficiency were created. Nowadays, common targets of CAR T-cells are antigenic surface receptors on hematologic cancer cells, for example CD19 which is frequently exposed by B-cell malignancies. Furthermore, there are already trials in testing the efficiency in eradicating solid tumors by recognizing and binding to surface molecules like EFGRvIII or Her2

Figure 6: Conventional manufacturing process of CAR T- (cf. June and cells (Adapted based on Levine et al. 2017: 93f.) 
Sadelain 2018: 66f.; Gomes-Silva and Ramos 2018: 2). The general strategy of engineering autologous $T$ cells to express CARs can be summarized in facilitating the recognition of a specific tumor antigen by using the detection abilities of monoclonal antibodies. Thus, thus the dependence of presenting the antigen to the $T$ cells to establish a memory prior to being able to detect the tumor antigens for eradication is circumvented (cf. Zhao et al. 2018: 540).

To be able to offer a personalized therapy approach, there exist a variety of different designs and combinations of CAR T-cell components, but the general manufacturing procedure is similar (Fig. 6): firstly, peripheral blood mononuclear cells (PBMC) are separated by leukapheresis from the patient's whole blood. After the isolation of T lymphocytes from the PBMC, those cells are activated ex vivo to induce their proliferation. This process is needed to transfer the gene modulation producing the exposure of CARs. Thus, the modification process is carried out during $T$ cell activation. There are several methods to reach the gene transfer encoding the specific CAR which in general can be categorized in two groups: viral or nonviral systems. The former transmit a lentiviral or retroviral vector into the patient's T cells ex vivo in order to induce a CAR encoding RNA. This molecule is then incorporated permanently by the T cells' genome via the action of reverse transcriptase. As a result, it is passed on to the daughter cells after mitosis. Since the risk of mutagenesis is quite high when utilizing viral gene transfer, nonviral systems have been developed as an alternative. As an example, the transposon system can be mentioned. This transfection instrument is transferred into the $T$ cell genome in form of by plasmid electroporation or into the cytoplasm in form of CAR mRNA to avoid direct gene manipulation. Another nonviral alternative can be found in gene editing tools such as CRISPR to cut apart the $T$ cell DNA and directly insert the CAR encoding DNA. The most effective, tolerable and cost-efficient genetic engineering method used for CAR gene transfer can be seen in lentiviral vectors. For modulated T cell proliferation, bioreactors are conventionally used which enable temperature, movement velocity, gas transfer and nutrient supply control. Finally, T cells expressing CARs are directly reinfused into the patient or cryopreserved for later use (cf. 
Wang and Rivère 2016: 1-3; Levine et al. 2017: 92f.; Gomes-Silva and Ramos 2018: 3f.).

In order to demonstrate the efficacy of the current manufacturing process of CAR T cells and the enormous potential of this therapy to replace the conventional mainstay in cancer treatment, Novartis, a pharmaceutical company based in Switzerland, realized a global phase II trial collaborating with the University of Pennsylvania, USA. This study focused on the investigation of the performance of the CAR T-cell therapy CTL019 in curing relapsed or refractory diffuse large B-cell lymphoma (DLBCL) that only shows a survival rate of $60 \%$ for relapsed patient. For the trial, 99 adult patients from ten different countries which already had received at least two sets of conventional chemotherapy or rejected an autologous stem cell transplant (ASCT) were administered with CTL019. 58\% of all enrolled patients experienced cytokine release syndrome (CRS) and $21 \%$ suffered from neurologic side effects but no person died during treatment. After half a year, 30\% of the infused patients responded completely to the therapy and 37\% partly which shows the enormous potential of this approach in cancer treatment. Thus, in 2017, Novartis applied to the Food and Drug Administration (FDA) and to the European Medicines Agency (EMA) for using CTL019 for the treatment of relapsed or refractory DLBC in adults which was approved in the USA at the beginning of 2018 (cf. Althoff and Phillips 2017: 1-5).

This successful trial shows the variety of advantages CAR T-cell therapy offers for the treatment of hematological cancers: first of all, CAR T cells are precisely specialized in detecting cancer cells since they expose a specific antigen which is individual for each cancer and each person. Furthermore, tumor antigen recognition does not depend on MHC memory function via genetic modification. This is especially advantageous since most tumors hide from being detected by innate immune cells such as dendritic cells (DCs). Another related advantage of CAR T-cells consists in their capability of recognizing tumor antigens in several phenotypical forms. Moreover, through specifically positioning costimulatory domains, the negative effect on the 
pathways of co-stimulation by cancer cells to avoid $T$ cell activation can be prevented (cf. Zhao et al. 2018: 544; Gomes-Silva and Ramos 2018: 2).

On the other hand, there still exist several challenges needed to overcome to reach FDA or EMA approval for treating more cancer types and patients with CAR T-cell therapy. Firstly, the manufacturing process of CAR T cells is complicated, time-consuming, costly and, hence, not yet eligible for commercialization. Furthermore, several therapy-associated side effects were observed such as the cytokine release syndrome (CRS) which is caused by an overstimulation of the immune system via an immense release of cytokines. Moreover, autologous B cells can be eradicated by CAR T cells in case of selecting CD19 as the tumor antigen which normal B cells also express. Other frequent side effects of CAR T-cell therapy are of neurological nature such as seizures or brain edema (cf. Zhao et al. 2018: 544ff). Most of these cytotoxic effects diminish when the targeted cancer cells are eradicated or CAR T cells are removed from the body. In comparison, chemotherapy, belonging to the current cancer treatment mainstay, causes non-reversible cytotoxic effects by generating permanent genetic alterations of various tissue types (cf. June and Sadelain 2018: 67). Another constraint of CAR T-cell therapy can be found in the lacking capability to also recognize antigens hidden in the intracellular space of the cancer cells (cf. Gomes-Silva 2018: 2). Furthermore, this treatment strategy is still mainly limited to hematological malignancies because of the difficulty of identifying target antigens exposed by solid tumors such as melanomas. This is mainly due to their enormously protective microenvironment (cf. Zhao et al. 2018: 541).

As it can be seen, the treatment strategies of using CAR T cells "are not optimized, require frequent administration, are associated with systemic toxicities and only show modest efficacy" (Shukla and Steinmetz 2016: 1116). As a consequence, there an urgent need for a novel technological approach to overcome all these limitations arises in order to exploit the potential of CAR T-cell therapy for cancer treatment. This novel technological approach could be found in nanotechnology which is yet being applied, for example by administrating nanoparticles in order to improve immune stimulation of $T$ cells 
and the tumor microenvironment. In the future, the application of more nanotechnological fields such as microfluidics has the potential to further increase the efficacy of CAR T-cell therapy in order to commercialize the treatment approach (cf. Shukla and Steinmetz 2016: 1116). 


\section{Introduction to Human T-Cell Culture}

T lymphocytes are the main subject of immunotherapies since they are able to eradicate pathological organisms which already have invaded a host cell. As a prerequisite, they need to get previously activated to expand and adopt effector functions. For the activation step, an antigen presenting cell (APC) such as a dendritic cell (DC) is required to uptake and degenerate target antigens in order to express them on their surface. This procedure is required for $\mathrm{T}$ cell recognition using specific MHC proteins. Besides the cytotoxic effector $T$ cells with the capability of eradication pathogen there exists a second type of T lymphocytes: helper effector T cells. This type of T lymphocytes supports the elimination process by promoting phagocytosis, cytotoxic $T$ cell recruitment and antibody secretion by B cells (cf. Alberts et al. 2007: 1539ff).

The first step in eradicating a pathogen from the host's body is the recognition of the target antigen by T lymphocytes presented to them by an APC. In this procedure, two major receptor complexes are involved: the $T$ cell antigen receptor and the MHC protein expressed on the APC surface. The former is composed of three different proteins $(\gamma, \delta, \varepsilon)$ which are able to interact with antibodies against the CD3 complex. Antigen presenting cells such as dendritic cells, macrophages or B lymphocytes are capable of expressing three different types of receptors on their surface: MHC, costimulatory proteins and adhesion molecules. MHC proteins present target antigens ingested by the APC to the $T$ cell ensuring their activation. Similarly, costimulatory proteins support the activation process by establishing a connection to specific coreceptor which can be generally divided in two classes: CD4 which is characteristic for helper T cells and CD8 which is normally displayed on the surface of cytotoxic $T$ cells. Additionally, adhesion molecules are required to strengthen the connection between T lymphocyte and APC, hence prolonging the interaction time (cf. Alberts et al. 2007: 1539ff; Smith-Garvin, Koretzky and Jordan 2009: 592ff). 
T cell activation is achieved by combining two signals: the first signal is generated by a pathologic antigen interacting with a APCs resulting in its exposure on the cell surface via an MHC protein. The second signal is caused by costimulatory proteins expressed on the APC, for example B7 proteins that are ligands to the CD28 co-receptor expressed by T cells. Both signals need to be stimulating the $T$ cell at the same time to avoid apoptosis or inactivation of the cell. Using this mechanism, the immune system prevents autoimmunity by eliminating $T$ cells targeted to self-antigens. The next step of the immune response following the $\mathrm{T}$ cell activation consists in activated $\mathrm{T}$ cells commencing their effector function. In this way they induce and regulate their own proliferation in an autocrine fashion by simultaneously secreting their own growth factor interleukin-2 (IL-2) and upregulating the IL-2 receptor (IL-2R) on their surface. This activates a cascade of complex gene regulation pathways supporting T cell proliferation and differentiation (cf. Alberts et al. 2007: 1569ff; Lipkowitz et al. 1984: 36).

In order to be able to perform adaptive cell therapy with the aim of treating cancer, autologous human T lymphocytes have to be cultured ex vivo. This is a process of high complexity since in vivo $T$ cell development is characterized by a multi-step system. The initial signal for in vivo $\mathrm{T}$ cell proliferation is generated by biologically stimulating the immune cell via antigen-binding. In vitro, $T$ lymphocytes can be activated either chemically or biologically. The former activating process is based on administering a substance imitating antigen property. The latter, on the other hand, can include activating signals originating from single antigens in case of adaptive immunity, from antigens presented to the T cells by APCs or from antibodies corresponding to a T-cell surface receptor (cf. Sarkar et al. 2015: 2f.). These activating substances are not able to induce $T$ cell proliferation. This can be accomplished only by the lymphocytotrophic cytokine interleukin-2 (IL-2), triggering the expression of IL-2 affine receptors on T cells. Thus, the normal functioning of IL-2 as T cell growth factor is facilitated, as previously explained. IL-2 is a minuscule glycoprotein whose functioning is not specific for antigens, hence not directing the specialized immune response. This is done by the requirement of previ- 
ous activation of the $\mathrm{T}$ cell by an antigen in order to be able to bind IL-2 by respective receptors. Functionally, IL-2 is needed for the completion of T cell mitosis which cannot be reached just by antigen activation. Hence, this cytokine is crucial for $\mathrm{T}$ cell proliferation and function. In several assays, the strong dependence of $\mathrm{T}$ cell proliferation on the IL-2 concentration the cells are exposed to has been proofed (cf. Robb and Lin 1984: 247; Dupuis and Bastin 1988: 238f., 244; Cantrell and Smith 1983: 1895f.; Cantrell and Smith 1984: 1312).

On basis of this knowledge, the often-observed variability of $T$ cell growth in vitro can be explained by the appearance and disappearance of IL-2 receptor on these cells. These processes can be mediated by re-introducing the original activating stimulus by an antigen or antibody physiologically or by a lectin non-physiologically. Furthermore, it can be observed in the studies that a reexposure of $T$ cells to their activating stimulus results in faster receptor expression. Consequently, cell proliferation proceeds quicker which can be of importance in the context of adaptive cell therapies since cells need to be produced in a short time period as patients urgently need to be treated (Fig. 7). Not only the IL-2 concentration and duration of binding to its receptor on the $T$ cell surface effects efficient proliferation, but also the density of the re-

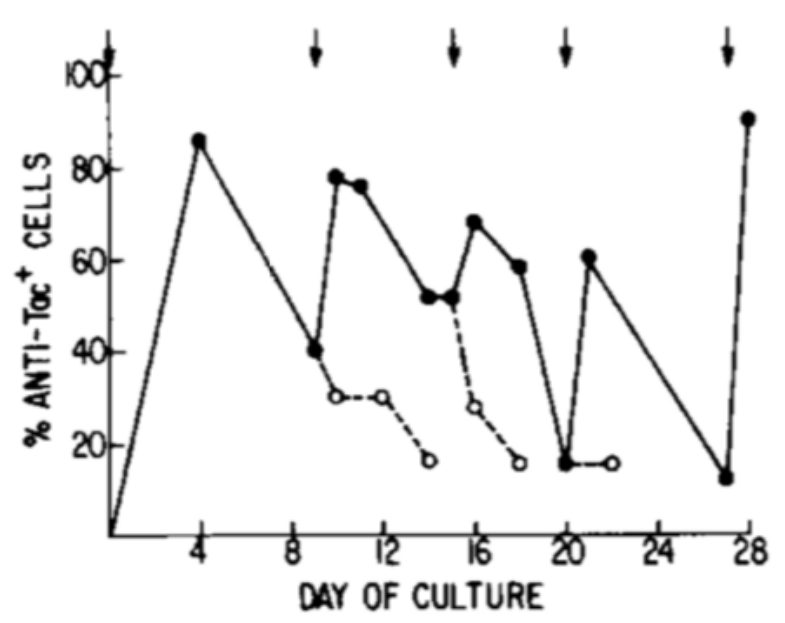
ceptor in the outer cell membrane. This is because $T$ cells with a higher receptor concentration can be induced to expand for a longer time period as their response to decreasing IL-2 concentrations is slower (cf. Cantrell and Smith 1983: 1895f., 1906ff; Cantrell and Smith 1984: 1312ff).

For in vitro $\mathrm{T}$ cell culture, this multi-step activation process has to be mimicked for efficient cell proliferation. This can be reached by the administration Figure 7: Effect of repetitive PHA- of anti-CD3/anti-CD28 monoclonal antibodstimulation (Arrows: PHA-stimulation; black 
ies since the initial signal for T cell activation in vivo is the occupancy of the CD3 antigen, a T cell co-receptor, by an antigen presenting cell (APCs) such as an anti-CD3 antibody. For complete T cell activation, further signaling is needed via interactions between APCs and the immune system. This is physiologically induced by the presentation of anti-CD28 to the respective surface receptors on T cells, resulting in strong autocrine IL-2 production, thus enhancing T cell survival and expansion (cf. Boulougouris et al. 1999: 1809).
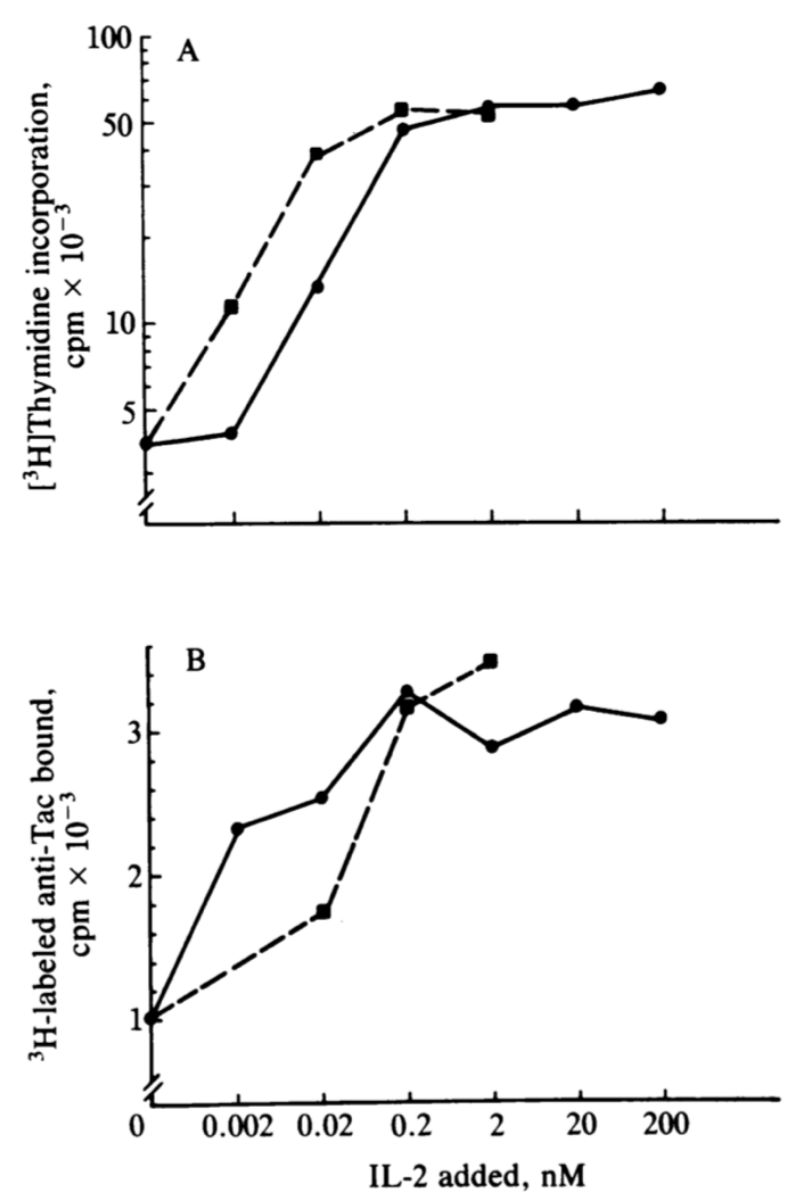

Consequently, the use of beads covered with anti-CD3 and anti-CD28 monoclonal antibodies are a more physiological approach of in vitro $T$ cell stimulation compared to the use of lectins. These molecules are able to recognize specific structures of glycoproteins expressed by $T$ cells as antigen receptors. Furthermore, they have a mitogenic effect on $T$ cells since they induce cell division and, thus, proliferation. The mostly used lectins are phytohemagglutinin (PHA) and concanavalin A

(Con A). Besides lectins, phorbol esters such as phorbol 12-myristate 13-

Figure 8: IL-2 induces the expression of its own expression using purified Jurkat IL-2 (rectangles) or recombinant IL-2 (circles) which can be seen in the rise in T cell proliferation determined by the incorporation increase of IL-2 receptor numbers measured by ${ }^{3}[\mathrm{H}]$ thymidine after 36 hours (A) and in the increase of $\mathrm{IL-2}$ receptor numbers measured by ${ }^{3} \mathrm{H}$-labeled anti-Tac binding after 12 hours (B) (Source: Depper et al. 1985: 4233) acetate (PMA) can be used to support $\mathrm{T}$ cell proliferation since they also show a mitogenic effect. As those nonphysiological substances are less expensive than monoclonal antibodies but have a 
similar effect, they are conventionally - and successfully - used in culturing T lymphocytes in vitro (cf. Trickett and Kwan 2003: 251f.; Dupuis and Bastin 1988: 238f.).

As proposed in this chapter, the induction of $\mathrm{T}$ cell proliferation is thought to consist of two main steps: firstly, a signal generated by a mitogen or an antigen needs to activate $T$ lymphocytes. This, in turn, leads to the mitotic progression of the cells from $G_{0}-G_{1}$ phase into $S$ phase which is associated with the induction of IL-2 receptor (IL-2R) expression. The second step in the initiation of $T$ cell proliferation is a signal generated by the hormone-like lymphokine IL-2 binding to its receptor on the T cell membrane. This finally induces the expansion of those cells that contain IL-2 receptors and, hence, activates them. The expression of this receptors seems to be continuously downregulated. Thus, the administration of IL-2 without repeatedly activated T cells should not lead to cell growth. Experiments carried out by Depper et al. proved the contrary: the research group demonstrated that the upregulation of the IL-2 receptor expressed on T cells theta were previously activated by a lectin can directly be achieved by applying IL-2. Hence, the assumption is admitted that IL-2 is able to generate both the activating and proliferative signals needed for $\mathrm{T}$ cell expansion (Fig. 8). The only prerequisite for this mechanism is the activation of resting $T$ lymphocytes by lectins or antigens at an earlier time point. This finding is of importance because IL-2 seems to be able to induce the re-expression of its own receptor but not the original generation on the plasma membrane of resting $T$ cells. Furthermore, it has been shown that, once the IL-2 receptor is expressed by a $T$ cell, its persistence only depends on the presence of sufficient IL-2. This experimental result states that independence from the activating stimulus generated by an antigen or lectin is reached. Even though T cells secrete IL-2 in a transient manner in vivo, the IL-2 receptor is expressed on the cell surface for a prolonged time period. Its exposure starts after the first IL-2 pulse produced by the T cell since it is required for the receptor upregulation. As of the second stimulation of the IL-2R, the cell growth functions in an autocrine manner (cf. 
Mookerjee and Pauly 1990: 138ff; Depper et al. 1985: 4230; Lipkowitz et al. 1984: 36; Cantrell, Collins and Crumpton 1984: 347).

Moreover, the number of IL-2 receptors diminishes when the activating or the proliferative signals are absent. This leads to the hypothesis that there exists a desensitization mechanism similar to the processes observed in G-protein coupled receptors (GPCRs). These mechanisms seem to limit the receptor signaling in order to avoid overstimulation which could lead to uncontrolled cell growth. The expression of IL-2 receptors on the T cell membrane is proven to be transient. Hence, this could be caused by short-term desensitization. As a consequence, IL-2 receptors would turn into a refractory state but persist on the $T$ cell plasma membrane similar to the mechanism found in GPCRs (cf. Rajagopal and Shenoy 2018: 9ff). A possible reason for this behavior could be the cessation of an immune response, thus preventing an overreaction of the immunologic system (cf. Greene et al. 1986: 29f.). Furthermore, GPCRs show diminished responses to the binding of their agonist during a prolonged period of time due to down-regulating processes. T lymphocytes could use the same manner to avoid excessive proliferation. Moreover, elevated cell growth is required for rapidly treating cancer patients with CAR T-cells. Hence, the conventional used protocol for the step of T cell expansion of continuous administration of IL-2 could be contra-productive since this would trigger down-regulation of IL-2 receptors as a defensive mechanism from overstimulation and carcinogenesis. As a consequence, the application of IL-2 as a T cell growth factor needs to be adjusted to the presence or absence of the respective receptor on the cell membrane, i.e. IL-2 needs to be infused whenever the number of binding sites is decreasing due to down-regulation in order to exploit its capability to reintroduce the expression of its own receptor. 
In order to use in vitro cultured $\mathrm{T}$ cells for immunotherapeutic treatments against malignant structures, studies on the most efficient method to grow those cells ex vivo have to be carried out to reach the best results for the patient. For this purpose, leukemic cell lines such as the Jurkat (also called JM) are used due to their advantages of "unlimited quantity, lack of contamination by normal leukocytes and their convenient availability" (Schneider, Schwenk and Bornkamm 1977: 621). This cell line was originally extracted from the peripheral blood of a 14-year old male human suffering from acute lymphoblastic leukemia (ALL) that relapsed after treatment with chemotherapy. Since Jurkat cells show similarities to healthy $T$ lymphocytes, it was established as an important in vitro model system for investigating $T$ cell physiology.

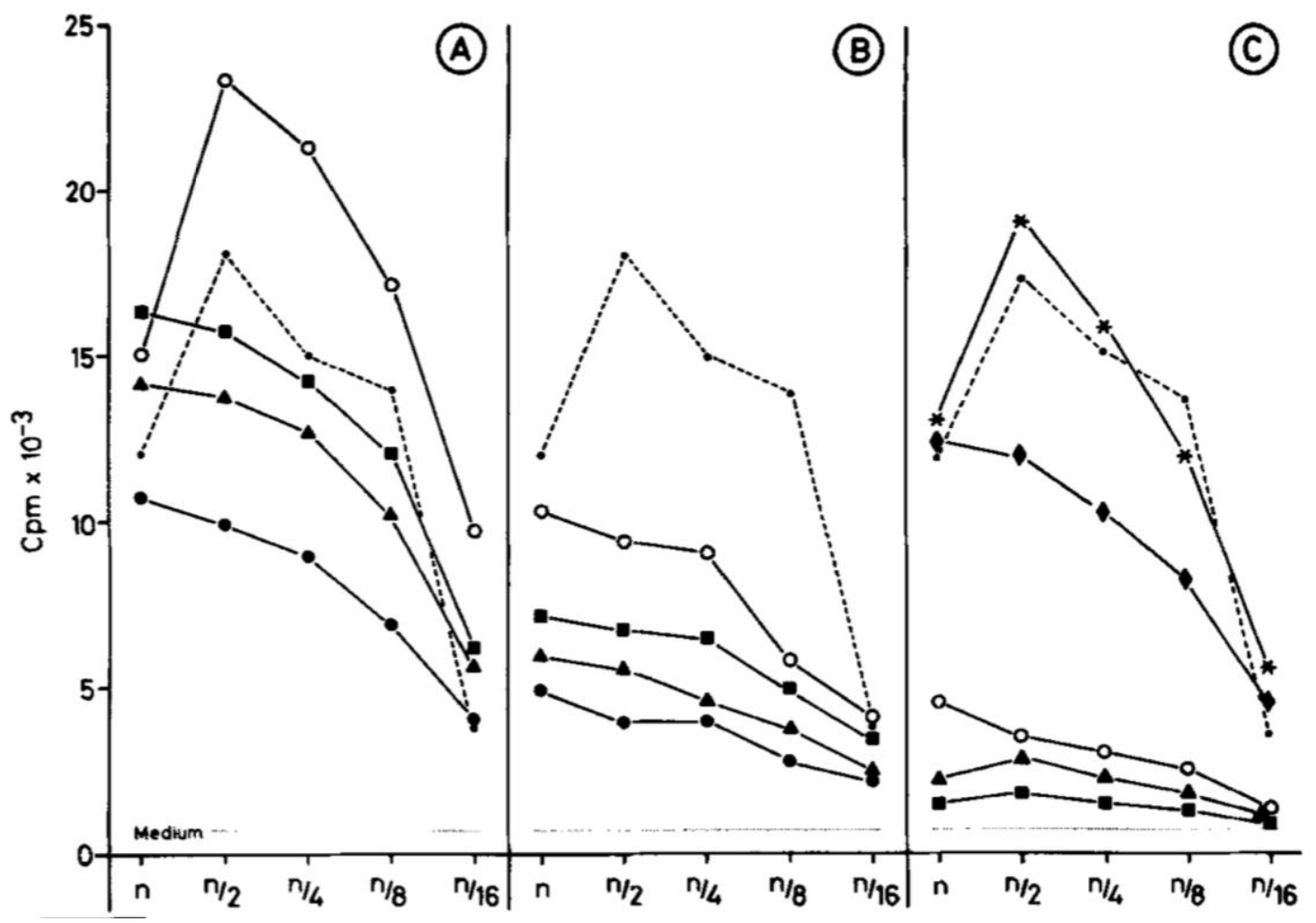

Figure 9: Production of II-2 by Jurkat-JMN cell line (A) and normal PBMCs $(B)$, previously stimulated by PHA (C) and cultured in different medium compositions (white circle: PHA and TPA; black circle: HS and FCS; black triangle: TPA; starlet and diamond: additional cultures using 50\% CM) (Source: Pawelec, Krammer and Wernet 1982: 389) 
Nowadays, several studies have shown that these cells suffer from some mutational gene expression especially in signaling pathways. For example, Jurkat cells show an accelerated cell growth. This made it possible for them to survive chemotherapeutic treatment. Consequently, it is assumed that they produce their growth factor interleukin-2 (IL-2) without the need for a preactivation by an antigen or lectin (Fig. 9). Due to the diverse gene alterations found in this cell line, the optimal combination and dose of growth factors needed to grow $T$ cells in needs to be determined in trials carried out with human T lymphocytes directly isolated from peripheral blood (cf. Schneider, Schwenk and Bornkamm 1977: 621, 623, 625; Gioia et al. 2018: 1, 7; Pawelec et al. 1982: 387). 


\section{Introduction to Microfluidics}

Microfluidics can be defined as "the manipulation and analysis of minute volumes of fluid" (Sommer et al. 2009: 1) offering the alteration of several scientific applications. This is reached through drastically reducing the general component size, thus increasing efficiency of biological assays (cf. Sommer et al. 2009: 1). Microfluidic technologies emerged following the upswing of the microelectronic industry in the 1990s. The main difference between microfluidics and microelectronics can be found in the transferred matter: the former is based on the transmission of electrons within an electric circuitry. The latter offers a broader range of transport capabilities since a variety of liquid reagents can be passed through a micro-tubing. Each fluid has different flow characteristics and each application has specific requirements regarding the device geometry. Consequently, the selection of the material of microfluidic devices is a critical step in production. This complex choice is facilitated in the microelectronic manufacturing as silicone is used as an universal material since decades (cf. Sommer et al. 2009: 3f.; Lee and Lin 2008: 386-388). Since the mid-1990s, polydimethylsiloxane (PDMS) is widely used for the fabrication of microfluidic devices. It can be defined as "[an easy-tofabricate,] transparent elastomer [that] offers chemical resistance and biocompatibility" (Bourguignon et al. 2018: 1). Furthermore, it counts "low cost, flexibility, and rapid prototyping" (Sommer et al. 2009: 19) among its several advantages (cf. Bourguignon et al. 2018: 1; Sommer et al. 2009: 19).

In the last decades, photolithography has been established as conventional production method for microfluidic devices which is based on the sensitive reaction of specific materials to UV light (Fig. 10). This capability of photoresists is exploited in order to obtain a female master mold for the fabrication process. The production procedure principally consists in protecting selected parts of wafer made of the negative photoresist SU-8 from UV light. As a result, a relief of the desired microchannel design is generated which can be used as a master mold for the next fabrication step. After the master mold production, the elastic polymer PDMS is poured over it in order to obtain a 
microfluidic chip. This microdevice contains the designed geometry as concave channels which can be closed by bonding the PDMS block to a crystalline microscope slide (cf. Sommer et al. 2009: 20f.).

Figure 10: Microfluidic manufacturing process via photolithography (Source: Sommer et al. 2009: 20)

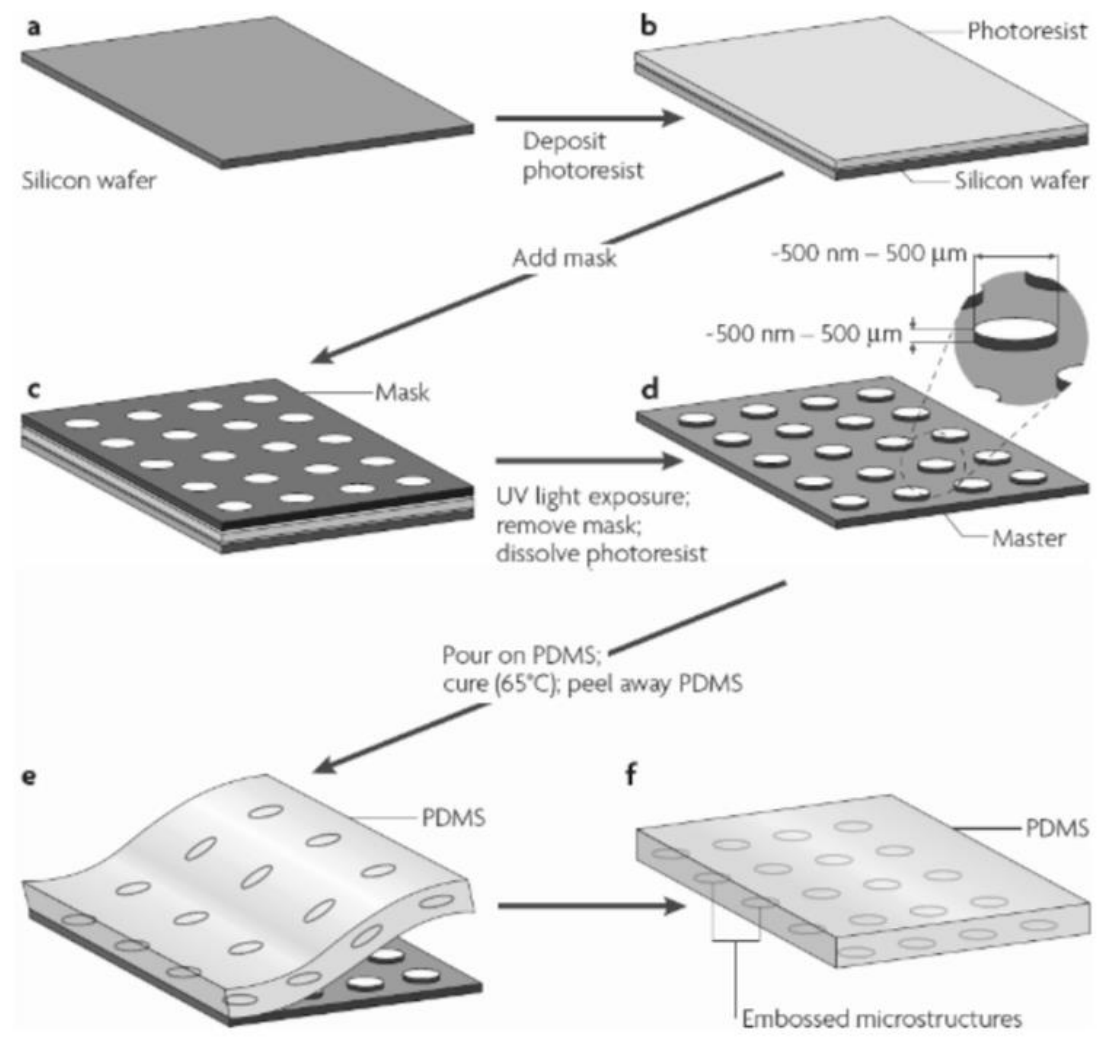

In the course of time, this manufacturing method has been revealed to show several disadvantages such as fragility, limited size and need for a clean room. To circumvent those obstacles and significantly reduce fabrication costs, an alternative production method for microfluidic devices was proposed by Bourguignon et al. The research group developed a procedure based on the use of the photopolymer Flexcel fabricated by Kodak in order to obtain the master mold (Fig. 11). Firstly, the channel design is transmitted to the photopolymeric film with the help of lasers. Next, this polymer is adhered to a printing plate for the process of flexography via repeated exposure to UV light. After this, the photopolymeric film is removed from the flexographic plate since the channel geometry was transferred to the latter by the exposure to UV light. Finally, that plate is put into contact with the solvent PRO- 
SOL N-1 and dried afterwards, obtaining a female master mold. Besides, the obtained mold additionally can be covered with silicon dioxide $\left(\mathrm{SiO}_{2}\right)$ to avoid the permanent bond between Flexcel and PDMS. Without this coating, a second mold made from an epoxy resin has to be created in order to guarantee the removal of the final PDMS chip from its master mold (cf. Bourguignon et al. 2018: 1ff).

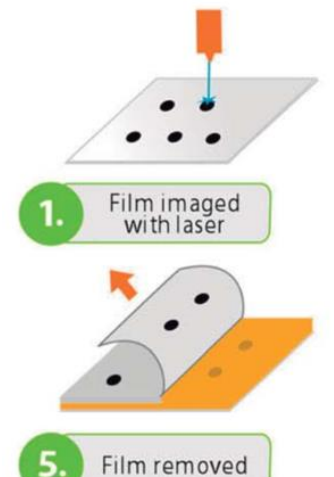

5. Film removed
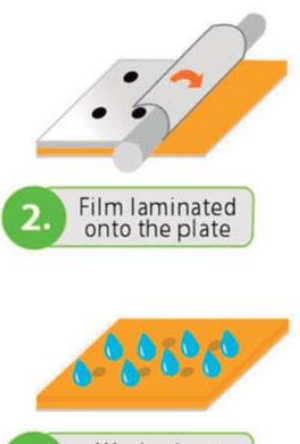

6. Washed out

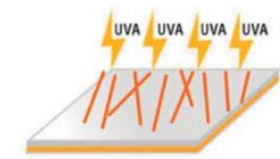

3. Reverse side exposed with UVA light

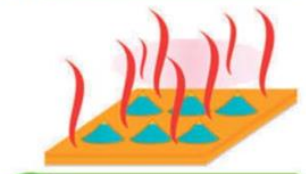

7. Dried with warm air

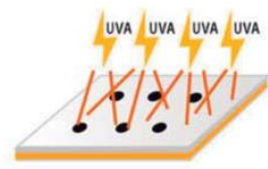

4. Front side exposed with UVAlight

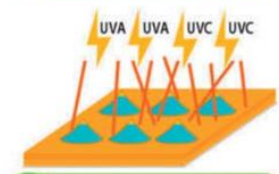

8. Finished with UVA

Figure 11: Microfluidic manufacturing process via flexographic printing (Source: Bourguignon et al. 2018: 2)

As a result of the flexible design and fabrication process, microfluidic devices can be utilized in various scientific fields since they provide several general advantages for biological research. First of all, the devices allow for a more precise control of the fluid flow within the chips which enables the imitation of physiological flow of blood or other body fluids. Furthermore, an environment that closely imitates the physiologic situation can be generated offering more realistic models for more dynamical studies. This is supported by the chips' micro-scale geometry approximating to scales of biological systems like the human body. Finally, microfluidic devices offer the potential of drastic cost reduction in comparison to conventional research methods since they require fewer fluid volume for performing assays which often contribute the costliest part of the experiment (cf. Hung et al. 2005: 1; Mehling and Tay 2014: 1ff; Zhang and Van Noort 2011: 297f.; McCormick et al. 2017: 2). 


\subsection{Microfluidic Devices for Cell Culture}

Nowadays, cell culture can be seen as "an essential tool in biological science, clinical science, and biotechnology" (Hung et al. 2005: 1). Moreover, it is applied in order to increase the knowledge about cell physiology by studying cellular behavior in various assay types such as interaction or response studies (cf. Liu et al. 2008: 5955).

Currently, cell culture experiments are realized by manually analyzing static well plate systems. These platforms do not mimic in vivo conditions since cells sediment at the ground due to lacking exposure to a fluid flow such as the physiologic blood flow. Consequently, the results of such bulk assay often are imprecise since they do not consider single-cell behavior. In order to increase the throughput of cell culture, experiments can be automated by expensive, bulky and complex robotic systems. The main issues of conventional cell culture methods are the labor-intensive and time-consuming manipulation, the lack of physiology, low cost-effectiveness and the missing feature of real-time analysis and long-time tracking. Consequently, a cheaply fabricated, more physiologic, high-throughput cell culture system scale offering realtime analysis is urgently needed. All the named features can be accomplished by a microfluidic device. Through the drastic miniaturization of all experimental components and the unification of them in a single device, microfluidics approximate the physiologic cell environment more closely. Further advantages of these devices are controlled, minute fluid flows and threedimensional micro-scale designs and reduced fabrication and operating costs by diminishing fluid volumes. Furthermore, they offer single-cell analysis in real time, thus inducing a high temporal and spatial resolution. Another benefit of microfluidic devices for cell culture can be seen in the most commonly used material PDMS which offers optimal optical properties for imaging due to its transparency (cf. McCormick et al. 2017: 2; Mehling and Tay 2014: 95ff; Hung et al. 2005: 1f.; Zhang and Van Noort 2011: 297f.). 
A remaining challenge of culturing cells in microfluidic devices is the maintenance of non-adherent cells inside the chips since they could potentially be released during media change. In the last decades, much research was done focusing on the growth of adherent cells in microfluidic devices. This might be a consequence of the fact that no additional cell trapping mechanism had to be developed, such as hydrodynamic traps, antibody-bonding or magnetic fields (cf. Shah et al. 2011: 1002; Dixon et al. 2014: 1f.). Recent progress in creating microfluidic devices capable of non-adherent-cell proliferation was reached by the research of Dixon. This research group proposed a microfluidic device for the culture of the human leukemic cell line HL-60 using a hydrodynamic cell trap. This mechanism captured the cells during automated cell seeding and media changes (cf. Dixon et al. 2014:1) (Fig. 12).

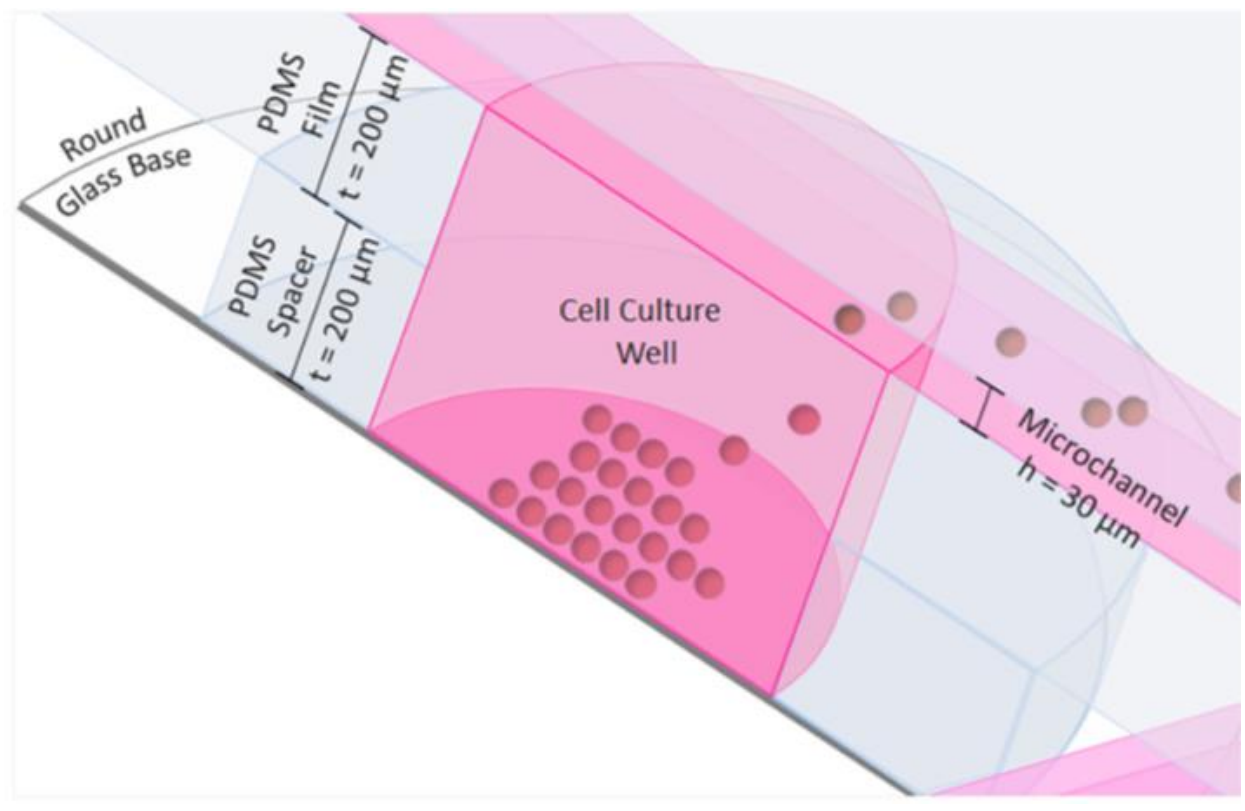

Figure 12: Microfluidic non-adherent cell culture device developed by Dixon et al. (Adapted based on Dixon et al. 2014: 8)

Other approaches for using microfluidic systems as micro-bioreactors for cell culture were presented by Peñaherrera et al. on the one hand who produced recombinant monoclonal antibodies in a microfluidic system (cf. Peñaherrera et al. 2016: 126). On the other hand, Shah and colleagues developed a general micro-bioreactor for non-adherent cell culture based on media change by perfusion. Thus, the flow rates were drastically reduced and, consequently, undesired cell release was prevented (cf. Shah et al. 2011: 1002f.). 


\subsubsection{Microfluidic Devices for the Cancer Treatment}

The recent mainstay in cancer treatment consisting in surgery, chemotherapy and radiation shows a stagnancy in its curing rates. As a result, the focus should shift towards targeted therapies such as immunotherapies and more personalized medicine. The main limitation of this novel approaches is their manufacturing process which is time-consuming. The reason for this obstacle can be found in the fact that cells are cultured (in case of adaptive cell therapies) and genetically engineered (in case of CAR T-cell therapy) in large amounts of volumes which drastically increasing therapeutic costs. In order to improve efficiency and throughput of immunotherapies, microfluidic systems can be used because of their several advantages for cell culture as described in the previous chapter. On the other hand, this gives rise to another issue: most immune cells that need to be modified during cancer immunotherapies are non-adherent cells. Consequently, more complex microfluidic devices would be required (cf. Sommer et al. 2009: 6ff).

The main challenge in developing a microfluidic device that can be used for immunotherapies is the imitation of the tumor microenvironment. This main cancer property is composed of "supporting stroma cells, extracellular matrix (ECM), lymphatic vessels and blood vessels" (Adriani et al. 2016: 1475). As a consequence, it constructs a barrier for immune cells such as $T$ lymphocytes to reach the tumor in order to establish a direct interaction for its eradication. In order to gain knowledge on how to overcome the limitation exposed by the tumor microenvironment, tumor models are being developed. Those ex vivo systems also offer the advantage of estimating the patient's individual response to immunotherapeutic treatments since they might induce a high risk of various side effects. Conventionally, only two dimensions are used to study tumor tissues. Unfortunately, this scheme does not meet the characteristics of cancer cells accumulating in vivo. Another possibility to establish tumor models is realizing the experiments in mice which has the issue of ethical questions and costliness (Fig. 13). Consequently, a third dimension is added to ex vivo tumor models in order to generate realistic conditions with 
the aim of obtaining accurate preclinical results (cf. Adriani et al. 2016: 1475f.). For their implementation, the diverse advantages of microfluidics can be exploited which consist in high temporal and spatial resolution, reduction of reagent volumes needed, transparency resulting in optimal imaging conditions, precise fluid control, immobilization of single cells and cell pairs to study their interactions and migration and the possibility of real-time and long-term cell analysis (Fig. 13) (cf. Adriani et al. 2016: 1477; Dura et al. 2015: 2).

(a) 2D standard tissue culture

(b) In vivo mouse model
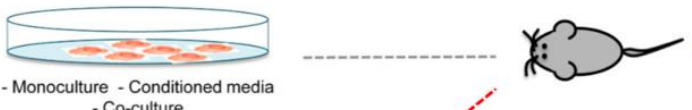

(c) 3D microfluidic technology for $T$ cell cancer immunotherapy

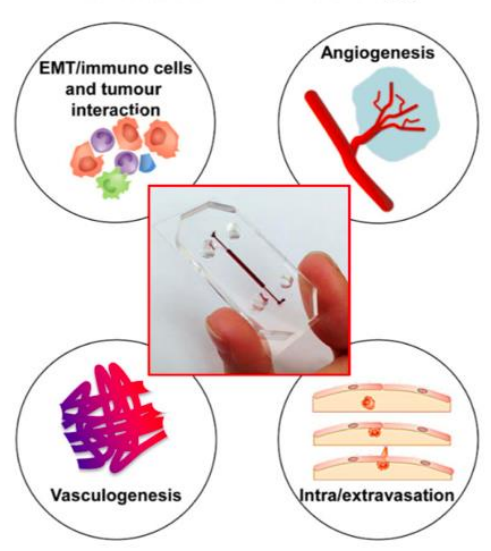

Advantages of 3D microfluidic tumor models

- Multicellular co-culture in a 3D ECM-

like matrix

Reduce reagents

Control oxygen level

Control spatiotemporal parameters

Visualise in real-time cell interaction/migration/adhesion

- Modulate cytokine administration

Address engineered T cell efficacy in a physiologically relevant TME 
3D assay

Chemotaxis migration in xyz direction

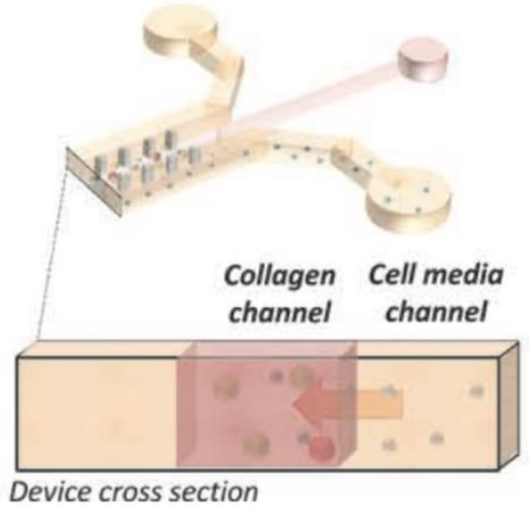

Figure 14: Microfluidic device for the assessment of the efficacy of engineered $T$ cells developed by

Pavesi et al. (Adapted based on Pavesi et al. 2017: 3)
In the recent past, various 3D tumor models for preclinical purposes have been developed. For example, Bersini et al. proposed a system to study the metastasis production in different organs by several cancer types such as breast cancer or prostate cancer. Furthermore, Bischel and colleagues created a 3D tumor model to study the behavior of ductal carcinoma cells. Moreover, the research group of Bai used a similar system to perform research on the immune interaction between macrophages and adeno-

carcinoma cells (cf. Adriani et al. 2016: 1477f.). The most recent model to study the interaction processes between immune cells and the tumor environment has been developed by Pavesi et al. The main objective of this research group was to study the eradication efficacy of adaptive cell therapies regarding solid tumors. This represents a novelty in cancer research since CAR T-cell therapies currently are only capable of curing non-solid, hematologic cancers. With the help of their device, solid cancer cells can be fixed within an extracellular-matrix-mimicking gel creating a physiological 3D structure. This used to establish interactions between artificial ECM and later infused $\mathrm{T}$ cells. Consequently, the proposed system can help gaining knowledge in selection characteristics of tumor antigens. Moreover, it offers insights in the immunosuppressive barriers of the tumor microenvironment which have to be overcome by the immune system (Fig. 14). Applying this device instead of 2D systems or murine models, costs can be drastically reduced, and negative side effects caused by $T$ cell incompatibility can be prevented (cf. Pavesi et al. 2017: 1f., 14).

Since a main characteristic of cancer cells is heterogeneity, research has to be adapted to meet the requirements for studying individual, heterogenous 
cell responses. Conventionally, single cells are analyzed using flow cytometry which provides a high-throughput analysis platform for multiple cell types. On the other hand, it is mainly limited by a low spatiotemporal resolution, thus not permitting a real-time observation of cell-cell interactions and singlecell behavior. The use of microfluidics could potentially overcome those limitations by providing a dynamic approach for cell analysis. Yet, there exist several trapping strategies for adherent cells such as nanowells, but systems for isolating non-adherent cells from their neighbors are still scarce. The approach providing the best performance in single-cell analysis are droplet microfluidics. This strategy is based on the generation of microbubbles by unifying an aqueous phase normally containing cell growth media and an oil phase. Since this phase is immiscible, the mixing with the aqueous phase is avoided (cf. Sarkar et al. 2015: 2; Garstecki et al. 2009: 164f.).

In immunotherapeutic cancer therapy, droplet microfluidics could be applied for tracking immune cell responses, hence overcoming the limitations of conventional static approaches. For example, Konry et al. developed a microfluidic droplet generation device capable of measuring the cytokine production on single-cell level by encapsulating $T$ cells in individual droplets. Furthermore, the analysis of the interaction dynamics between immune cells and tumor cells is crucial in developing an immunotherapeutic approach. For this purpose, Sakar and colleagues have developed a microfluidic device for encapsulating distinct immune cells. Thus, the interactions between $T$ lymphocytes and dendritic cells (DCs) can be monitored as they are trapped in the same droplet (Fig. 15) (cf. Seah, Hu and Merten 2018: 49-54; Sakar et al. 2015: 2f.). 


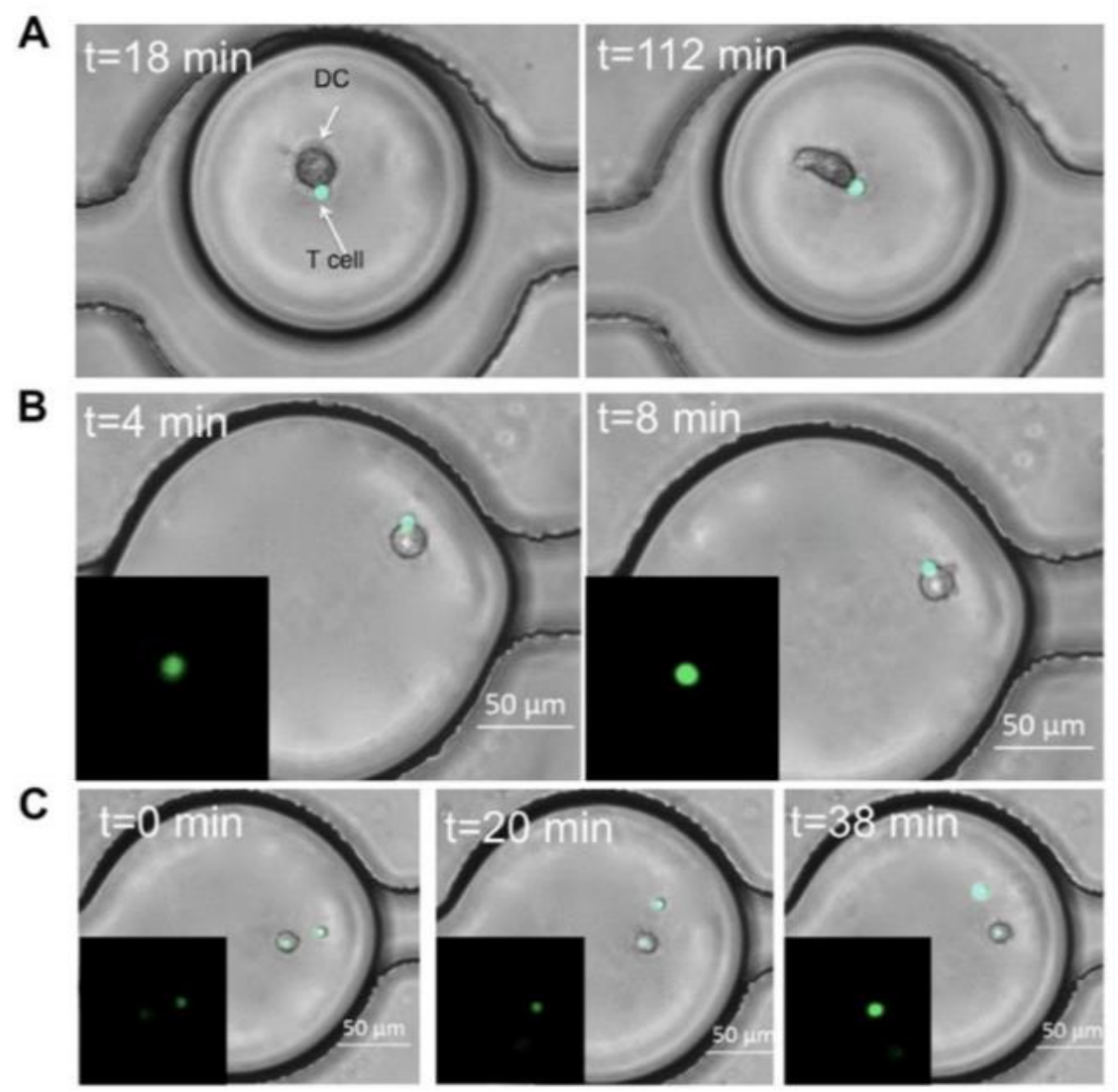

Figure 15: Single-cell interactions between DCs and T cells encapsulated in a microdroplet (Adapted based on Sakar et al. 2015 3)

In summary, there is still a need for gaining more profound knowledge about the function of the immune system and its several components in order to improve the approaches of cancer therapy. As described in this chapter, microfluidics play a major role in cancer research due to their enormous potential in performing assays at single-cell level while decreasing "the ethical and economic burden of animal models" (Adriani et al. 2016: 4178). Furthermore, they directly set the focus of research on the conditions inside the patient's body to control undesired side effects (cf. Seah, Hu and Merten 2018: 60; Adriani et al. 2016: 4178). 


\section{Introduction to Machine Learning}

In general, computational biology aims to "numerically describe a system" (Kording et al. 2018: 61) in order to ultimately obtain a prediction of the possible outcomes of diverse interventions into the system. Aspiring an increase of understanding of basic principles, biological research is often based on the development of computational models. These schemes are used to collect and describe data to be able to predict the functional mechanisms of biological systems. The main limitation of biomedical modeling is the requirement of profound understanding of the basic driving mechanisms of the investigated system. Another obstacle in this context is the continuously increasing complexity of collected data. To overcome this impediment of a lack in human capability in understanding complex relations, machine learning algorithms can be applied. Their main benefit is that they "[rely] on minimal human insight" (Kording et al. 2018: 62) since they are controlled by self-teaching feedback mechanisms for constant process evaluation. These supervised learning approaches are able to make predictions on a very simple basis without generating complex mathematical models. This is possible as they are programmed to identify strong relationships in collected data without applying any mathematical nor biological theories. Consequently, machine learning algorithms are not capable of providing advices based on the results of data analysis. Nevertheless, they have the potential to surpass humans in diverse analytical tasks such as image recognition (cf. Kording et al. 2018: 1ff; Chen and Asch 2017: 2507).

In the case of cancer research, especially the knowledge and data regarding the process of carcinogenesis is drastically augmenting, "finally [having] reached an unmanageable complexity" (Groten et al. 2016b: 7). Consequently, heterogeneity as the main property of tumors cannot be integrated since it is not fully understood by humans. The whole complexity of the process of evolution-based carcinogenesis can only be assessed by computational models and artificial intelligence. This is because they can analyze processes "which are [...] determined by probability and chance and bear a great poten- 
tial to evolve unpredictable effects" (Groten et al. 2016b: 8). Furthermore, machine learning algorithms cannot only be utilized for analytical predictions but also for simulation purposes. Hence, they provide the possibility of realtime and long-term observation of the carcinogenesis process and following adjustments (cf. Groten et al. 2016b: 6ff).

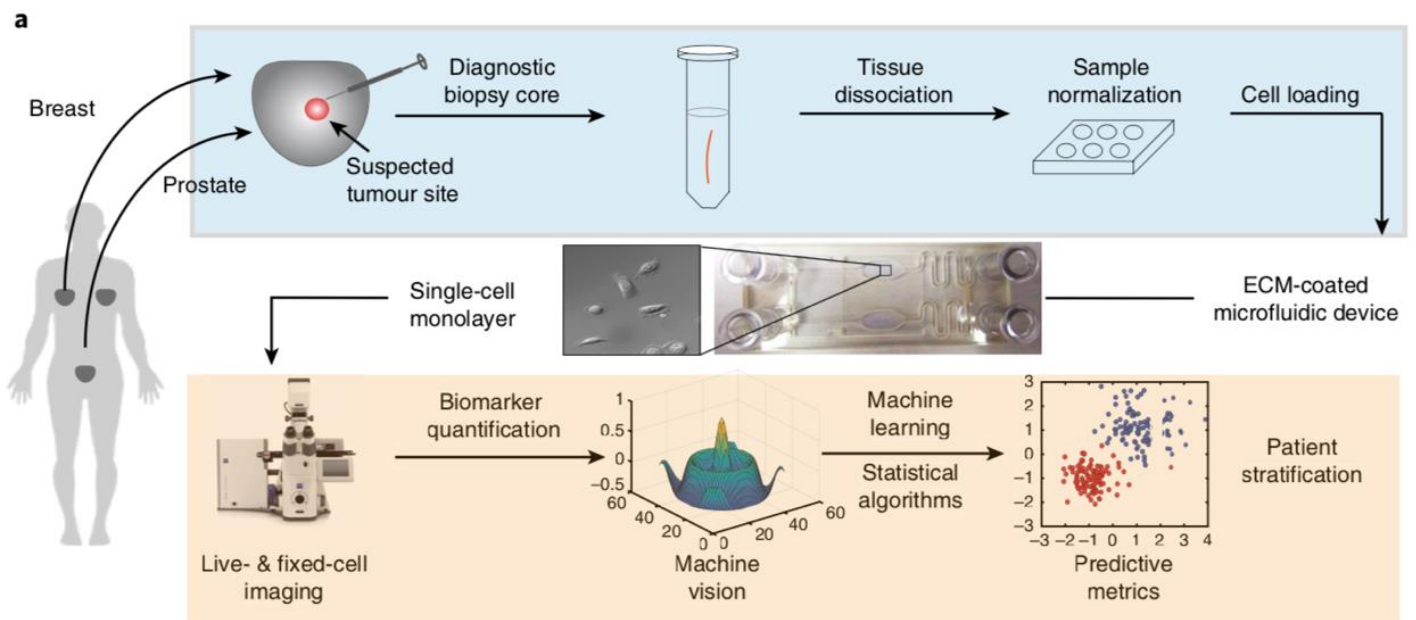

Figure 16: Basic concept of the system for predicting individual tumor aggressiveness developed by Manak et al. (Adapted based on Manak et al. 2018: 2)

In the field of cancer research, machine learning approaches currently have been applied with increased frequency. For example, they could potentially estimate the degree of adverse pathology of each individual patient in order to determine the tumor's aggressiveness and risk degree. To reach this objective, single-cell morphology and behavior under precisely controlled conditions could be used as biomarkers. As a result, this would improve cancer diagnosis and therapy through analyzing and classifying tumor progress of individual patients. In addition to cell morphology, cellular migration and protein dynamics can be utilized as phenotypic tumor biomarkers. They focus on the regulation of intracellular signaling dynamics crucial in carcinogenesis and morphology characteristics of tumor cells such as "cell-spreading velocity, tortuosity, [...], cell migration velocity, cell area and cell perimeter" (Manak et al. 2018: 3) (Fig. 16). 


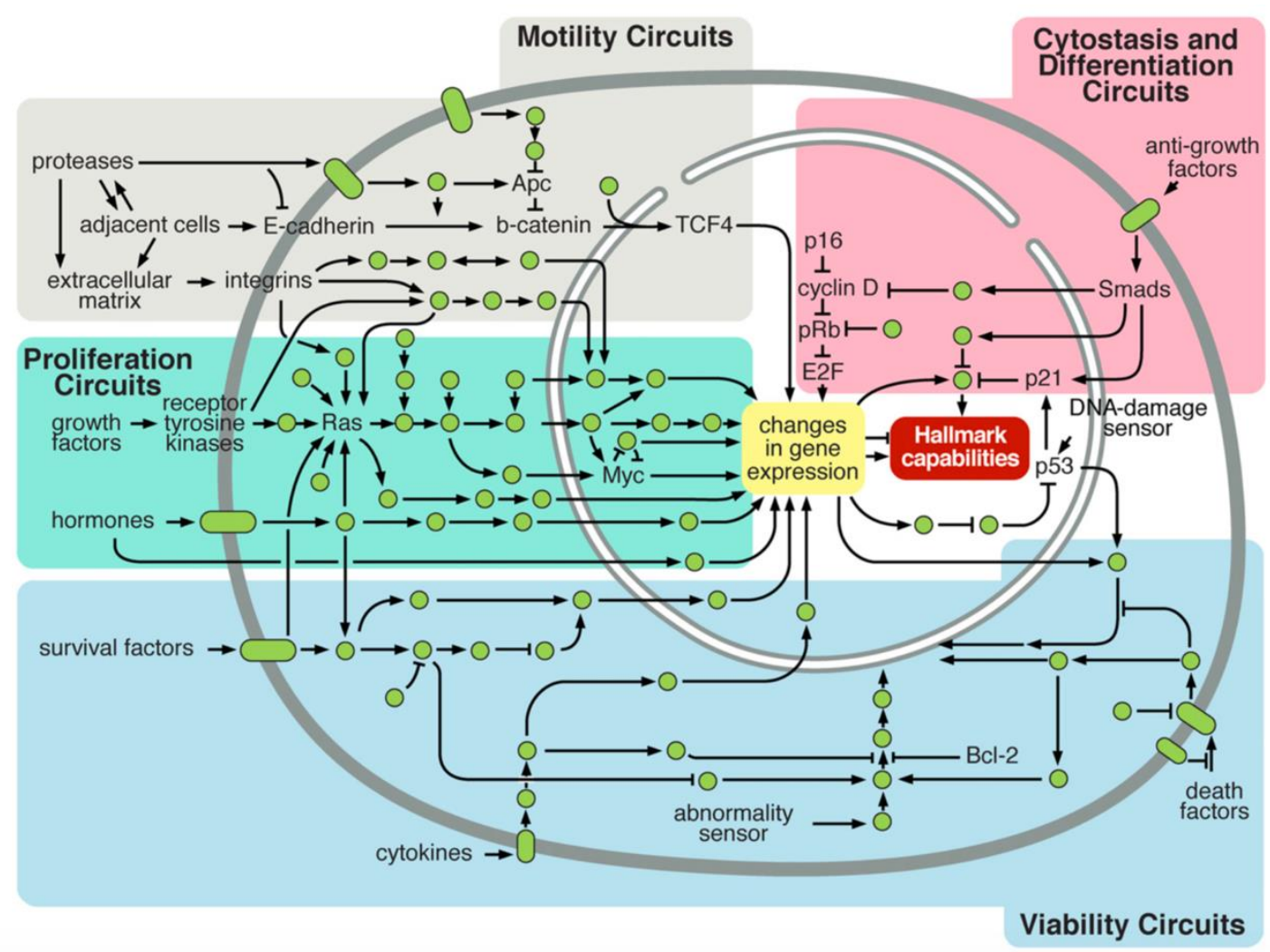

Figure 17: Intracellular signaling circuits that control cancer cell function presented by Hanahan and Weinberg (Source: Hanahan and Weinberg 2011 : 657)

As a result, the tumor's overall potential of infiltrating other organs, thus generating metastases, can be determined. Thus, the limitations of measuring selected static biomarkers which are restricted in precision and spatiotemporal resolution can be overcome. For this purpose, the research group of Manak determined the cancer cell perimeter and its migration dynamics by microscopic imaging. Their aim consisted in providing a machine vision algorithm with the collected data to analyze previously elected biomarkers. As a consequence, adverse pathology in individual patients and even in individual cells could be predicted enabling personalized medicine (cf. Manak et al. 2018: 1ff).

Another approach of integrating machine learning into cancer research is proposed by Hanahan and Weinberg. They visualized the interactions between the six basic cancer hallmarks presented by them in 2000 within integrated circuits (Fig. 17). The numerous cancer-influencing factors and their effects are represented as nodes and branches. Hence, subsystems capable 
of being reprogrammed in order to approximate the normal cellular function to tumor cells are generated. The main limitation of this approach is that the developed circuit cannot include every cancer progress-influencing molecule. Furthermore, many processes in carcinogenesis are not completely understood by humans (cf. Hanahan and Weinberg 2011: 656f.).

To overcome these obstacles, Groten et al. presented an interactive simulation model based on machine learning on order to increase knowledge regarding cancer development (cf. Groten et al. 2016b: 3) (Fig. 18).

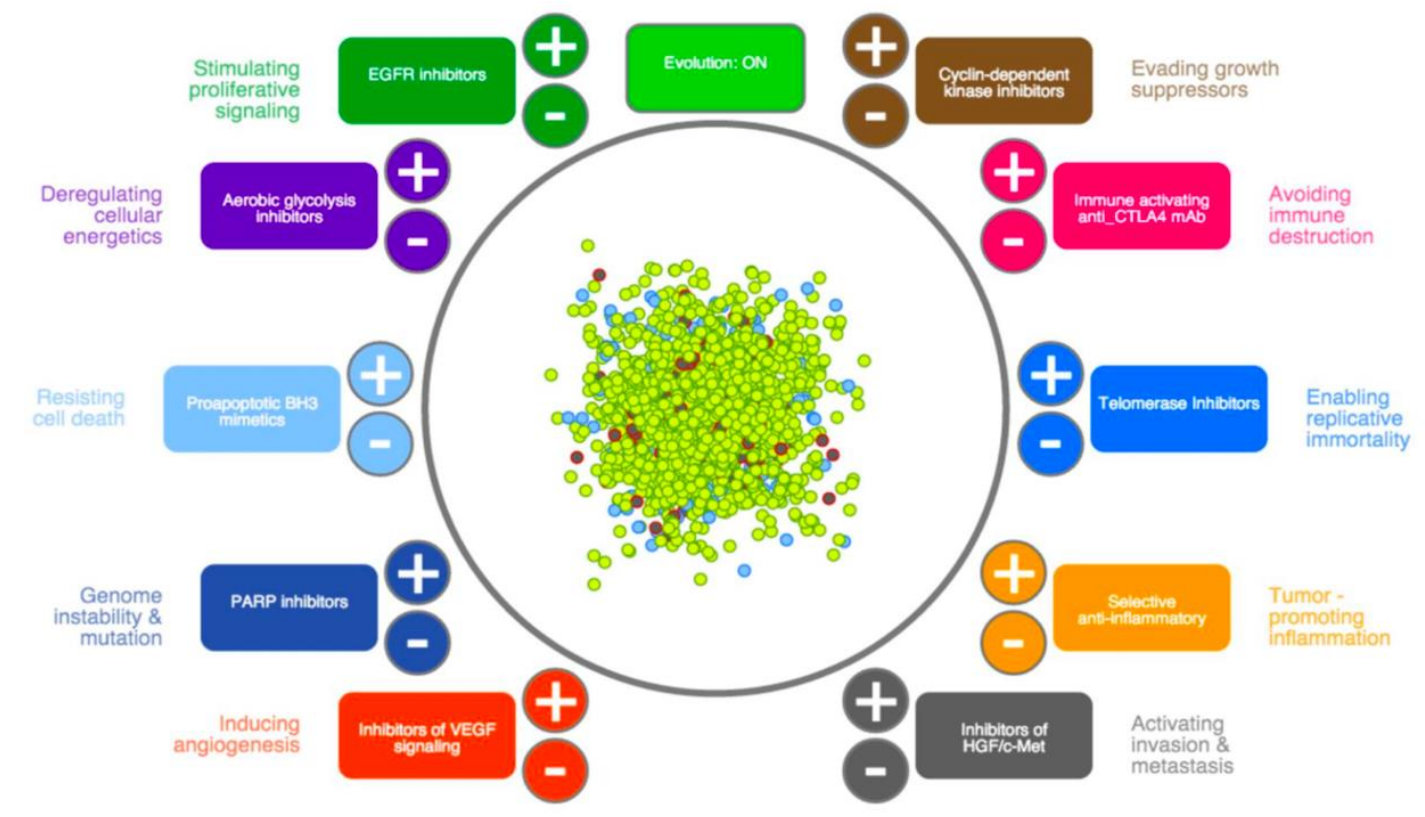

Figure 18: Surface of the carcinogenesis simulation model developed by Groten et al. (Source: Groten et al. 2016b: 19) 


\section{Experiments}

The American oncologist Robert Gatenby once said that cancer is "an evil entity that just keeps recurring and overcoming your best efforts" (Willyard 2016: 167). Thus, he insinuated the issue of cancer spreading in the form of metastases. These dispersing cancer cells drastically restrict treatment options since they tend to show a higher probability of resistance to conventional therapy strategies such as chemotherapy. As previously described, cancer is thought to underlie basic evolutionary principles. Consequently, it is assumed that therapy-resistant tumor cells already can be found in cancerous tissue before starting therapy administration. This event can be explained by resistant tumor cells losing the selective competition against nonresistant cancer cells. During treatment, this changes since resistant cells can adapt to the normally cytotoxic environment with greater efficacy. Conventionally treatment schedules assume that the maximum of tumor cell eradication by injecting high doses of therapy increase the survival rate of patients. According to the evolutionary theory of cancer, this would result not in curing the patient but in giving rise to the proliferation of therapy-resistant cells. Moreover, these cells would possibly spread into metastases increasing the mortality of patients. To improve the curing rates of cancer therapy, the treatment should be adapted to tumor responses to the therapeutic substances.
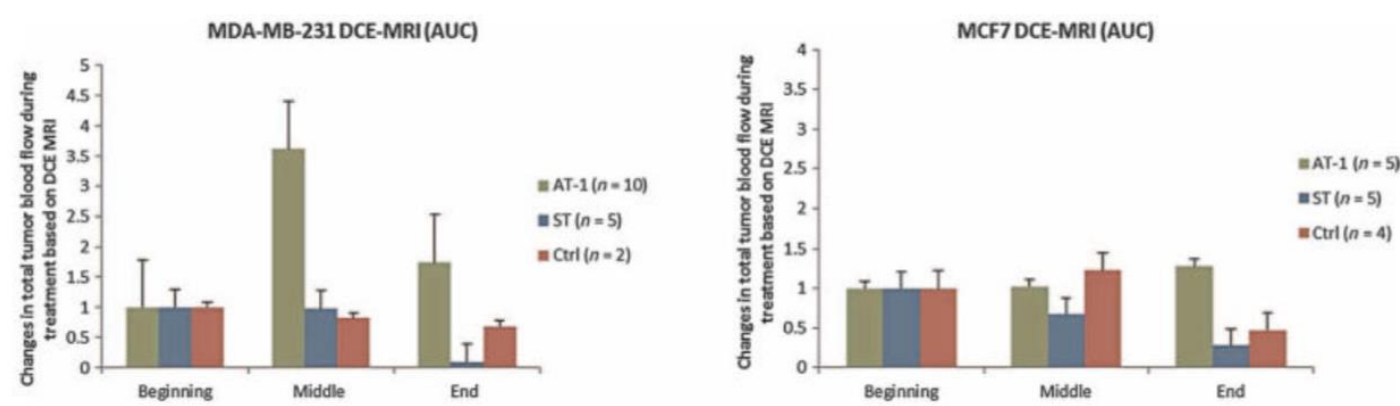

Figure 19: Changes in total tumor blood flow during different treatment regimens (AT-1: decreasing dose of drugs as the tumor responds; ST: conventional method of maximum dose; Ctr: control) (Source: EnriquezNavas et al. 2016: 5) 
Thus, the expansion of resistant cells could be inhibited by stopping the drug injection when cell death is detected via microscopic imaging and computational algorithms (Fig. 19) (cf. Willyard 2016: 167f.; Enriquez-Navas et al. 2016: 1ff).

Thus, this strategy to treat cancer is based on a schedule which precisely reacts to changes in cell morphology caused by treatment. Consequently, it can be transferred to the proliferation of human $T$ lymphocytes. Their activation depends on the pre-stimulation by antigen binding in vivo or by a lectin ex vivo. This process induces the expression of IL-2 receptors which are able to bind the main T-cell growth factor leading to cell proliferation. There are assumptions that those receptors crucial for complete $T$ cell activation disappear proportionally to the decrease of IL-2 concentration. Consequently, this would lead to a stop in proliferation which can be caused by a constant growth factor administration without renewing the cell activation. This receptor loss is reversible by re-stimulation but has a negative impact on the time needed for $\mathrm{T}$ cell proliferation and the number of cells generated. These parameters are crucial factors in cancer immunotherapies like CAR T-cell therapy since $T$ lymphocytes need to be rapidly expanded ex vivo in great amounts in order to directly transfer them back to the patient (cf. Cantrell and Smith 1983: 1895f.).

To overcome this great limitation of conventional static therapy strategies based on constant IL-2 administration or one single high-dose bolus, a new treatment schedule is proposed. This innovative strategy relies on the hypothesis that intermittent IL-2 administration prevents the receptors to decrease in number. By increasing the injection dose when a stagnancy or even decrease in growth is detected by self-taught image analysis algorithms, receptor downregulation is avoided. Another hypothesis which needs to be proven is the downregulation of IL-2 receptors as a protective mechanism from overstimulation which is induced by a constant growth factor administration. Therefore, a fluctuating treatment schedule adapted to the number of activated IL-2 sites on the cell surface is supposed to improve T cell proliferation without re-activation of the cells. There already is some evidence 
that a periodic perfusion schedule enhances cell culture in microfluidic devices. Giulitti and colleagues applied several schedules of medium supply to three different cell lines cultivated in microfluidic chips. They found out that a periodic perfusion with short injections and prolonged resting intervals inbetween was the most favorable method for cell culture resulting in a homogenous cell distribution and high cell viability (cf. Giulitti et al. 2013: 4440f.).

Moreover, the machine learning models previously described provide the possibility of real-time adjustments of the culture system. To further improve the platform for performing CAR T-cell therapy in a more efficient manner, bioreactors used for cell culture are miniaturized down to micro-scales. As a consequence, the control over microenvironment conditions would be increased. This, in turn, would approximate more closely the in vivo structures and drastically reduce treatment costs by decreasing reagent consumption.

In summary, the main objective of the experiments carried out in the course of this thesis is to develop a miniaturized, automated $T$ cell culture system. Furthermore, treatment schedules are to be controlled by machine learning algorithms in order to adapt growth factor administration to the presence of sufficient IL-2 receptors needed for efficient cell proliferation. To facilitate this, the cells inside the system are continuously tracked by microscopic imaging in order to measure their growth based on cell area expansion.

\subsection{Materials and Methods}

\section{Cell Lines and Culture}

The leukemic cell line Jurkat (ACC282, DSMZ) was cultivated using RPMI 1640 medium (Gibco ${ }^{\mathrm{TM}}$ ) supplemented with $10 \%$ fetal bovine serum (FBS) and $1 \%$ Pen Strep $(10,000$ Units $/ \mathrm{ml}$ penicillin, $10,000 \mu \mathrm{g} / \mathrm{ml}$ streptomycin; Gibco' ${ }^{\mathrm{TM}}$ ). The cells were incubated at $37^{\circ} \mathrm{C}$ in a humidified atmosphere con- 
taining $5 \% \mathrm{CO}_{2}$ and passed to a new flask containing fresh medium every two to three days depending on their confluency.

To obtain human peripheral blood T lymphocytes, peripheral blood mononuclear cells (PBMCs) were isolated from the peripheral blood of a healthy donor by Ficoll density gradient centrifugation (Lymphocyte Separation Media, anprotec) at $500 \times \mathrm{g}$ for 45 minutes without brake, followed by washing the obtained buffy coat twice with PBS. To further purify the obtained human $T$ lymphocytes, magnetic MACS $\odot$ separation using CD3 MicroBeads (Miltenyi Biotec $\mathrm{GmbH}$ ) was applied. In order to activate the T lymphocytes, magnetic beads covered with anti-CD3 and anti-CD28 monoclonal antibodies (Dynabeads $^{\mathrm{TM}}$ Human T-Activator CD3/CD28 for T Cell Expansion and Activation (11161D); Thermo Fisher Scientific Inc.) were used in a 1:1 bead-to-cell ratio. PBMCs were cultured in RPMI 1640 medium (Gibco' ${ }^{\text {TM }}$ ) supplemented with $10 \%$ fetal bovine serum (FBS), 1\% Pen Strep $(10,000 \mathrm{Units} / \mathrm{ml}$ penicillin, $10,000 \mu \mathrm{g} / \mathrm{ml}$ streptomycin; Gibco ${ }^{\top \mathrm{M}}$ ) and $20 \mathrm{ng} / \mathrm{ml}$ interleukin 2 (IL-2; human, $\left.10,000 \cup(5 \mu \mathrm{g} / \mathrm{ml}, 50 \mathrm{ml}) ; \mathrm{Gibco}^{\mathrm{TM}}\right)$ to support cell proliferation. The cells were incubated at $37^{\circ} \mathrm{C}$ in a humidified environment containing $5 \% \mathrm{CO}_{2}$. A subculture using growth medium supplemented with $20 \mathrm{ng} / \mathrm{ml} \mathrm{IL-2} \mathrm{was} \mathrm{made}$ each two to three days depending on cell confluency.

\section{Microfluidic Device Design and Fabrication}

Two different microchannel network designs are used: a non-connected (Fig. 20) and a connected design (Fig. 21). The former consists of four separate channels each containing 11 microchambers with an area of $5.3 \mathrm{~mm}^{2}$ each while the latter is composed of four linked microchannels also consisting of 11 microchambers with an area of $4.5 \mathrm{~mm}^{2}$ each. The microfluidic devices used for the experiments are constituted by two slabs: the lower slab contains the microchamber and channel network with its deepest zone of 425.3 $\mu \mathrm{m}$ in the center of each chamber. Thus, it shows a greater depth as the upper slab in order to create a trapping mechanism to capture suspension cells, allowing medium renewal without cell removal. The upper slab provides gas permeability and closes the channel network to the external environment. 
Consequently, the chip containing the separated channel network has a volume of $24.79 \mu \mathrm{l}$ per channel whereas the device composed of the nonconnected microchannel system shows a total capacity of approximately 224 $\mu \mathrm{l}$. The total height of both chip designs is approximately $0.5 \mathrm{~cm}$ to provide a focal distance sufficiently low to be able to focus cells that settled to the well ground. To provide higher stability and improve imaging conditions, the lower PDMS slab is bonded to a microscope glass coverslip.

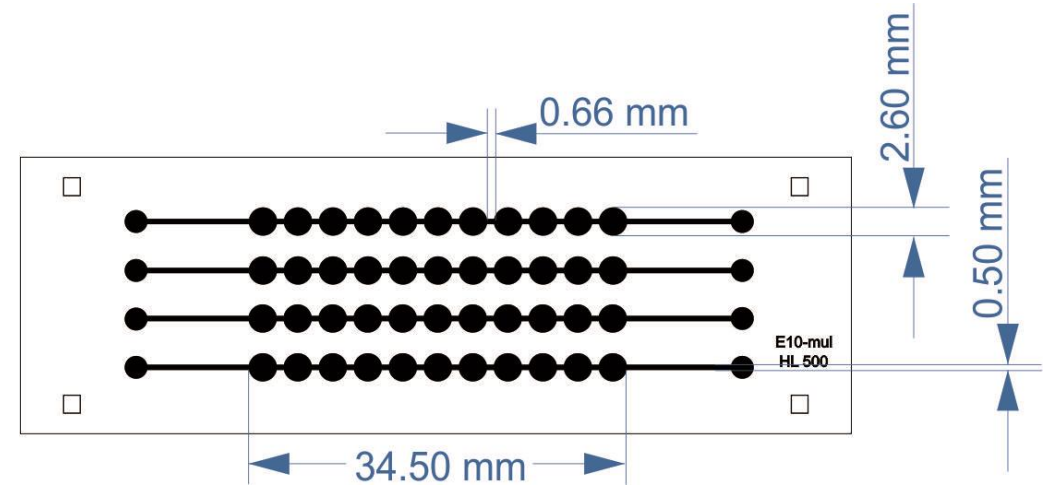

Figure 20: Dimensions of non-connected microchip design

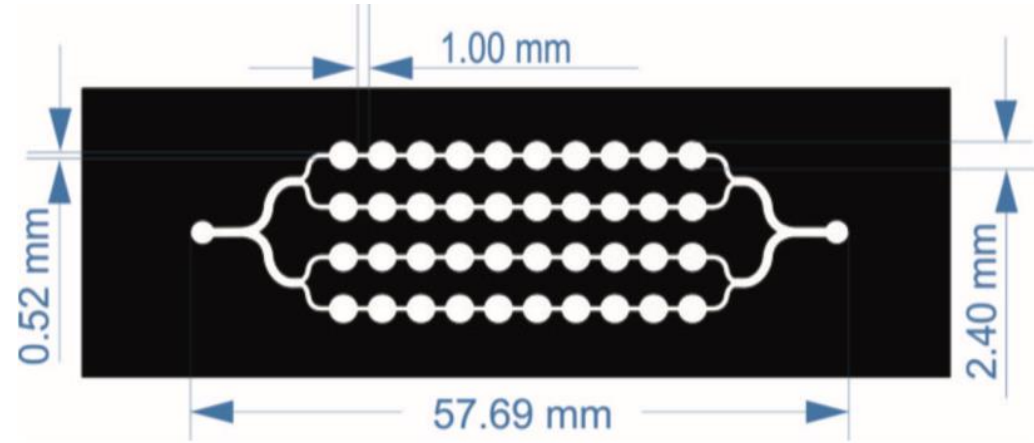

Figure 21: Dimensions of connected microchip design

Microfluidic devices were designed using the vector-based graphics software CorelDraw (https://www.coreldraw.com). In order to create a high-relief master mold needed for the production of the final device, the previously designed microchannel network was engraved into a photopolymeric film using an infrared laser. Next, the film was placed on top of a flexographic printing plate followed by exposure to UV light in order to transfer the channel design. Then, the plate was washed by a solvent and dried in an oven. To finalize the flexographic production process, UV light exposure was repeated to perma- 
nently engrave the microchannel design into the printing plate, also called Flexcel. To fabricate the high-relief master mold, the epoxy resin CRISTAL TACK (TECNARTE, Argentina) was mixed with a hardener in a 2:1 ratio and poured over the Flexcel. After a curing time of three days at room temperature, the duroplastic master mold could be removed from the flexographic plate and used for the fabrication of the final microfluidic device. For this, polydimethylsiloxane (SYLGARD ${ }^{\text {TM }} 184$ Silicone Elastomer Base, 1kg) was mixed with a curing agent (SYLGARD ${ }^{\mathrm{TM}} 184$ Silicone Elastomer Curing Agent) in a 10:1 ratio and stored at room temperature for two hours to remove air bubbles. Next, the liquid polymer was poured over the master mold and put in an oven set at $40^{\circ} \mathrm{C}$ overnight after storing it at room temperature for another two hours to remove any remaining bubbles. After curing, the PDMS slab was removed from the reusable master mold and provided with inlets and outlets for the establishment of connection to the external environment using a biopsy punch (Biopsy Punch with Plunger $\varnothing 1.0 \mathrm{~mm}$; Integra ${ }^{\circledR}$ Miltex $\left.{ }^{\circledR}\right)$. Finally, the PDMS slab containing the microchannel network was firstly bonded to a microscope glass slide and secondly to the other PDMS slab to provide stability. The bond was established by exposing both slabs to oxygen plasma generated by a high-frequency generator (230V, 50/60 Hz; ELECTRO-TECHNIC PRODUCTS INC., Chicago, Illinois) in order to generate hydrophilic conditions inside the channel network. After exposure, both PDMS slabs were immediately put into contact. Prior to use, the assembled microfluidic devices were sterilized by firstly injecting $0.5 \mathrm{M}$ sodium hydroxide $(\mathrm{NaOH})$. After 30 minutes, the device was rinsed with $70 \%$ ethanol to modify the natural hydrophobic surface of PDMS to show a hydrophilic character needed for operation. Sterile water was passed through the microchannels to completely remove $\mathrm{NaOH}$ and ethanol rests after another 30 minutes.

Besides self-fabricated microfluidic chips, different commercially available solutions were used. AIM cell culture chips (3D Cell Culture Chips (DAX-1); AIM Biotech Pte. Ltd.) are sterile and ready-to-use microdevices made of PDMS and polystyrene (PS) that provide three channels: a matrix channel in 
the middle supporting two lateral channels for the injection of a suspension containing adherent cells (Total volume: approx. $200 \mu$ depending on volume of medium injected) (Fig. 22). Since Jurkat cells and T lymphocytes are classified as cells of non-adherent type, there is no need for a supporting matrix which is why the central channel was utilized for cell culture while the lateral channels served as medium storage. Furthermore, the device provides medium reservoirs at each inlet and outlet to avoid evaporation during long-term culture, but which cannot be connected to conventional syringes or multichannel pipettes, thus not allowing the use of infusion pumps for cell seeding and medium renewal.
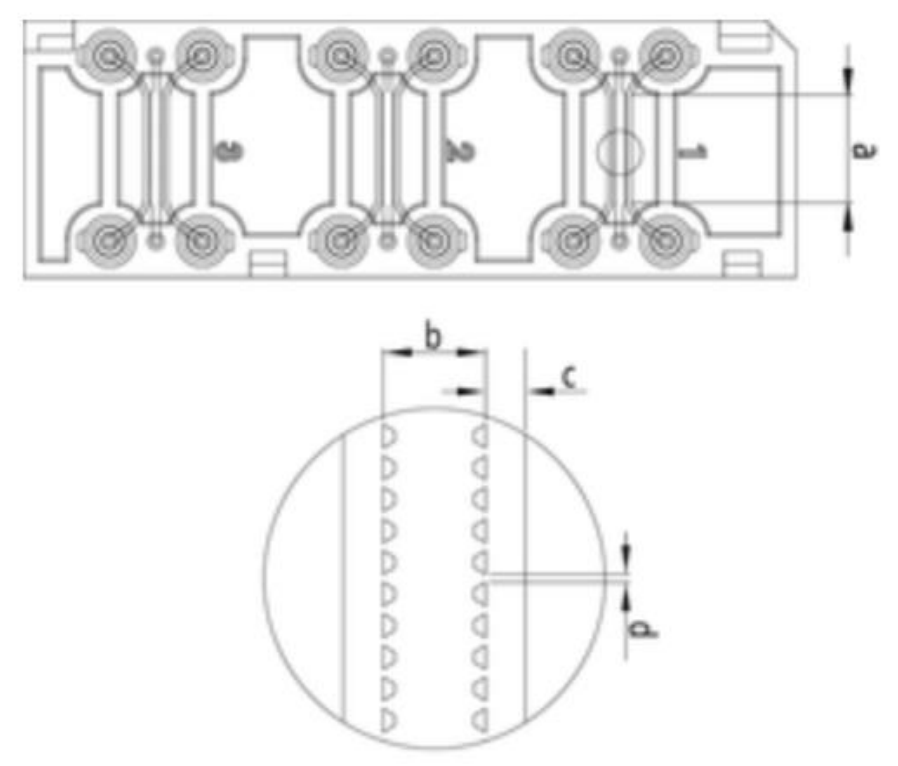

Figure 22: Dimensions of 3D Cell Culture Chip offered by AIM Biotech Pte. Ltd. (a: Length of channels: $10.50 \mathrm{~mm}$; b: Width of gel channel: $1.30 \mathrm{~mm}$; c: Width of media channels: $0.50 \mathrm{~mm}$; d: Gap between posts: $0.25 \mathrm{~mm}$; Height of channels: $0.25 \mathrm{~mm}$ ) (Source: https://www. aimbiotech.com/chips.html)

Another commercially obtained microdevice used for the assays realized in the course of this thesis project is the $\mu$-Slide $\mathrm{VI}^{0,4}$ offered by Ibidi ${ }^{\circledR} \mathrm{GmbH}$. This cell culture chip consists of six separated channels with a volume of 30 $\mu \mathrm{l}$ each (Fig. 23). Similar to the devices provided by AIM Biotech Pte. Ltd., the ibidi ${ }^{\circledR}$ chips also offer medium reservoirs at each inlet and outlet to avoid evaporation which, moreover, are connectable to conventional syringe types. Thus, they allow cell seeding and medium changes via infusion pumps. The 
company does not specify the exact material the slides are made of, but it defines the main characteristics: high optical quality, low autofluorescence and gas permeability. The microdevices are shipped in a sterile packaging and, thus, are ready to use. Furthermore, an additional coverslip is delivered which remains sterility and humidity during imaging procedures outside of the incubator.

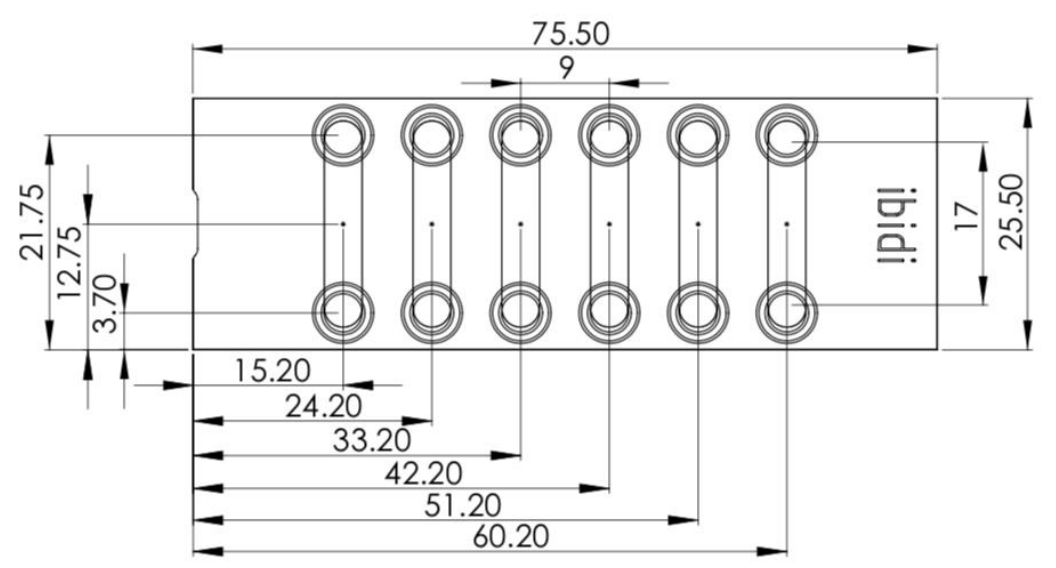

\section{Figure 23: Dimensions of the $\mu$-Slide V10,4 offered by Ibidi $\Theta \mathrm{GmbH}$}

Cell Seeding and Culture in Microfluidic Devices

Prior to seeding, cells were centrifugated at $500 \mathrm{xg}$ for five minutes in order to determine the cell concentration more precisely. This parameter was measured with an automatic cell counter (TC10 ${ }^{\mathrm{TM}}$ Automated Cell Counter, Bio-Rad Laboratories, Inc.) using Trypan Blue dye (0.40\%, $1.5 \mathrm{ml}$; Bio-Rad Laboratories, Inc.). For cell seeding, a concentration of $5.0 \times 10^{5}-1.0 \times 10^{6}$ cells $/ \mathrm{ml}$ was used for optimal growth conditions. After finalizing the sterilization procedure, Jurkat cells and T lymphocytes were seeded in self-fabricated microfluidic chips by syringe pumps (Adox AcTIVA A22 Syringe Infusion Pump; ADOX, Buenos Aires, Argentina) at a flow rate of $270 \mu \mathrm{l} / \mathrm{min}$ during one minute in case of the connected chip design. In case of the nonconnected design, a flow rate of $70 \mu \mathrm{l} / \mathrm{min}$ was applied during one minute per channel.

Since AIM devices are sterilized prior to shipping, cells can be injected directly into the chips via micropipettes. $30 \mu$ of cell suspension was administered 
into the central channel used as cell growth chamber. The lateral channels were filled with medium, injecting different volumes $(70 \mu \mathrm{l}, 50 \mu \mathrm{l})$ in opposite inlets and outlets in order to generate a flow gradient which guarantees the filling of the complete channel. Fresh RPMI 1640 medium (Gibco'M) supplemented with 10\% fetal bovine serum (FBS), 1\% Pen Strep (10,000 Units/ml penicillin, 10,000 $\mu \mathrm{g} / \mathrm{ml}$ streptomycin; Gibco ${ }^{\mathrm{TM}}$ ) and growth factors (IL-2) was administered to both Jurkat cells and $T$ lymphocytes seeded in self-fabricated microdevices each two to three days using syringe pumps (Adox AcTIVA A22 Syringe Infusion Pump; ADOX, Buenos Aires, Argentina) at a flow rate of 5 $\mu / /$ min during 20 minutes in case of the connected chip design. In the case of the non-connected design, a flow rate of $1.3 \mu \mathrm{l} / \mathrm{min}$ was applied 25 minutes per channel. The medium change in AIM devices was carried out using micropipettes. After removing the used fluid, fresh medium was injected into the lateral channels in the same procedure used for cell seeding. Non-adherent cells are retained by triangular structures in the central channel with the aim of preventing cell removal during medium change or drug administration.

\section{$T$ cell activation and proliferation assay}

Jurkat cell line and human T lymphocytes were cultivated in 50 ml-flasks, self-fabricated microdevices with doubled height design and commercially available microfluidic solutions in order to compare cell growth in different geometric environments. RPMI 1640 medium (Gibco ${ }^{T M}$ ) supplemented with $10 \%$ fetal bovine serum (FBS) and 1\% Pen Strep (10,000 Units/ml penicillin, $10,000 \mu \mathrm{g} / \mathrm{ml}$ streptomycin; Gibco ${ }^{\mathrm{TM}}$ ) was used as basic growth medium. Prior to seeding human $\mathrm{T}$ lymphocytes in the different culture possibilities, the immortalized leukemic Jurkat cell line was cultivated to test seeding and culture procedures in the respective devices. When optimal seeding and culture conditions had been found, human T lymphocytes where cultured. In order to determine the concentrations of activation and growth factors for optimal $T$ cell proliferation, different lectins (phytohemagglutinin (PHA; $1 \mathrm{mg} / \mathrm{ml}$; Gib$\mathrm{Co}^{\mathrm{TM}}$ ), concanavalin A (Con A; Sigma-Aldrich, C2272-10MG) and the T cell growth factor interleukin-2 (IL-2; human, 10,000 U (5 $\mu \mathrm{g}, 50 \mathrm{ml})$; Gibco $\left.{ }^{\mathrm{TM}}\right)$ 
were administered in different combinations. When the growth medium was changed, the fresh medium was supplemented with the same activation and growth factor concentrations previously used for the respective assay to maintain the initial growth conditions. In order to improve $T$ cell activation, magnetic beads covered with anti-CD3 and anti-CD28 monoclonal antibodies (Dynabeads ${ }^{\mathrm{TM}}$ Human T-Activator CD3/CD28 for T Cell Expansion and Activation (11161D); Thermo Fisher Scientific Inc.) for more physiological culture conditions.

Proliferation was measured by an image analysis software developed in Fiji which determined the area occupied by cells in each image obtained every day of culture in order to measure cell proliferation. Bright field images were taken with Zeiss Axio Observer Inverted Microscope.

At the end of each experiment, remaining cells were extracted of the microdevice and counted by an automatic cell counter (TC10 ${ }^{\mathrm{TM}}$ Automated Cell Counter, Bio-Rad Laboratories, Inc.) using Trypan Blue dye $(0.40 \%, 1.5 \mathrm{ml}$; Bio-Rad Laboratories, Inc.) in order to control the performance of the image analysis software.

\section{Cell Staining Assay}

To overcome imaging issues that arose when human $\mathrm{T}$ lymphocytes were cultured for several days in self-fabricated devices, cells were stained using an orange fluorescent dye (CellTracker ${ }^{\text {TM }}$ Orange CMRA; molecular probes ${ }^{\circledR}$ by life technologies $\left.{ }^{\mathrm{TM}}\right)$ at a minimum concentration $(2.5-5 \mu \mathrm{M})$ to avoid cytotoxicity and background noise. To additionally reduce the later, RPMI 1640 medium without the $\mathrm{pH}$ indicator phenol red was used (RPMI-1640 Medium (R8755); Sigma-Aldrich $\circledast$ ). 


\subsection{Results and Discussion}

Testing of Cell Culture Conditions Inside Microfluidic Devices Using Leukemic Jurkat Cell Line

In order to test the effect of the different microchannel designs on cell growth proposed in this thesis, leukemic $\mathrm{T}$ lymphocytes of the Jurkat cell line were previously cultured in the respective devices. This cell line is not limited in quantity, shares several physiological aspects with healthy human $T$ lymphocytes and tends to be less sensible to environmental factors. Furthermore, the culture of this cell line is less difficult than the growth of healthy $T$ lymphocytes since they stem from an immortalized cell line. Firstly, $1.41 \times 10^{5}$ Jurkat cells $/ \mathrm{ml}$ were cultured in self-fabricated microfluidic chips containing a non-connected network consisting of four individual channels each including 11 chambers (Fig. 24). With the aim of establishing optimal seeding and drug treatment procedures, Jurkat cells were seeded in the device using different concentration of the T-cell-activating lectin concanavalin A (Con A). Cells in the first channel did not receive any stimulating agent while cells in the remaining three channels cells were injected in medium supplemented with 5 $\mu \mathrm{g} / \mathrm{ml}, 10 \mu \mathrm{g} / \mathrm{ml}$ and $15 \mu \mathrm{g} / \mathrm{ml}$ Con A. Since Jurkat cells are known to have the capability of producing their growth factor interleukin-2 (IL-2) in an autocrine manner, it was relinquished to administer IL-2 in combination with Con A. In order to track the effect of this treatment on cell growth, Jurkat cells within the microdevice were imaged during two days. The results of this as-

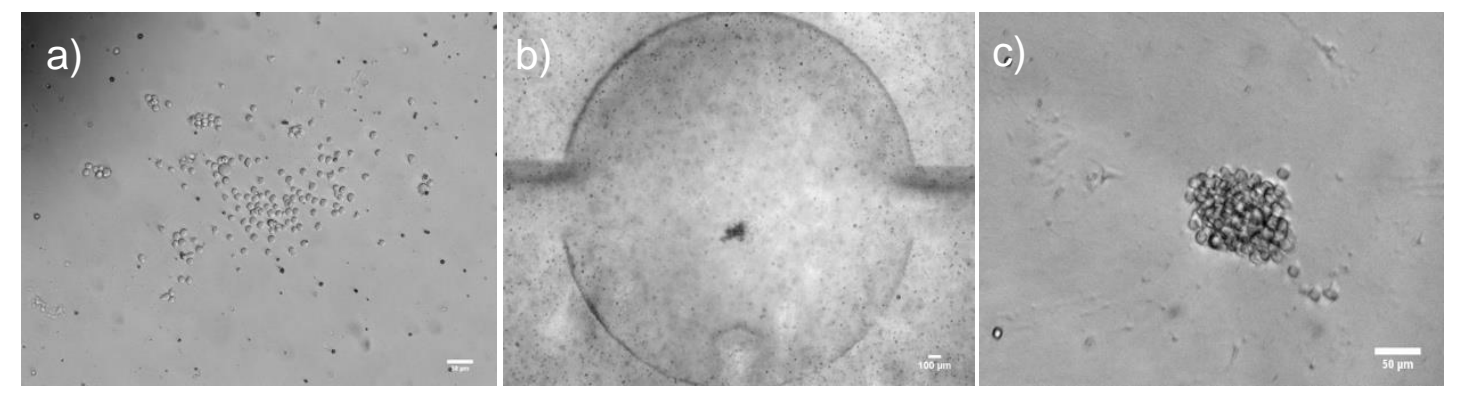




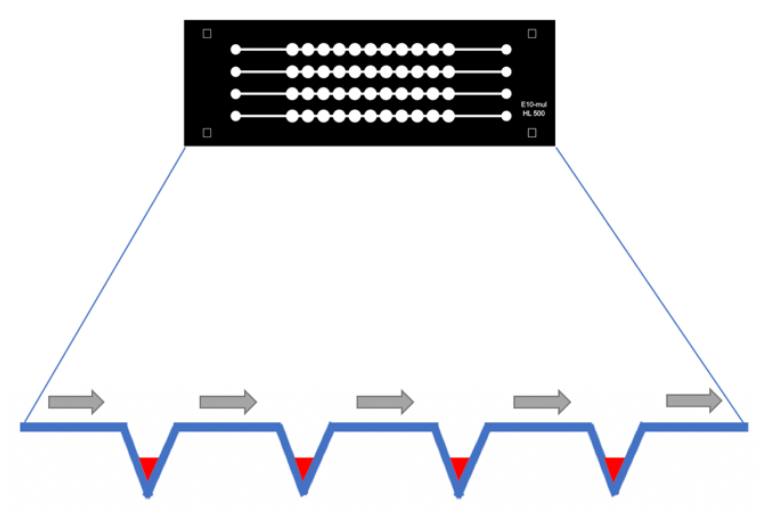

Figure 25: Longitudinal section of the microdevice explaining the cell trapping mechanism say show signs of cell proliferation since small cell accumulations formed in the center of each microchamber. This is due to a cell trapping mechanism generated by localizing the deepest point of each microchamber in the center. Thus, a cone-like structure is formed. As the medium flow passes above the chambers, cells cannot be

removed (Fig. 25).

Since Jurkat cells are known to express mutations in their signaling pathways affecting cellular growth, it is not clear if the stimulation with Con A further supported cell proliferation. The main objective of this first assays were to test and improve culture conditions in microfluidic chips using a robust cell line. Thus, standardized procedures for cell seeding and medium change could be established. Consequently, the focus was not on reaching an increase in cell expansion since the determination of the reason of cell growth is difficult in the case of leukemic Jurkat cells.

Next, the cell culture conditions in commercially acquired 3D Cell Culture Chips (AIM Biotech Pte. Ltd.) were additionally analyzed by seeding $1.41 \mathrm{x}$ $10^{5}$ Jurkat cells $/ \mathrm{ml}$ since the devices were used differently than the manufacturer indicated in the operating instructions. The central channel was not used to place a matrix for establishing a 3D culture environment as T lymphocytes do not adhere to these structures but float in suspension. Consequently, this channel was used to seed the cells while the two actual cell culture channels on the sides were used to introduce the growth medium. The triangular structures found in the middle channel retaining the matrix also served to protect non-adherent $\mathrm{T}$ lymphocytes from getting removed during medium changes. 
In order to optimize seeding and medium change procedures and to examine the effects of the lectin phytohemagglutinin (PHA) commonly used to stimulate T cells ex vivo, $1.19 \times 10^{6}$ Jurkat cells $/ \mathrm{ml}$ were cultured in commercial 3D microdevices (AIM Biotech Pte. Ltd.). Cells were exposed to two different lectin concentrations while the first of the three microchannels the device offers was used as a negative control that not contained any growth factor. Medium supplemented with PHA was renewed each second day. As of the third day of culture, when optimal culture conditions have been established, images were taken every day to track cell proliferation.

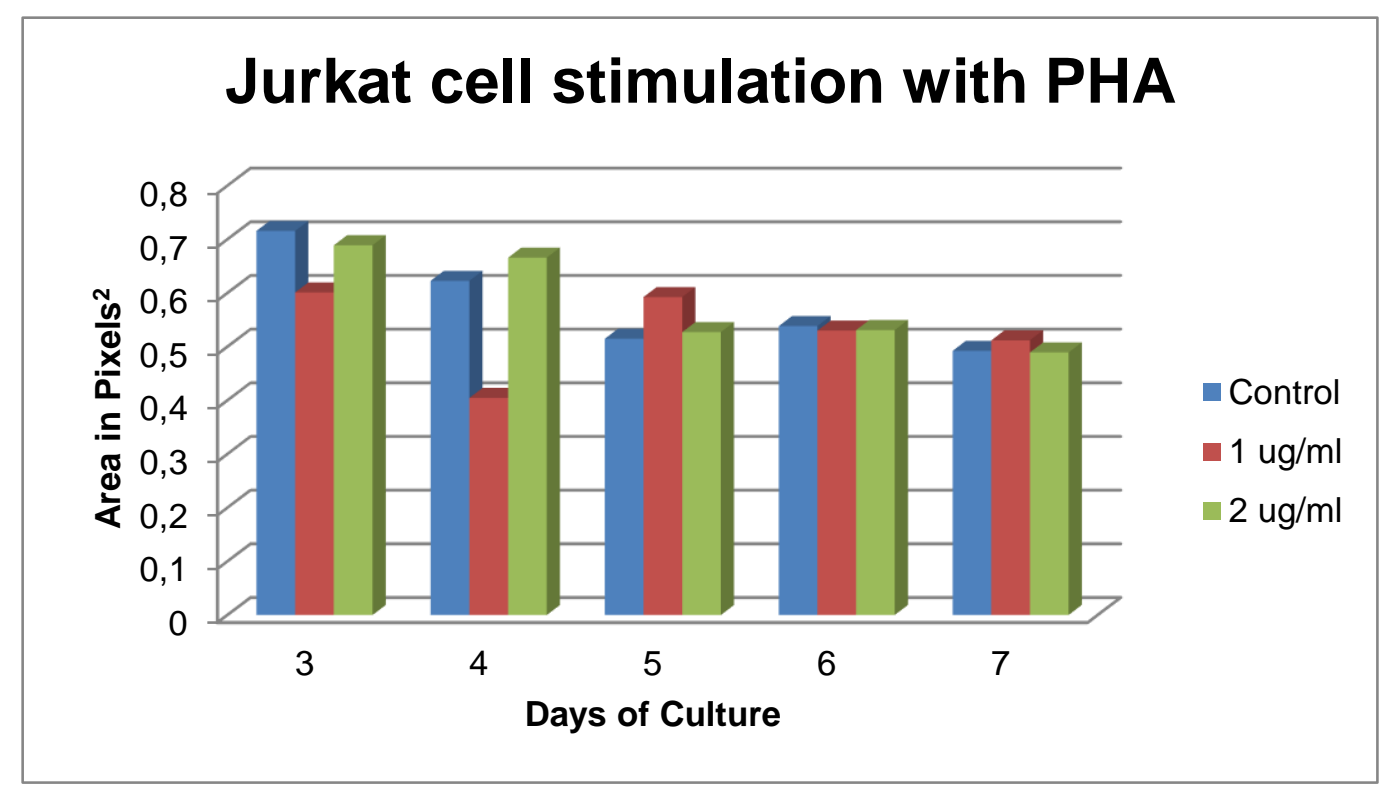

Figure 26: Change in area occupied by Jurkat cells treated with two different concentrations of PHA during five days of culture in a commercial microdevice

As it can be seen in Fig. 26, Jurkat cell growth was characterized by various fluctuations: at the beginning, the control cells show the highest proliferation which was continuously decreasing in the course of time. This phenomenon could also be observed in the cells treated with $2 \mu \mathrm{g} / \mathrm{ml} \mathrm{PHA}$. The administration of $1 \mu \mathrm{g} / \mathrm{ml}$ PHA resulted in the highest fluctuations in cell expansion. At the end of the assay, Jurkat cells cultured without and with the lectin almost occupy the same area, thus having proliferated in the same extent. These results are not very significant since Jurkat cells are known to express mutations in their proliferative signaling pathways, thus not showing a normal cell 
a)

Figure 27: a) $10 \times 10^{6}$ Jurkat cells/microchannel after three days of culture (10X); b) $1 \times 10^{7}$ Jurkat cells/microchannels after three days of culture (10X)

growth behavior. Hence, this experiment served to practice the handling of the common T-cell-stimulation agent PHA and for the further optimization of the culture conditions and procedures in commercial microchips on the on hand. On the other hand, the self-developed image analysis software could be tested to measure the changes in area occupied by cells.

The next experiment carried out using the Jurkat cell line had the aim to determine the optimal cell concentration for growth conditions inside the microfluidic chips. Hence, in a self-fabricated microdevice two different concentrations, $1 \times 10^{6}$ cells $/ \mathrm{ml}\left(25,000\right.$ cells/channel) and $1 \times 10^{7}$ cells $/ \mathrm{ml}(250,000$ cells $/ \mathrm{ml}$ ), were seeded and observed for three days. Since those concentrations seemed to be too high leading to an excessive cell growth (Fig. 27), the experiment was repeated with lower cell concentrations consisting in $1 \times 10^{6}$
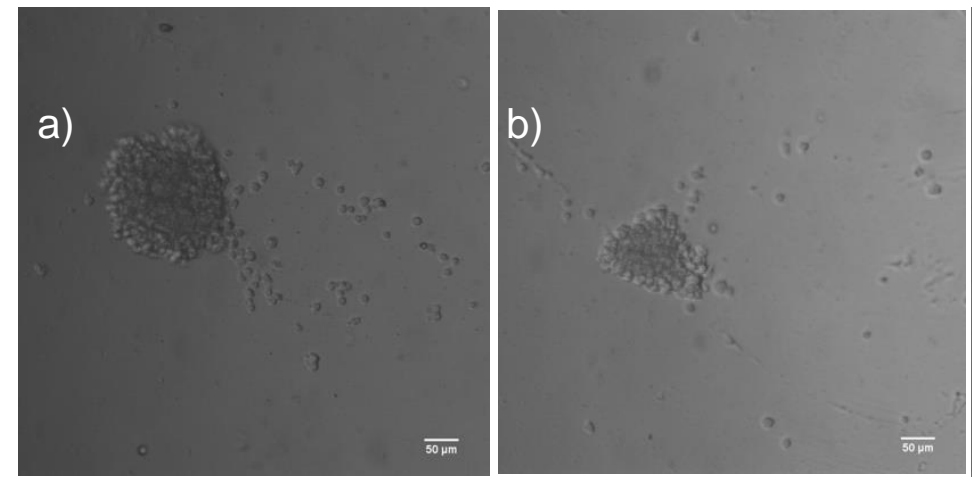

C)
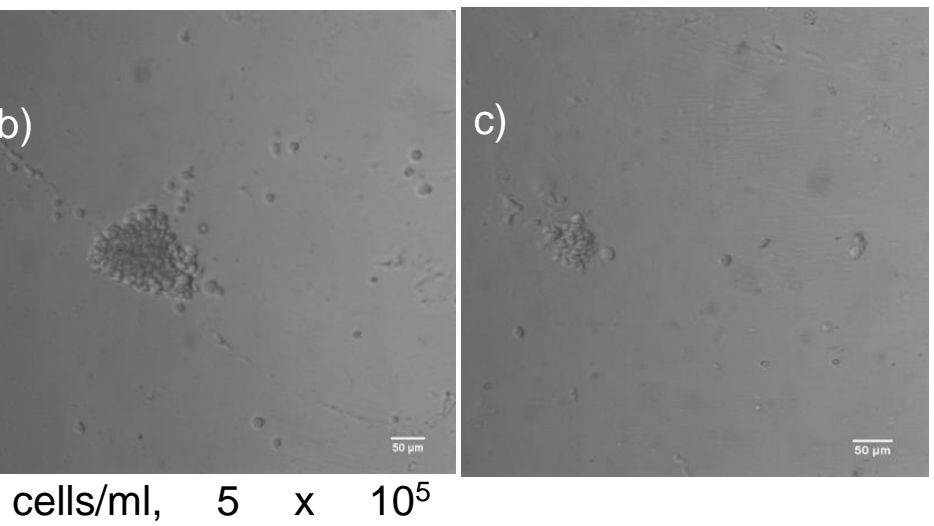

Figure 28: Different Jurkat cell concentrations after three days of culture in the microdevice (2.5X): a) $1 \times 10^{6} \mathrm{cells} / \mathrm{ml}$; b) $5 \times 10^{5} \mathrm{cells} / \mathrm{ml}$; c) $2.5 \times 10^{5}$ cells/ml 
cells $/ \mathrm{ml}, 2.5 \times 10^{5} \mathrm{cells} / \mathrm{ml}$ and $1 \times 10^{5} \mathrm{cells} / \mathrm{ml}$ (Fig. 28).

This assay was also used to define the optimal flow rate for changing the growth medium which was finally set to $1.3 \mu \mathrm{l} / \mathrm{min}$. Moreover, the results show that a cell concentration lower than $2.5 \times 10^{5} \mathrm{cells} / \mathrm{ml}$ is not advantageous since cells are not able to form agglomerations settling at the deepest point in the center of each microchamber. Hence, they get removed during medium renewal. The best cell concentration favoring optimal optics and culture conditions seems to be $5 \times 10^{6} \mathrm{cells} / \mathrm{ml}$ since at this cell number agglomerations can easily be detected but are not demanding too much space and nutrients.

Next, it was intended to improve the imaging conditions in the self-fabricated microdevice by firstly reducing the height of the chip and increasing the stability by bonding the unified PDMS slabs to a glass slide. With this change in design, clusters of Jurkat cells could be imaged with a higher resolution using
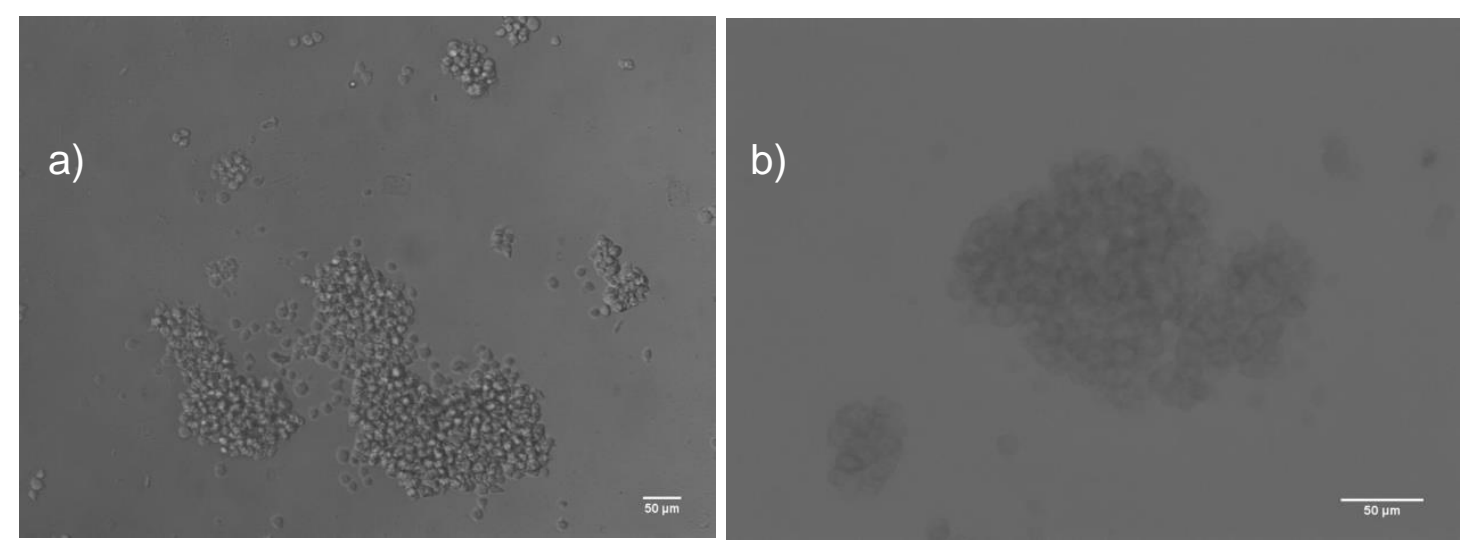

the $10 \mathrm{X}$ and the $20 \mathrm{X}$ magnification

Figure 29: $5.05 \times 10^{5}$ Jurkat cells/ml imaged with 10X (a)) and 20X (b)) magnification

(Fig. 29). 
Testing of Cell Culture Conditions Inside Microfluidic Devices Using Human T Lymphocytes

In order to test if the culture conditions defined as optimal for the Jurkat cell line also support the expansion of human T lymphocytes, $3.69 \times 10^{5} \mathrm{cells} / \mathrm{ml}$ $(9,225$ cells/channel) were seeded in a self-fabricated microdevice with four non-connected channels supplemented with $2 \mu \mathrm{g} / \mathrm{ml}$ PHA and without. Furthermore, cells were exposed to $10 \mathrm{ng} / \mathrm{ml}, 15 \mathrm{ng} / \mathrm{ml}$ and $20 \mathrm{ng} / \mathrm{ml} \mathrm{IL-2,} \mathrm{re-}$ spectively, directly after isolation from PBMCs. Photos were taken right after cell seeding and after three days of culture in the microdevice.

After cultivating the lymphocytes for several days in the device, they become undetectable since other structures similar to cells appear which cannot be distinguished from living organisms (Fig. 30). This problem did not arise when realizing comparable experiments with the Jurkat cell line. As in this assay, the protein IL-2 was used compared to experiments with Jurkat cells, the changes in material could be associated to a reaction with this substance.
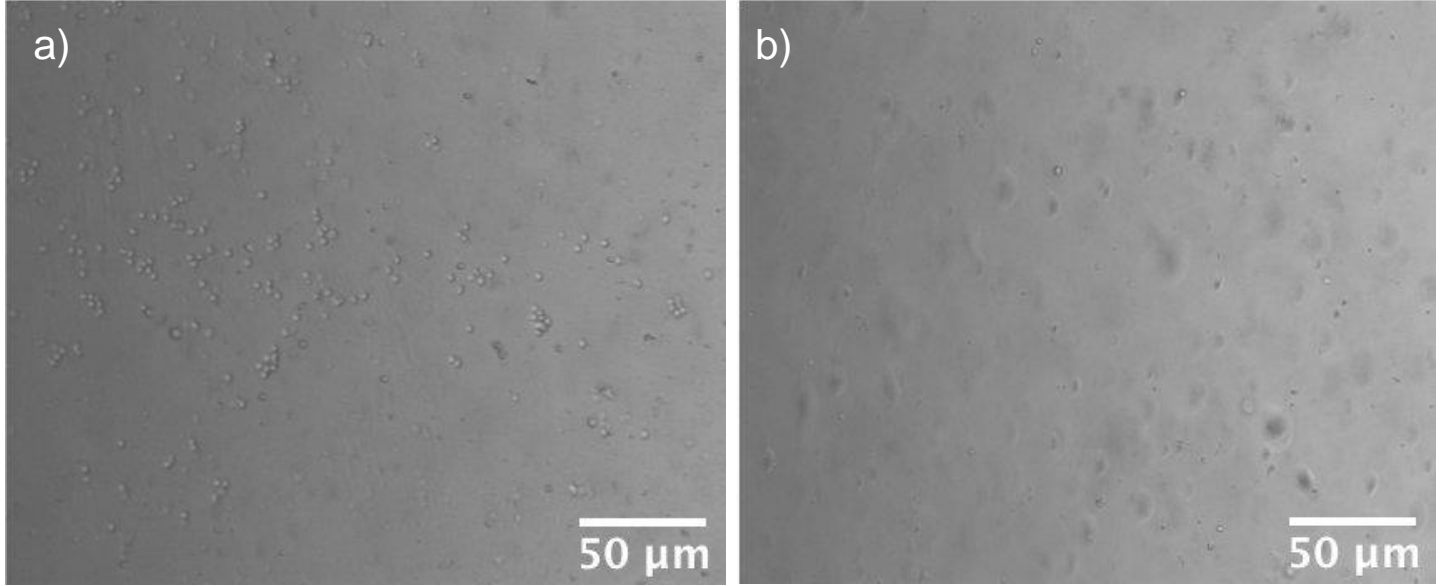

Figure 30: a) Human T Lymphocytes after seeding (10X); b) Human T Lymphocytes after three days of culture (10X) 


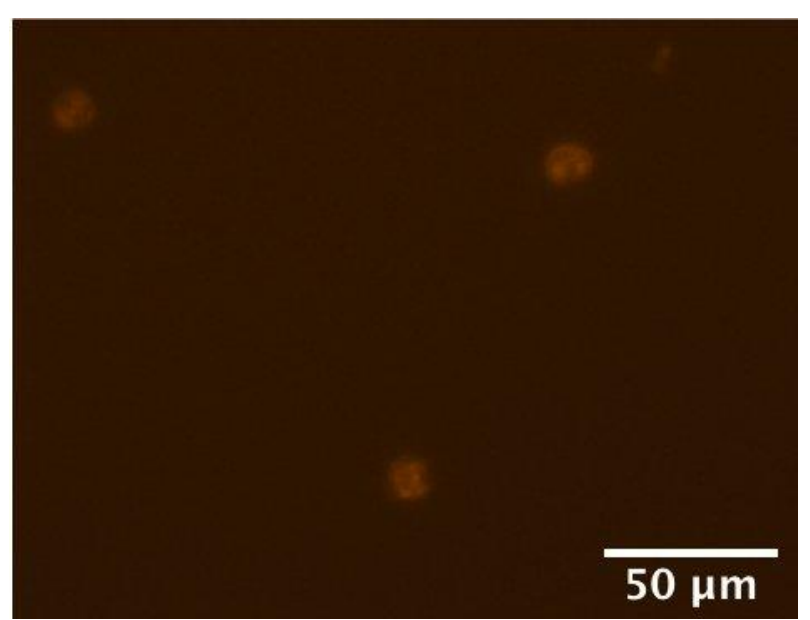

Figure 32: Jurkat cells stained with CellTracker ${ }^{T M}$ concentration of $25 \mu \mathrm{M}$ (40X)

To maintain the detectability of human $T$ lymphocytes in selffabricated microdevices, cells were stained with an orange fluorescent dye (CellTracker ${ }^{\mathrm{TM}}$ Orange CMRA; molecular probes ${ }^{\circledR}$ by life technologies ${ }^{\mathrm{TM}}$ ). Then they were seeded in commercial six-channel microdevice ( $\mu$-Slide VI0.4; ibidi $\left.{ }^{\circledR}\right)$ at a concentration of $1.06 \times 10^{5}$ cells/ml (3,180 cells/channel). In advance of this experiment, Jurkat cells were stained with the fluorescent dye to test imaging conditions and possible cytotoxic effects. First, the maximum CellTracker ${ }^{\mathrm{TM}}$ concentration of $25 \mu \mathrm{M}$ was used since cells needed to be tracked for several days, but this seemed to be too high. As Fig. 32 shows, the cells were shining very bright probably being intoxicated and strong background noises arose. Consequently, the CellTracker ${ }^{\mathrm{TM}}$ concentration was diminished in the following assay to the minimum value of $5 \mu \mathrm{M}$. Since the background noise was still high, it was associated to the RPMI 1640 medium (Gibco ${ }^{\top M}$ ) containing the $\mathrm{pH}$ indicator phenol red. Thus, the next assays were carried out with varying CellTracker ${ }^{\mathrm{TM}}$ concentrations $(2.5 \mu \mathrm{M}, 5 \mu \mathrm{M})$ using modified RPMI 1640 without phenol red
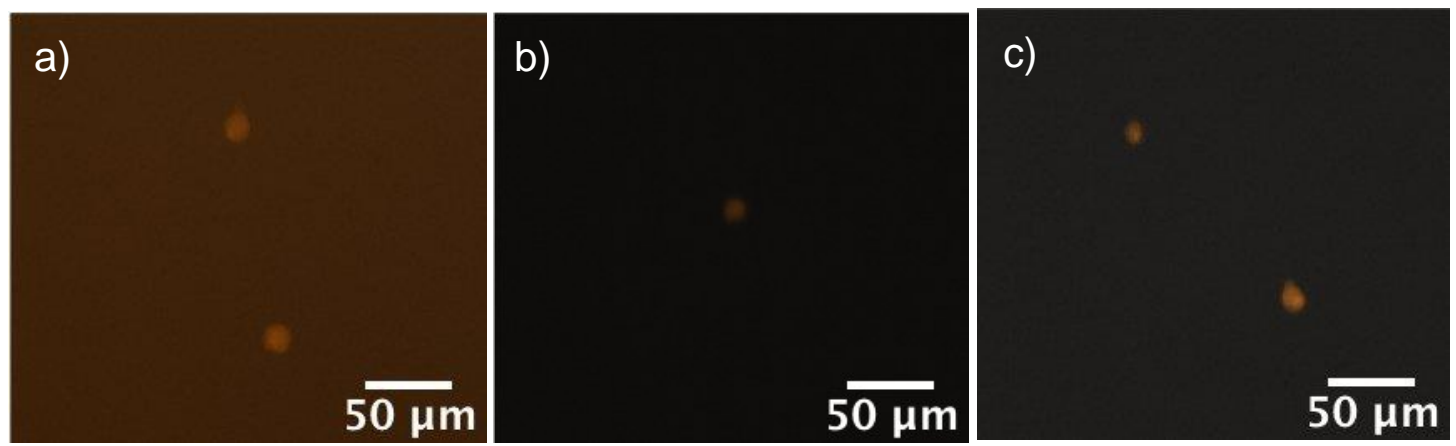

Figure 31: a) Jurkat cells in RPMI 1640 containing phenol red stained with a CellTracker'T concentration of $5 \mu M(20 X)$; b) Jurkat cells in RPMI 1640 without phenol red stained with a CellTracker ${ }^{T M}$ concentration of $\left.5 \mu M(20 X) ; c\right)$ Jurkat cells in RPMI 1640 medium without phenol red stained with a CellTracker ${ }^{T M}$ Concentration of $2.5 \mu \mathrm{M}(20 \mathrm{X})$ 
(Sigma-Aldrich ${ }^{\circledR}$ ) which drastically reduced the background noise (Fig. 31).

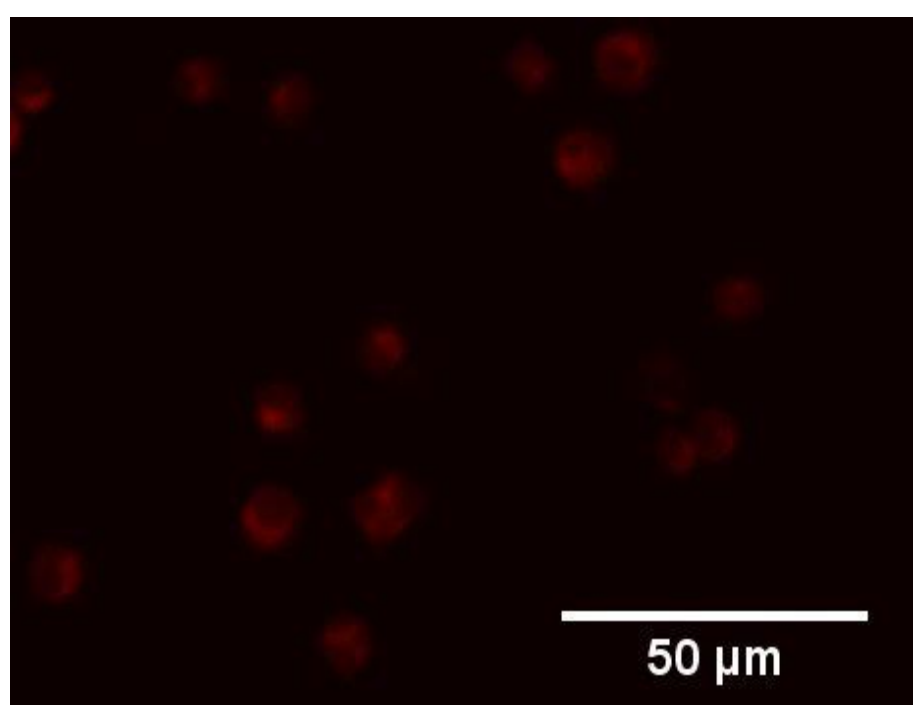

After determining the staining conditions for optimal imaging results and cell health, a less cytotoxic red fluorescent dye (CellTracker ${ }^{\mathrm{TM}} \quad$ Red CMTPX; molecular probes $\AA$ by life technologies $^{\mathrm{TM}}$ ) was used to stain

Figure 33: $5 \times 10^{5} \mathrm{~T}$ cells $/ \mathrm{ml}$ stained with $2.5 \mu \mathrm{M}$ CellTrackerTM Red CMTPX (40X)

human $\mathrm{T}$ lymphocytes to overcome imaging difficulties in self-fabricated

PDMS chips. The dye was used in a concentration of $2.5 \mu \mathrm{M}$ and cells were cultured in phenol red-free RPMI 1640 medium (Fig. 33).

In order to completely avoid cell staining the enhanced microdevice design previously tested with Jurkat cells (thinner PDMS layers for better focal distance bonded to a glass slide for higher stability) was applied in T-cell culture. To be able to localize the T cells, the magnetic beads used for their activation were focused since cells and beads should be at the same level. This

a)

b)

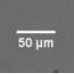

Figure 34: Magnetic beads used for $T$ cell activation seeded in a selffabricated microchip and focused using the 10X (a)) and the 20X (b)) magnification 
was possible using the 10X and the 20X magnification (Fig. 34). In conclusion, the initial problem of focusing $T$ lymphocytes cultured in self-fabricated devices could be overcome.

Determination of Optimal Stimulation Combinations and Schedules to Enhance T-Cell Proliferation in Microfluidic Devices

With the intention to induce proper proliferation of human $\mathrm{T}$ lymphocytes a physiologic activation method was applied, using magnetic beads coated with anti-CD3 and anti-CD28 monoclonal antibodies (Dynabeads ${ }^{\mathrm{TM}}$ Human TActivator CD3/CD28 for T Cell Expansion and Activation (11161D); Thermo Fisher Scientific Inc.). These metallic structures mimic the in vivo interaction between an antigen presenting cell and a $T$ cell. After bringing the magnetic beads into contact with the cells in a ratio of 1:2, the human $T$ lymphocytes were seeded into an AIM Biotech microdevice at a concentration of $8 \times 10^{4}$ cells $/ \mathrm{ml}(2,320 \mathrm{cells} / \mathrm{ml})$. To be able to determine if the T cells were activated, morphology changes were observed since they serve as a significant marker for $T$ cell activation. When a $T$ lymphocyte establishes a connection to an antigen presenting cell (APC), an immunological synapse (IS) is formed between the two cells. This connection is sustained by the $\mathrm{T}$ cell receptor/MHC protein complex, costimulatory proteins and adhesion molecules. The formation of the IS induces the T cell to change its morphological shape from round to elongated and/or flattened. This process is mainly driven by the increase of intracellular $\mathrm{Ca}^{2+}$ levels resulting in a dynamic mitochondria accumulation in the IS. This, in turn, guarantees a prolonged aperture of the $\mathrm{Ca}^{2+}$ channels which permits a higher $\mathrm{Ca}^{2+}$ influx. As a result, the cytoskeleton is affected by mobilizing filamentous actin (F-actin) that, hence, initiating morphological changes from spherical to elongated. This alteration is associated with a mobile T cell scanning its environment for APCs. After the binding between these two cells, the $T$ cell shape turns from elongated to round again and the cell becomes flattened which can be seen as an indicator for effec- 
tive activation (cf. Lin et al. 2015: 1f., 5-7, 10-13). The change in cellular shape from spherical to elongated can be observed in Fig. 35 which proofs the success of $\mathrm{T}$ cell activation. On the second day of culture the proportion of elongated cells had reduced the majority of the T cells being round (Fig. 36).

Furthermore, more lose beads not interacting with a cell were observed which could be seen as an evidence that the $T$ cell activation was carried out successfully.
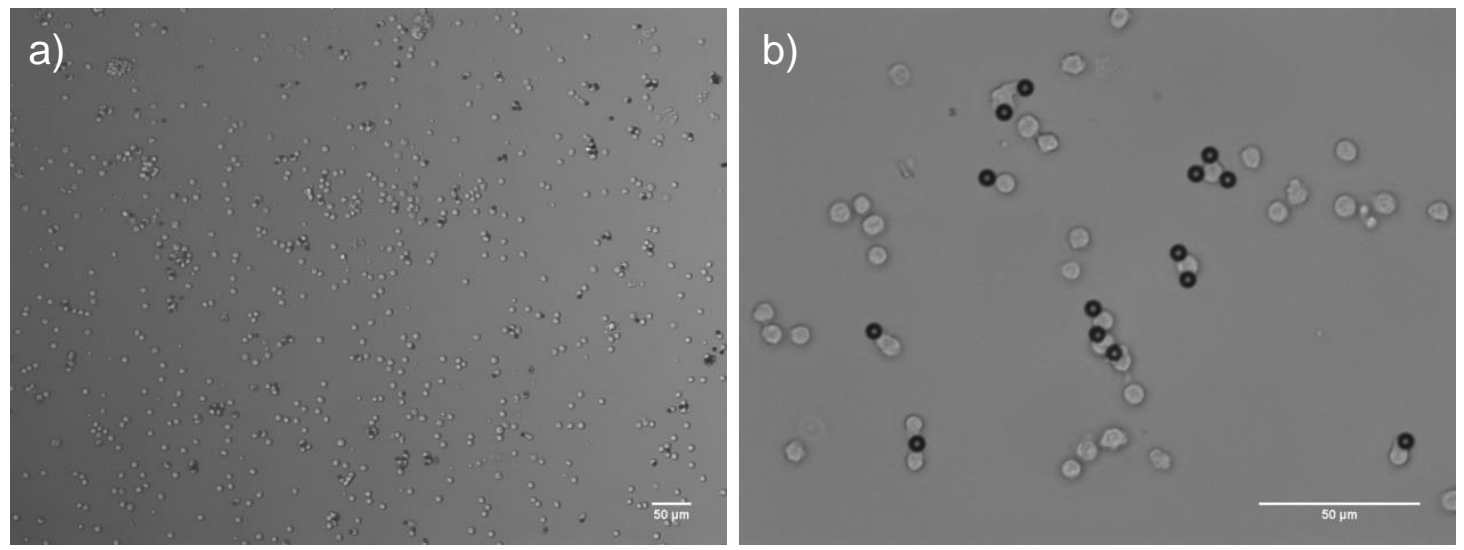

Figure 35: $8 \times 10^{4}$ freshly isolated human T lymphocytes $/ \mathrm{ml}$ activated with CD3/CD28 beads in AIM Biotech microdevice on day 1 of culture (a): 10X; b): 40X)

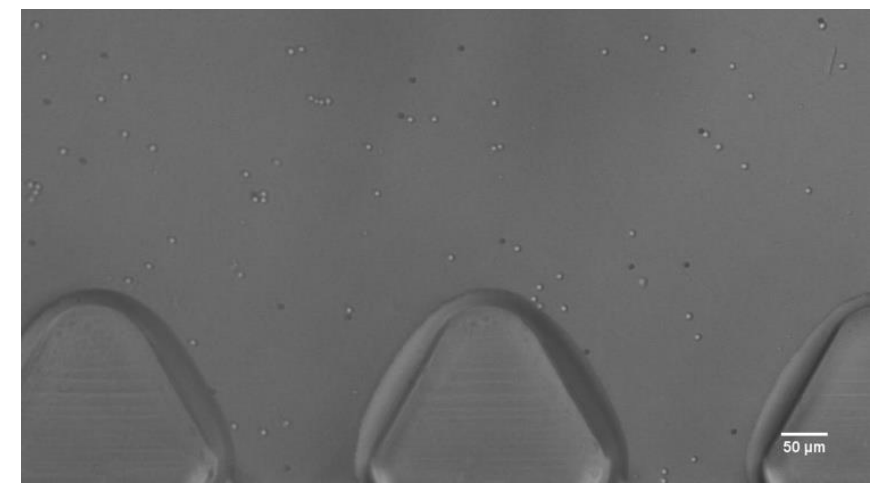

Figure 36: $8 \times 10^{4}$ human $T$ lymphocytes $/ \mathrm{ml}$ activated with $C D 3 / C D 28$ beads on day 2 of culture in AlM Biotech microdevice (10X)

The in vitro cell cycle of a T lymphocyte is generally composed of three main phases: the induction phase is characterized by a reduction in cell viability occurring in the first two days after activating them ex vivo which can be ob- 
served by controlling the cell number which is decreasing. Next, the proliferation phase is initiated inducing a fast increase in the number of cells. As of the fifth day after ex vivo activation, $T$ cells enter the lysis phase. This cell state is characterized by a reduction of cell viability due to a lack of nutrients, accumulation of cell debris or due to the interaction of the $T$ cell with its specific target antigen, lasting up to two weeks. Conclusively, this cell cycle model is hardly to reproduce since it depends upon several factors such as the cell number initially seeded into the culture platform, the regularity of medium changes and stimulation renewals. Moreover, the type of stimulus used for the initial $\mathrm{T}$ cell activation needs to be taken into consideration since different stimuli target different subpopulations of T lymphocytes (cf. Stewart, Cramer and Steward 1975: 241ff).

In order to reproduce the in vitro cell cycle of $T$ lymphocytes described above, $1.28 \times 106$ freshly isolated and activated $\mathrm{T}$ lymphocytes $/ \mathrm{ml}$ were seeded in a 24-well plate $(512,000$ cells/well). The cells were treated with IL2 or cultured without any additional growth factor. Furthermore, they were monitored for nine days until reaching undetectable cell number levels (Fig. 37). It can be seen that both, cells treated with IL-2 or grown without any growth factor, did not enter the proliferation phase but continuously decreased in cell number until reaching undetectable quantities at day nine

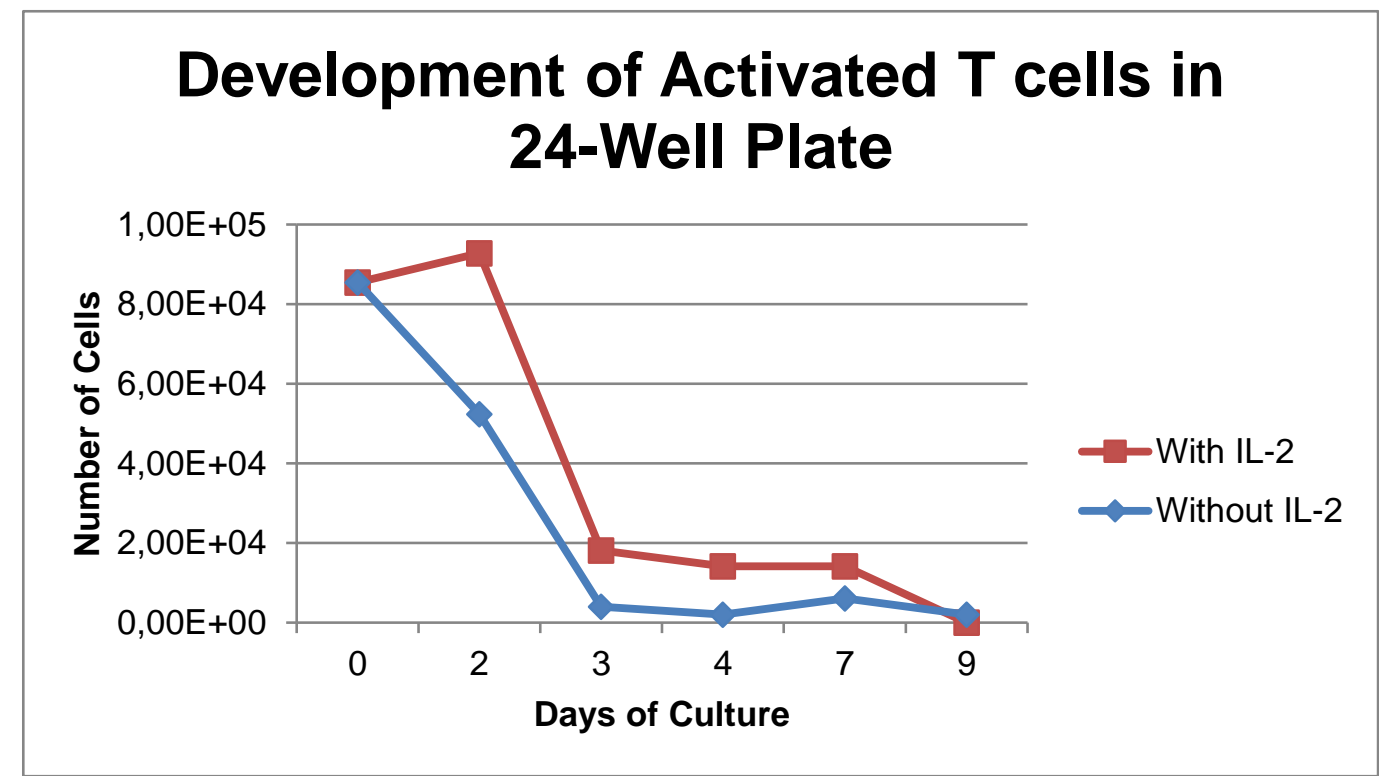

which means that they yet have entered the lysis phase at approximately day three of culture. Moreover, it can be observed that the cells treated with IL-2 
always show a higher cell number than the cells cultured without additional growth factor. Consequently, this indicates that $\mathrm{T}$ lymphocytes require further IL-2 that needs to be supplied in a regular schedule for in vitro culture.

In order to test how healthy human T lymphocytes would react to the miniaturized culture environment in microfluidic devices, they were directly seeded in a commercially obtained microdevice (AIM Biotech Pte. Ltd.). Furthermore, the cells were activated by magnetic beads coated with CD3 and CD28 antibodies in a 1:1 ratio (Dynabeads ${ }^{\mathrm{TM}}$ Human T-Activator CD3/CD28 for T Cell Expansion and Activation (11161D); Thermo Fisher Scientific Inc.) in each of the three channels the chip offers. In order to determine the optimal concentration of seeded cells per channel for the activation and proliferation processes, the first channel of the device was supplemented with $5 \times 10^{5}$ cells $/ \mathrm{ml}(15,000$ cells/channel) whereas in the remaining two channels $1 \mathrm{x}$ $10^{6} \mathrm{cells} / \mathrm{ml}$ (30,000 cells/channel) were seeded in order to test the reproducibility of this cell culture platform. Moreover, each of the three channels was supplemented with $20 \mathrm{ng} / \mathrm{ml} \mathrm{IL-2}$ to examine the effect of the cell concentration on the growth rate. Cells in all channels were restimulated each third day by the renewal of the initial IL-2 concentration in the growth medium.

During 11 days of observation, the T lymphocytes in all three channels occupy approximately the same area of the microfluidic device (Fig. 38). Conclu-

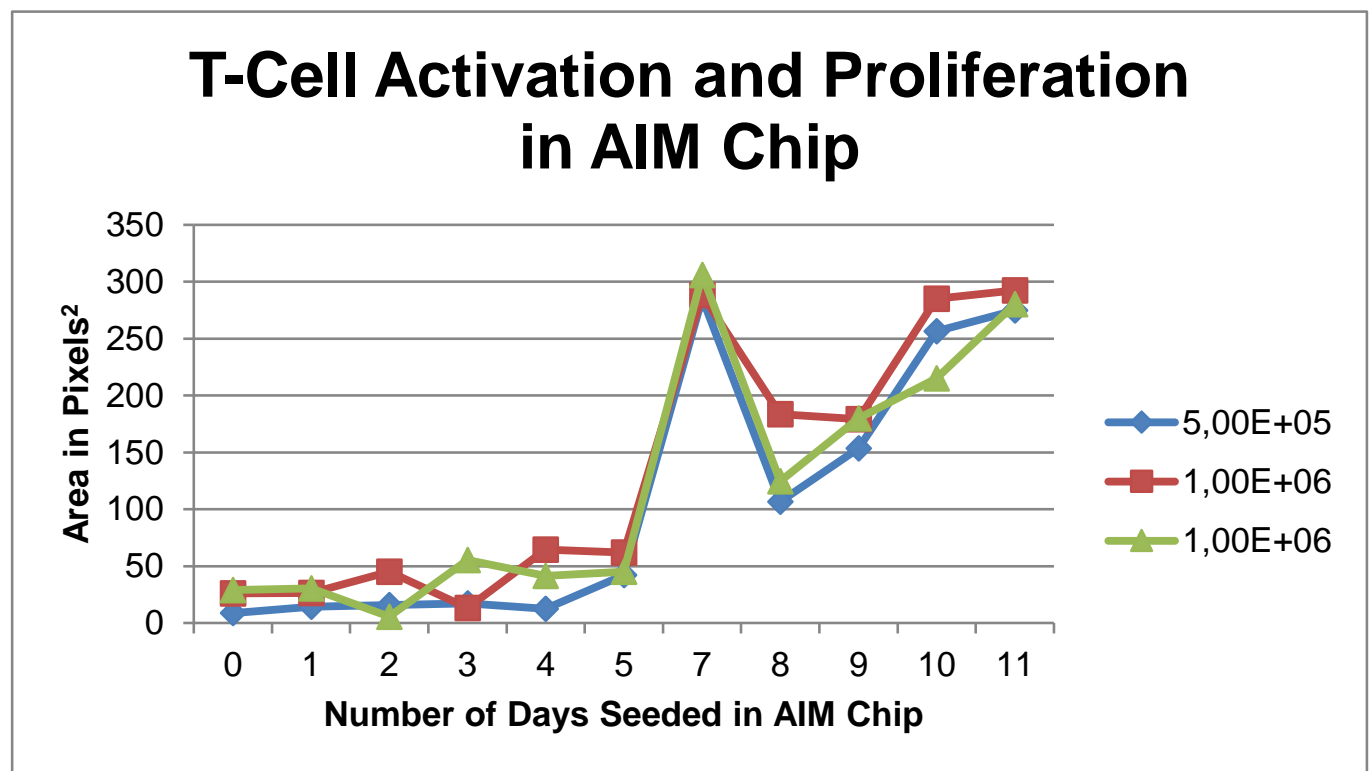

Figure 38: Changes in area occupied by human T lymphocytes directly seeded in microfluidic devices and, moreover, activated by magnetic 81 beads and stimulated with $20 \mathrm{ng} / \mathrm{ml} \mathrm{lL}-2$ 
sively, seeding a lower cell number per channel is more advantageous. This can be explained by the fact that the nutrients and growth factors which the medium contains last for a longer time period making a less frequent restimulation schedule possible, as it can be seen in Fig. 39. This graph shows a clearly high growth rate when cells are grown in a lower initial concentration. Furthermore, $T$ cells seem to need five days for adjusting to the new microenvironment since growth factor renewal has little or no effect on the area occupied by the cells. As of day seven, IL-2 receptors seem to be suddenly expressed in large quantities which appears to result in overstimulating the cells. As a consequence, a decrease in cell growth and even cell death can be observed since the occupied area is diminishing. Nevertheless, the T lymphocytes seem to recover from this overstimulation, thus, beginning to upregulate again the IL-2 receptors needed for their expansion.

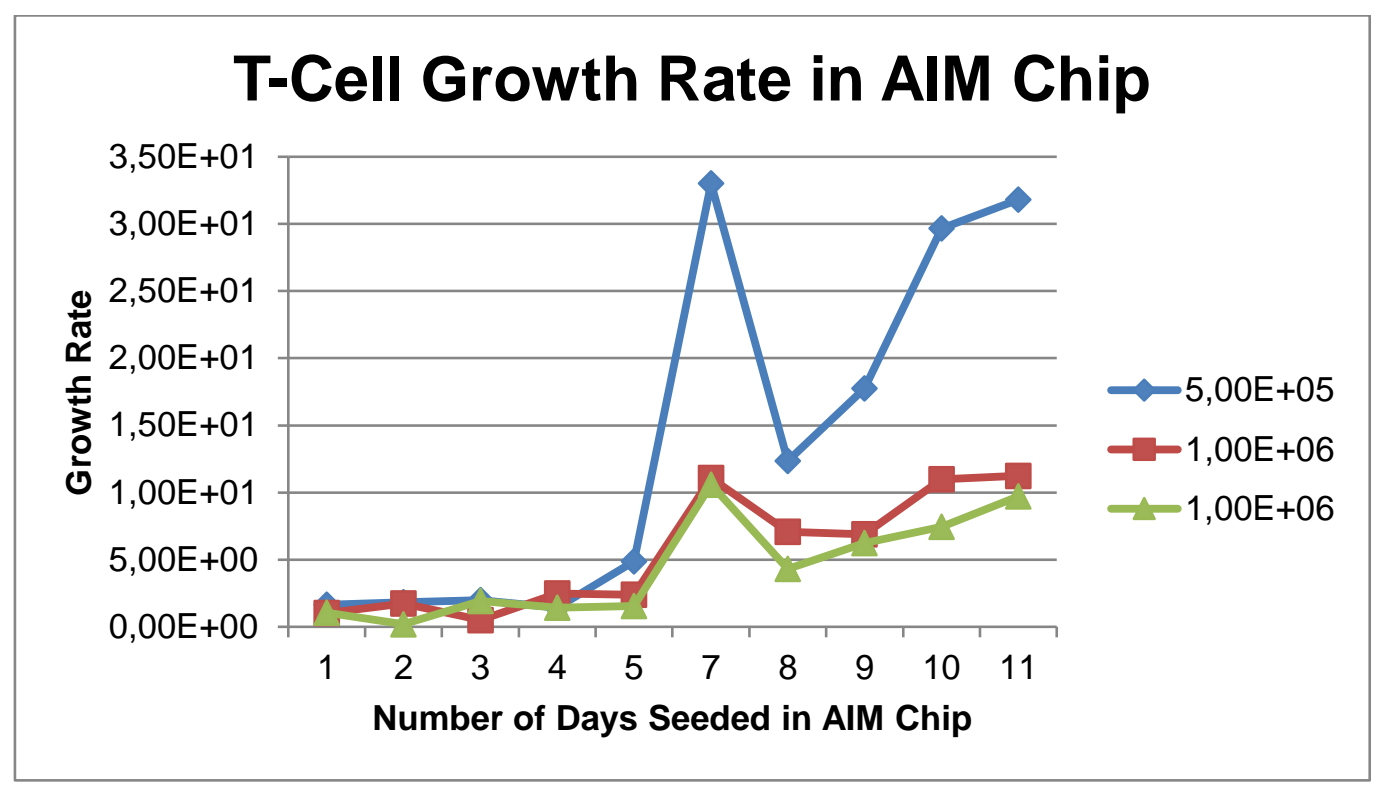

Figure 39: Changes in growth rate of human T lymphocytes directly seeded in microfluidic devices and, moreover, activated by magnetic beads and stimulated with $20 \mathrm{ng} / \mathrm{ml} / \mathrm{L}-2$

With the intention of testing if the cultivation of freshly isolated human T lymphocytes in a conventional culture flask prior to seeding them into microfluidic devices could facilitate the adaption of the cells to a new microenvironment, $T$ cells were seeded in commercially obtained microfluidic devices (AIM Biotech Pte. Ltd.) after culturing them in a $5 \mathrm{ml}$-culture flask supplemented with 
magnetic CD3/CD28 beads in a 1:1 ration (Dynabeads' ${ }^{\text {TM }}$ Human T-Activator CD3/CD28 for T Cell Expansion and Activation (11161D); Thermo Fisher Scientific Inc.) and with $20 \mathrm{ng} / \mathrm{ml} \mathrm{IL-2.} \mathrm{After} \mathrm{their} \mathrm{introduction} \mathrm{into} \mathrm{the} \mathrm{micro-}$ chips at a concentration of $1.39 \times 10^{5} \mathrm{cell} / \mathrm{ml}(4,170 \mathrm{cells} / \mathrm{channel})$, the $T$ cells were supplemented with different concentrations of IL-2 circling around the standard value of $20 \mathrm{ng} / \mathrm{ml}(0 \mathrm{ng} / \mathrm{ml}, 10 \mathrm{ng} / \mathrm{ml}, 15 \mathrm{ng} / \mathrm{ml}, 20 \mathrm{ng} / \mathrm{ml}, 25 \mathrm{ng} / \mathrm{ml})$ every three days which can be seen as a second stimulation after receiving the first stimulus in the culture flask. Compared to the $T$ lymphocytes that were directly seeded in a microdevice after their isolation from whole blood, these cells show a shorter time span needed for adapting to the new microenvironment since they slowly start to proliferate as of day three of culture (Fig. 40). First, the T cells that do not receive a second IL-2 stimulus appear to show the best proliferative behavior which can be explained by the lack of growth factor overstimulation that the repeatedly stimulated cells might experience. This observation changes as of day six of culture (Fig. 40) since the T lymphocytes receiving a second IL-2 stimulation seem to recover from the excessive stimuli and begin to expand which is determined by measuring the

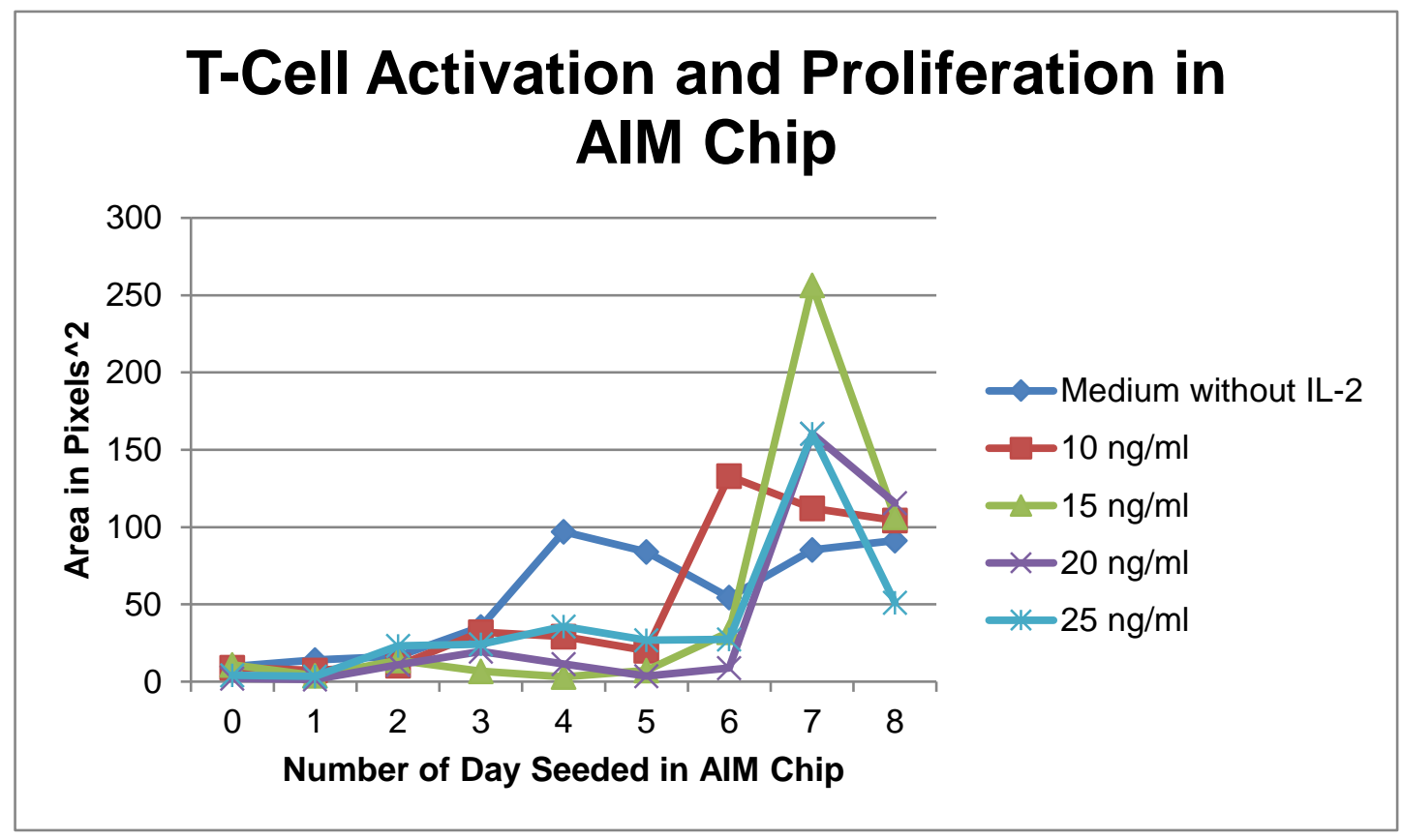

Figure 40: Human T lymphocyte proliferation measured in the area occupied by the cells with different IL-2 concentrations as a second stimulus 
area they occupy in the microfluidic device.

In order to determine the growth factor concentration that has the biggest positive effect on cell proliferation, the growth rates of the cells being supplemented with different levels of IL-2 were compared. Conclusively, the concentration of $20 \mathrm{ng} / \mathrm{ml} \mathrm{IL-2}$ appears to induce the largest cellular expansion surpassing the growth rate of the remaining cells by approximately the fourfold at day seven when the actual cell proliferation starts (Fig. 41).

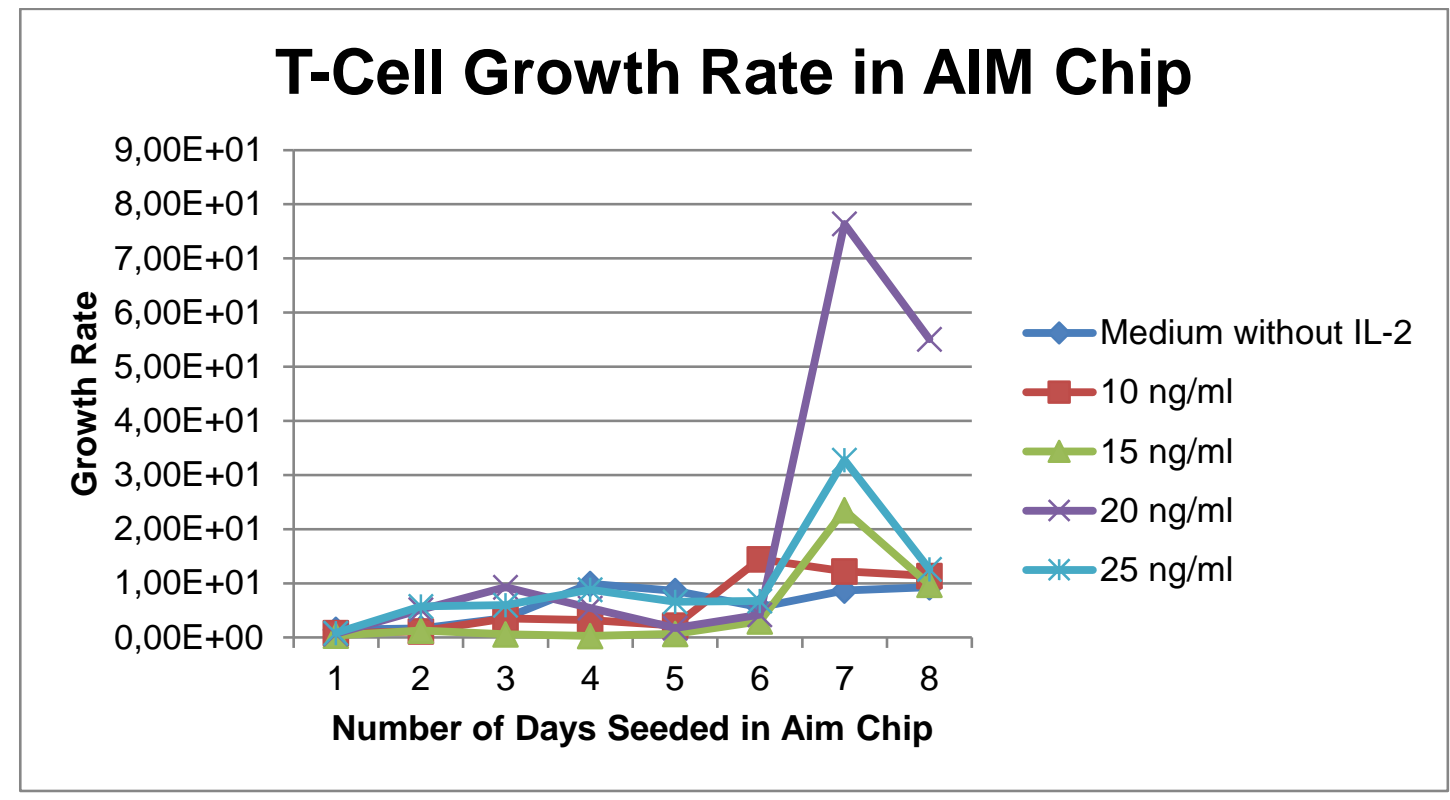

Figure 41: Human T lymphocyte proliferation measured in the growth rate with different IL-2 concentrations as a second stimulus

At the end of the experiment, the initial and the final cell number were compared after eight days by determining the absolute cell numbers using an automatic cell counter after removing them from the device. As a result, the concentration of $10 \mathrm{ng} / \mathrm{ml} \mathrm{IL-2}$ appears to have the most advantageous effect on cell proliferation (Fig. 42) concluding that a higher IL-2 level results in overstimulation and, hence, receptor downregulation. The privilege of this measurement is that it reveals the absolute outcome of each experiment while the comparison of area occupied by the cells only shows the proliferative behavior of the $T$ cells in the course of time without offering a final result. 


\section{Absolute Number of T Lymphocytes Stimulated with different IL-2 Concentrations}

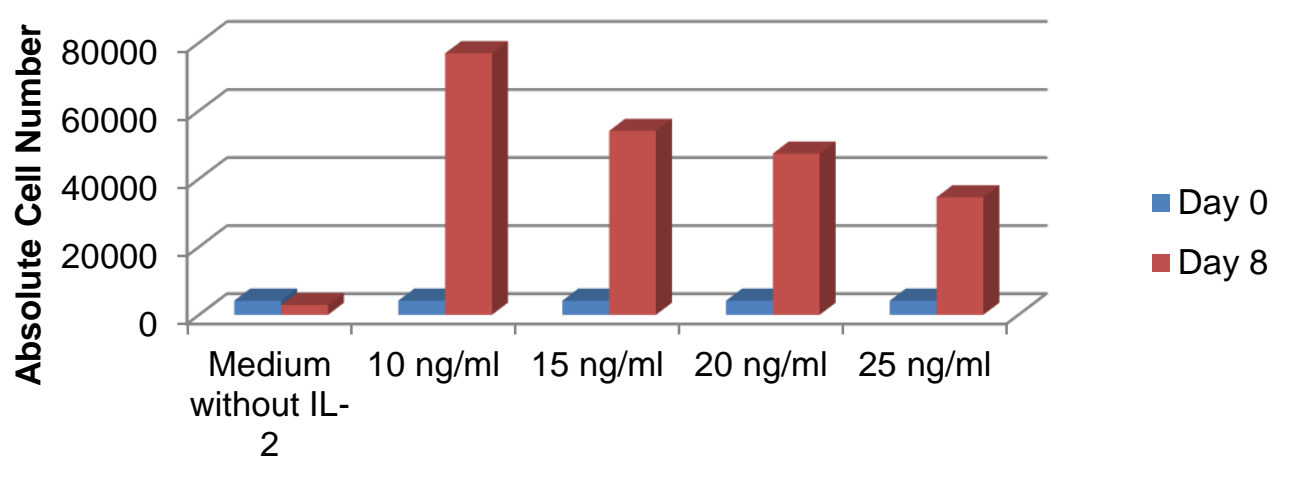

Figure 42: Absolute numbers of human T lymphocytes stimulated with different IL-2 concentrations measured with an automatic cell counter after removing the cells from the microdevice

In Fig. 40, significant differences in cell area on day eight cannot be detected but are present in Fig. 42 since it considers the absolute cell number. Hence, a correlation between the cell area detected by the analysis software and the absolute cell number counted by an automatic cell counter has to be proofed. This was done by seeding four different $\mathrm{T}$ cell concentrations in separate channels of a microdevice. The area occupied by the introduced cells was

\section{Correlation Between Cell Area and Cell Number}

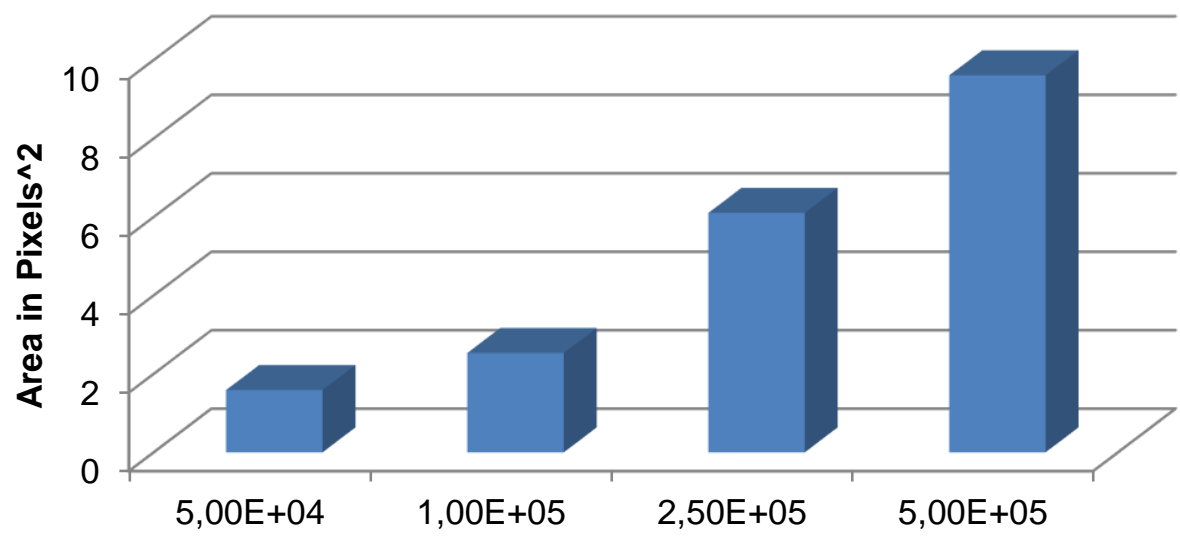

Figure 43: Clear correlation between cell area measured by software and cell number measured by automatic cell counter 
then directly measured using the analysis software (Fig. 43). Conclusively, it can be said that there is a clear correlation between cell area and cell number, supporting the use of the software for future experiments.

Evaluation of the Performance of the Different Microfluidic Devices Used for the Experiments

In order to decide for a microfluidic cell culture platform that offers properties which are essential for cell culture, long-term assays and imaging, an evaluation matrix (Fig. 44) was elaborated considering the three microdevices used in the course of this thesis project.

Due to its capacity to trap cells in its central channel by triangular structures impeding cell removal and its low focal distance and excellent light transmittance, the AIM Biotech 3D Cell Culture Chip (DAX-1) received the highest score. Furthermore, it is made of the biocompatible polymer PDMS, offers three separate channels for different experimental conditions and is inexpensive. The total score of this microfluidic device is reduced because its surface cannot be coated with poly-L-lysine due to the low channel height which leads to clogging. Furthermore, long-term imaging cannot be realized with the IncuCyte ${ }^{\circledR}$ S3 Live-Cell Analysis System (Essen BioScience) although the device fits in the tray holder of this microscope.

The self-fabricated microchip consisting of two polymer slabs additionally bonded to a glass slide for enhanced stability has the great advantage of an advanced cell trapping mechanism avoiding any cell removal during medium changes. Furthermore, it offers four separate channels each containing 11 chambers which results in a maximum of 44 reproduced experiments. Since it is also made of PDMS, its offers biocompatibility, inexpensiveness and transparency. Since a connection between this microdevice and a syringe pump can be established, it is suitable for long-term and automatized assays. The biggest issue of this microfluidic chip consists in its high focal distance 
which impedes focusing $T$ lymphocytes using a magnification greater than 10X. Furthermore, it is not compatible with the IncuCyte ${ }^{\circledR}$ microscope. Which additionally reduces its total score which is similar to the score reached by the third microfluidic device used for the experiments carried out in the course of this project.

The Ibidi $\mu$-Slide $\mathrm{VI}^{0,4}$ is made of a biocompatible and transparent polymer which is not clarified resulting in a low focal distance and a suitable cell culture environment. Besides, its offers six separate channels for different experimental conditions and the chips can be obtained for free in order to test them. Furthermore, the slide can be connected to syringe pumps and is compatible with the IncuCyte ${ }^{\circledR}$ microscope for automated long-term analyses. The main drawbacks of this microdevice are the lacking cell trapping mechanism. 


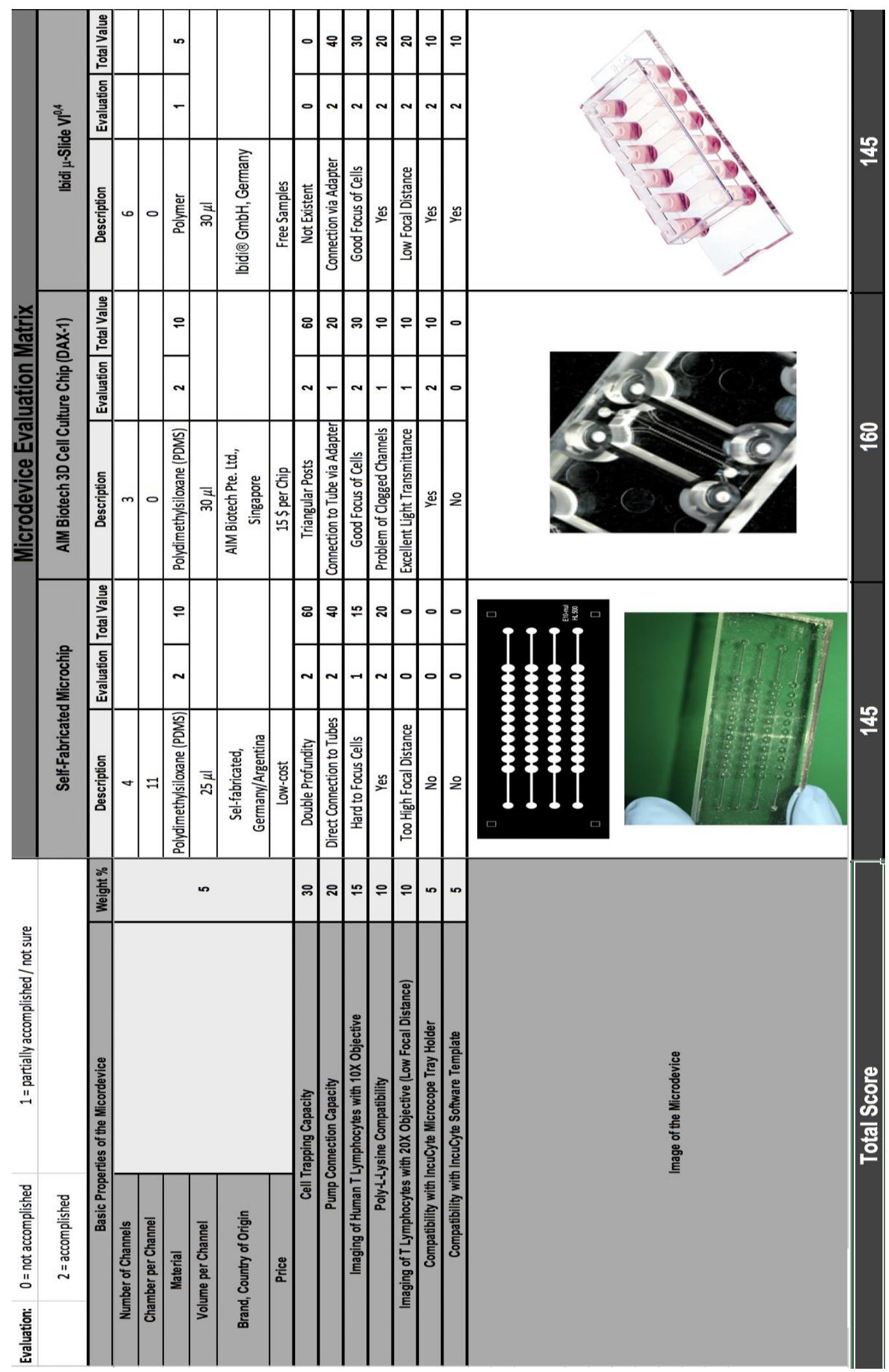

Figure 44: Evaluation matrix considering the microfluidic cell culture platforms used in the course of this thesis project 


\section{Outlook}

In the course of this thesis project, the culture conditions for T lymphocytes in microfluidic devices were optimized. This was reached by adjusting the design of a self-fabricated polymer microchip, the cell activation process and the growth factor exposure to the physiological requirements of $\mathrm{T}$ lymphocytes. Thus, the first milestone in reaching the final goal of this project that consists in developing a fully automated $T$ cell culture system that reacts to the cellular needs in real-time, is set. Furthermore, an image analysis program written in Fiji was developed in order to determine the area occupied by cells. In the near future, the cells inside the microdevice need to be imaged for longer time periods, treating them with different growth factor schedules. This intermittent treatment approach is then to be automatized by using Matlab software. This program has the purpose to use the area occupied by

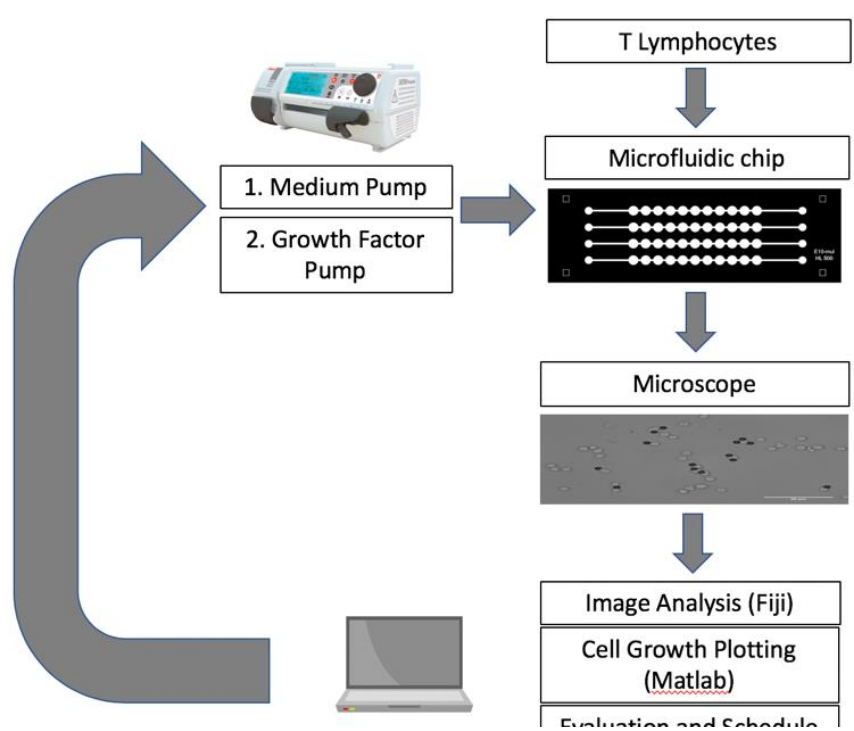

Figure 45: Closed-loop system for automated and portable T-cell culture cells calculated by the selfdeveloped image analysis software as an input in order to determine whether cell growth is declining or increasing. On basis of this information, the Matlab program will adjust the growth factor concentration and schedule. Accomplishing all those tasks, a closed-loop system will be established, providing automatization, compactness and portability

(Fig. 45).

Another future task to be realized is the development of a neuronal network that is capable of taking over the responsibility of the Matlab program. Therefore, a prolonged training phase is needed. During this learning process, 
quantity of images that show the cells in different situations (e.g. dying, growing) will be shown to the neuronal network.

When optimal automated cell culture conditions are established, the next step consists in transfecting the $T$ lymphocytes inside the microfluidic device. Hence, the cells will express a chimeric antigen receptor (CAR) specific for a tumor antigen. Furthermore, the efficacy of the CAR T-cell in killing this tumor could be also tested within the microchip. It is anticipated that an autonomous system using the feed-back-loop and subsequently optimization of culture conditions by machine learning will accelerate further development of this approach towards ultimately applying it clinically.

Since microfluidic devices as well as CAR T-cell therapy are currently stateof-the-art, they attract the interest of several companies. Carrying out CAR Tcell manufacturing in microfluidic cell culture platforms offers the possibility of drastic cost reduction making this highly efficient cancer therapy approach accessible worldwide. 


\subsubsection{Industrial Interest for Microfluidic Devices}

By now, microfluidic devices are mainly applied in laboratory environments, thus inhibiting the introduction of microfluidic products into the market. This can be explained by the still high manufacturing cost compared to some conventional methods, for example in the case of simple bedside drug screening tests. Furthermore, the complexity of microfluidic systems is often elevated since several active components are needed for efficiently performing an assay such as pumps and sensors. Consequently, most microfluidic approaches still are lacking user-friendliness. Consequently, this can be reached only by reducing the production cost on the one hand and the complexity of handling the system on the other hand since "the market [is] 'user-driven' rather than 'technology-driven"' (Sommer et al. 2009: 29). With overcoming this obstacle of convincing potential users, an increase of investments in microfluidics research could be achieved. Hence, microfluidic devices used in laboratories could be made suitable for mass production and, thus, market introduction. Currently, there can be observed a trend in large enterprises like Intel Corporation, Samsung or General Electrics establishing a division for microfluidics in their Research and Development departments. By doing this, they plan to enhance the performance of their existing products which can be seen as the first step to the commercialization of microfluidic technology (cf. Sommer et al. 2009: 28f.; Lee and Lin 2008: 386).

Moreover, the demand of potential customers of a simple, inexpensive device with several application fields has to be satisfied for successful market introduction. As a consequence, some general requirements of the respective target field have to be assessed in the device development. For the use in in vitro diagnostics, microfluidic systems need to apply a simple method for presenting the results of for example self-tests in monitoring vital parameters (e.g. blood sugar level). In the pharmaceutical industry, microfluidic devices could be used for screening and testing the potential side effects of novel drugs. These applications would require low operating costs and highthroughput via the parallelization of assays. In the agricultural industry, soil- 
and water-analyses could be altered by microfluidic methods since they are portable and offer multiplexing capabilities (cf. Mark et al. 2009: 311f.).

In summary, the commercialization and worldwide distribution of microfluidic devices could save many lives. Another aspect that supports this statement is the application of microfluidics for immunotherapies against cancer, as shown in this thesis. There is still a dependence of cancer types and survival rates - and, thus, treatment possibilities - on the socioeconomic status of the country in which patients are living (cf. Bray et al. 2018: 2). Thus, there is a need for sharing knowledge and, hence, an equalization of treatment possibilities and survival chances. This could be overcome by the simple and automatic system based on microfluidics and machine learning techniques developed in the course of this thesis. As a result, immunotherapy could be distributed as a novel and more efficient treatment strategy, outperforming the conventional cancer therapy approaches of surgery, chemotherapy and radiation (cf. Gomes-Silva and Ramos 2018: 1). 
7.1.2 Industrial Interest for CAR T-Cell Therapy

The main limitations in the commercialization of CAR T-Cell Therapy are the strong dependence on the use of autologous $T$ cells for the manufacturing process, the restriction to hematological malignancies and the occurrence of severe side effects. The former obstacle could be solved by the production of off-the-shelf CAR T-cells using donated cells. These cells could be used universally which would drastically reduce the high costs of the genetic engineering of autologous immune cells. A first step in improving the performance of CAR T-cell manufacturing from a financial view could be the use of nanotechnology. This approach could minimize costs by system miniaturization as shown in this thesis (cf. June and Sadelain 2018: 70f.; Levine et al. 2017: 92).

The use of universal CAR T-cells with non-self-origin could possibly elevate the severe side effects of adaptive cell therapies which mostly are caused by autoimmune reactions. The optimal solution of this commercialization-limiting factor would be the development of an "switch-off" mechanism to mute the interaction with the patient's immune system. Another - and currently more realistic and feasible - approach to avoid side effects is the development of prediction systems. These software-based solutions could determine the risk of autoimmunity of each patient before starting the treatment. Hence, the affinity of CARs for self-antigens potentially causing an autoimmune reaction would be defined to reach "the optimal balance between effective antitumor activity and autoimmunity in vivo" (Zhong et al. 2013: 6973) (cf. Smith, A. et al. 2016: 64f.; Zhong et al. 2013: 6973).

Another limitation in commercializing CAR T-cell therapy is the restriction in cancer types the treatment strategy can fight since it was originally designed to cure patients suffering from hematologic malignancies. In the recent past, efforts on researching the treatment of solid tumor such as melanoma with CAR T-cells have increased. These studies are supported by the fact that other immunotherapeutic approaches such as checkpoint inhibition or tumor- 
infiltrating lymphocytes (TIL) already are able to fight this cancer type. The main difficulty in applying CAR T-cells to treat solid tumors is the determination of tumor antigens expressed to the outside. This is because solid tumors normally use a highly immunosuppressive microenvironment to protect themselves (cf. Gomes-Silva and Ramos 2018: 6; June and Sadelain 2018: 70f.).

In summary, it can be said that CAR T-cell therapy not only has "the potential to transform therapy for cancer" (June and Sadelain 2018: 70) but also offers the possibility to improve the treatment of other diseases like autoimmunity inflammation or fibrosis. Hence, the therapeutic manufacturing should be adapted to be applicable worldwide, in developed countries as well as in emerging nations (cf. June and Sadelain 2018: 71). 


\section{References}

Adriani, Giulia, Pavesi, Andrea, Tan, Anthony T., Bertoletti, Antonio, Thiery, Jean Paul, Kamm, Roger D. (2016): Microfluidic models for adoptive cellmediated cancer immunotherapies, in: Drug Discovery Today, Vol. 21 (9), pp. 1472-1478

Alberts, Bruce, Johnson, Alexander, Lewis, Julian, Raff, Martin, Roberts, Keith, Walter, Peter (2008): Molecular Biology of the Cell, $5^{\text {th }}$ edition, New York: Garland Science

Althoff, Eric, Phillips, Fiona (2017): Primary analysis results from Novartis pivotal JULIET trial show Kymriah ${ }^{T M}$ (tisagenlecleucel) sustained complete responses at six months in adults with $r / r D L B C L$, a difficult-to-treat cancer, pp. 1-6 (Annex)

Baker, Monya (2016): 1,500 scientists lift the lid on reproducibility, in: Nature, Vol. 533, pp. 452-454

Boulougouris, George, McLeod, Julie D., Patel, Yusuf I., Ellwood, Claire N., Walker, Lucy S. K., Sanson, David M. (1999): IL-2-Independent Activation and Proliferation in Human T Cells Induced by CD28, in: The Journal of Immunology, Vol. 163 (4), pp. 1809-1816

Bourguignon, Natalia, Olmos, Carol M., Sierra-Rodero, Marina, Ana Peñaherrera, Rosero, Gustavo, Pineda, Pedro, Vizuete, Karla, Arroyo, Carlos R., Cumbal, Luis, Lasorsa, Carlos, Perez, Maximiliano S., Lerner, Betiana (2018: Accessible and Cost-Effective Method of PDMS Microdevices Fabrication Using a Reusable Photopolymer Mold, in: Journal of Polymer Science, Part B. Polymer Physics, pp. 1-10

Bray, Freddie, Ferlay, Jacques, Soerjomataram, Isabelle, Siegel, Rebecca L., Torre, Lindsey A., Jemal, Ahmedin (2018): Global Cancer Statistics 2018. GLOBOCAN Estimates of Incidence and Mortality Worldwide for 36 Cancers in 185 Countries, in: CA. A Cancer Journal for Clinicians, pp. 1-31 
Cantrell, Doreen A., Smith, Kendall A. (1983): Transient Expression of Interleukin 2 Receptors. Consequences for T Cell Growth, in: The Journal of Experimental Medicine, Vol. 158 (6), pp. 1895-1911

Cantrell, Doreen A., Smith, Kendall A. (1984): The Interleukin-2 T-Cell System. A New Cell Growth Model, in: Science, Vol. 224 (4655), pp. 1312-1316

Chen, Daniel S., Mellman, Ira (2013): Oncology Meets Immunology. The Cancer-Immunity Cycle, in: Immunity, Vol. 39 (1), pp. 1-10

Cantrell, D. A., Collins, M. K. L., Crumpton, M. J. (1988): Autocrine regulation of T-lymphocyte proliferation. Differential induction of IL-2 and IL-2 receptor, in: Immunology, Vol. 65, pp. 343-349

Chen, Jonathan H., Asch, Steven M. (2017): Machine Learning and Prediction in Medicine. Beyond the Peak of Inflated Expectations, in: The New England Journal of Medicine, Vol. 376 (26), pp. 2507-2509

Depper, Joel M., Leonard, Warren J., Drogula, Cynthia, Krönke, Martin, Waldmann, Thomas A., Greene, Warren C. (1985): Interleukin 2 (IL-2) augments transcription of the IL-2 receptor gene, in: Proceedings of the National Academy of Sciences, Vol. 82, pp. 4230-4234

Ding, Li, Ley, Timothy J., Larson, David E., Miller, Christopher A., Koboldt, Daniel C., Welch, John S., Ritchey, Julie K., Young, Margaret A., Lamprecht, Tamara, McLellan, Michael D., McMichael, Joshua F., Wallis, John W., Lu, Charles, Shen, Dong, Harris, Christopher C., Dooling, David J., Fulton, Robert S., Fulton, Lucinda L., Chen, Ken, Schmidt, Heather, Kalicki-Veizer, Joelle, Magrini, Vincent J. Cook, Lisa, McGrath, Sean D., Vickery, Tammi L., Wendl, Michael C., Heath, Sharon, Watson, Mark A., Link, Daniel C., Tomasson, Michael H., Shannon, William D., Payton, Jacqueline E., Kulkarni, Shashikant, Westervelt, Peter, Walter, Matthew J., Graubert, Timothy A., Mardis, Elaine R., Wilson, Richard K., DiPersio, John F. (2012): Clonal evolution in relapsed acute myeloid leukaemia revealed by whole-genome sequencing, in: Nature, Vol. 481 (7382), pp. 506-510 
Dixon, Angela R., Rajan, Shrinidhi, Kuo, Chuan-Hsien, Bersano, Tom, Wold, Rachel, Futai, Nobuyuki, Takayama, Shuichi, Mehta, Geeta (2014): Microfluidic device capable of medium recirculation for non-adherent cell culture, in: Biomicrofluidics, Vol. 8 (1) (016503), pp. 1-14

Dupuis, Gilles, Bastin, Bânû (1988): Lectin Interactions with the Jurkat Leukemic T-Cell Line. Quantitative Binding Studies and Interleukin-2 Production, in: Journal of Leukocyte Biology, Vol. 43 (3), pp. 238-247

Dura, Burak, Dougan, Stepanie K., Barisa, Marta, Hoehl, Melanie M., Lo, Catherine T., Ploegh, Hidde L., Voldman, Joel (2015): Profiling lymphocyte interactions at the single-cell level by microfluidic cell pairing, in: Nature Communications, Vol. 6 (5940), pp. 1-13

Dura, Burak, Servos, Mariah M., Barry, Rachel M., Ploegh, Hidde L., Dougan, Stepanie K., Voldman, Joel (2016): Longitudinal multiparameter assays of lymphocyte interactions from onset by microfluidic cell pairing and culture, in: Proceedings of the National Academy of Science, Vol. 113 (26), pp. E3599-608

Enriquez-Navas, Pedro M., Kam, Yoonseok, Das, Tuhin, Hassan, Sabrina, Silva, Ariosto, Foroutan, Parastou, Ruiz, Epifanio, Martinez, Gary, Minton, Susan, Gillies, Robert J., Gatenby, Robert A. (2016): Exploiting evolutionary principles to prolong tumor control in preclinical models of breast cancer, in: Science Translational Medicine, Vol. 8 (327) (327ra24), pp. 1-8

Finn, O. J. (2012): Immuno-oncology. Understanding the function and dysfunction of the immune system in cancer, in: Annals of Oncology, Vol. 23 (Suppl. 8), pp. viii6-viii9

Garstecki, P. (2009): Formation of Droplets and Bubbles in Microfluidic Systems, in: Kakaç, S., Kosoy, B., Li, D. (Eds.): Microfluidics Based Systems, Dordrecht, The Netherlands: Springer, pp. 163-182 
Gioia, Louis, Siddique, Azeem, Head, Steven R., Salomon, Daniel R., Su, Andrew I. (2018): A Genome-wide Survey of Mutations in the Jurkat Cell Line, in: BMC Genomics, Vol. 19 (1) (334), pp. 1-13

Goldman, Lee, Schafer, Andrew I. (2012): Goldman's Cecil Medicine, 24 edition, Philadelphia: Elsevier Saunders

Gomes-Silva, Diogo, Ramos, Carlos A. (2018): Cancer Immunotherapy Using CAR-T Cells. From the Research Bench to the Assembly Line, in: Biotechnology Journal, Vol. 13 (2), pp. 1-8

Greene, Warner C., Depper, Joel M., Krönke, Martin, Leonard, Warren J. (1986): The Human Interleukin-2 Receptor. Analysis of Structure and Function, in: Immunological Reviews, Vol. 92, pp. 29-48

Groten, Jenny, Borner, Christoph, Mertelsmann, Roland (2016a): Understanding and Controlling Cancer. The Hallmark Concept Revisited. Chance, Evolution and Entropy, in: Journal of Science, Humanities and Arts, Vol. 3 (7), pp. 1-57

Groten, Jenny, Georg, Maximilian, Worm, Oliver, Borner, Christoph, Mertelsmann, Roland (2016b): Towards Simulating Carcinogenesis. Modeling and Simulating Carcinogenesis, Hematopoietic Tissue Homeostasis and Leukemogenesis, in: Journal of Science, Humanities and Arts, Vol. 3 (7), pp. $1-106$

Guo, Qingwei, Zhang, Leling, Li, Fu, Jiang, Guosheng (2012): The plasticity and potential of leukemia cell lines to differentiate into dendritic cells (Review), in: Oncology Letters, Vol. 4 (4), pp. 595-600

Hanahan, Douglas, Weinberg, Robert A. (2011): Hallmarks of Cancer. The Next Generation, in: Cell, Vol. 144, pp. 646-674

Hinrichs, Christina S., Rosenberg, Steven A. (2014): Exploiting the curative potential of adoptive T-cell therapy for cancer, in: Immunological Reviews, Vol. 257 (1), pp. 56-71 
Houot, Roch, Schultz, Liora Michal, Marabelle, Aurélien, Kohrt, Holbrook (2015): T-cell-based Immunotherapy. Adoptive Cell Transfer and Checkpoint Inhibition, in: Cancer Immunology Research, Vol. 3 (10), pp. 1115-1122

Hung, Paul J., Lee, Philip J., Sabounchi, Poorya, Lin, Robert, Lee, Luke P. (2005): Continuous Perfusion Microfluidic Cell Culture Array for HighThroughput Cell-Based Assays, in: Biotechnology and Bioengineering, Vol. 89 (1), pp- 1-8

June, Carl H., Sadelain, Michel (2018): Chimeric Antigen Receptor Therapy, in: The New England Journal of Medicine, Vol. 379 (1), pp. 64-73

Kording, Konrad Paul, Benjamin, Ari, Farhoodi, Roozbeh, Glaser, Joshua (2018): Rethinking the Role of Machine Learning in Biomedical Science, in: Braun, Robert D., Bhattacharyya, Rajan, Dykes, Katherine, Gutierrez, MariaPaz, Han, Xue, Munday, Jeremy, Shanechi, Maryam, Trcka, Marija (Eds.): Frontiers of Engineering. Reports on Leading-Edge Engineering from the 2017 Symposium, Washington, DC: National Academy of Science, pp. 61-71

Lee, Abraham P., Lin, Gisela (2008): Current and Future Trends in Microfluidics within Biotechnology Research, in: Wei-Cheng Tian, Erin Finehout (Eds.): Microfluidics for Biological Applications, Boston, MA: Springer Science \& Business Media, pp. 385-411

Levine, Bruce L., Miskin, James, Wonnacott, Keith, Keir, Christopher (2017): Global Manufacturing of CAR T Cell Therapy, in: Molecular Therapy. Methods \& Clinical Development, Vol. 4, pp. 92-101

Lipkowitz, Stanley, Greene, Warner C., Rubin, Albert L., Novogrodsky, Abraham, Stenzel, Kurt H. (1984): Expression of Receptors for Interleukin 2. Role in the Commitment of T Lymphocytes to Proliferate, in: The Journal of Immunology, Vol. 132, pp. 31-37

Lin, Wei, Suo, Yuanzhen, Deng, Yuting, Fan, Zhichao, Zheng, Yijie, Wei, Xunbin, Chu, Yiwei (2015): Morphological change of $C D 4^{+} T$ cell during con- 
tact with DC modulates T-cell activation by accumulation of F-actin in the immunology synapse, in: BMC Immunology, Vol. 16: 49, pp. 1-15

Liu, Ke, Pitchimani, Rajasekar, Dang, Dana, Bayer, Keith, Harrington, Tyler, Pappas, Dimitri (2008): Cell Culture Chip Using Low-Shear Mass Transport, in: Langmuir, Vol. 24 (11), pp. 5955-5960

Manak, Michael S., Varsanik, Jonathan S., Hogan, Brad J., Whitfield, Matt J., Su, Wendell R., Joshi, Nikhil, Steinke, Nicolai, Min, Andrew, Berger, Delaney, Saphirstein, Robert J., Dixit, Gauri, Meyyappan, Thiagarajan, Chu, Hui-May, Knopf, Kevin B., Albala, David M., Sant, Grannum R., Chander, Ashok C. (2018): Live-cell phenotypic-biomarker microfluidic assay for the risk stratification of cancer patients via machine learning, in: Nature Biomedical Engineering, Vol. 2 (10), pp. 761-772

Mark, D., Haeberle, S., Roth, G., Von Stetten, F., Zengerle, R. (2009): Microfluidic Lab-on-a-Chip Platforms. Requirements, Characteristics and Applications, in: Kakaç, S., Kosoy, B., Li, D., Pramuanjaroenkij, A. (Eds.): Microfluidics Based Microsystems. Fundamentals and Applications, Çesme-Izmir, Turkey: Springer, pp. 305-376

McCormick, Scott, Tong, Ziqiu, Ivask, Angela, Morozesk, Mariana, Voelcker, Nicolas H., Lombi, Enzo, Priest, Craig (2017): Optimization of binding Blymphocytes in a microfluidic channel. Surface modification, stasis time and shear response, in: Biofabrication, Vol. 10 (1) (014101), pp. 1-14

Mehling, Matthias, Tay, Savas (2014): Microfluidic cell culture, in: Current Opinion in Biotechnology, Vol. 25, pp. 95-102

Mookerjee, Basab K., Pauly, John L. (1990): Mitogenic Effect of Interleukin-2 on Unstimulated Human T Cells. An Editorial Review, in: Journal of Clinical Laboratory Analysis, Vol. 4, pp. 138-149

Pavesi, Andrea, Tan, Anthony T., Chia, Adeline, Colombo, Marta, Antonecchia, Emanuele, Miccolis, Carlo, Ceccarello, Erica, Adriani, Giulia, Raimondi, Manuela T., Kamm, Roger D., Bertoletti, Antonio (2017): A 3D micro- 
fluidic model for preclinical evaluation of TCR-engineered T cells against solid tumors, in: JCl Insight, Vol. 2 (12) (pii: 89762), pp. 1-18

Pawelec, Graham, Borowitz, A., Krammer, Peter H., Wernet, Peter (1982): Constitutive interleukin 2 production by the JURKAT human leukemic $T$ cell line, in: European Journal of Immunology, Vol. 12 (5), pp. 387-392

Peñaherrera, A., Payés, C., Sierra-Rodero, M., Vega, M., Rosero, G., Lerner, B., Helguera, G., Pérez, M. S. (2016): Evaluation of cell culture in microfluidic chips for application in monoclonal antibody production, in: Microelectronic Engineering, Vol. 158 (C), pp. 126-129

Rajagopal, Sudarshan, Shenoy, Sudha K. (2018): GPCR desensitization. Acute and prolonged phases, in: Cellular Signaling, Vol. 41, pp. 9-16

Robb, Richard J., Lin, Yuan (1984): T-Cell Growth Factor. Purification, Interaction with a Cellular Receptor, and in Vitro Synthesis, in: Goldstein, Allan L. (Ed.): Thymic Hormones and Lymphokines. Basic Chemistry and Clinical Applications, New York: Plenum Press, pp. 247-256

Rosenberg, Steven A., Packard, Beverly S., Aebersold, Paul M., Solomon, Diane, Topalian, Suzanne L., Toy, Stephen T., Simon, Paul, Lotze, Michael T., Yang, James C., Seipp, Claudia A., Simpson, Colleen, Carter, Charles, Bock, Steven, Schwartzentruber, Douglas, Wei, John P., White, Donald E. (1988): Use of Tumor-Infiltrating Lymphocytes and Interleukin-2 in the Immunotherapy of Patients with Metastatic Melanoma, in: The New England Journal of Medicine, Vol. 319: 25, pp. 1676-1680

Sarkar, Saheli, Motwani, Vinny, Sabhachandani, Pooja, Cohen, Noa, Korny, Tania (2015): T Cell Dynamic Activation and Functional Analysis in Nanoliter Droplet Microarray, in: Journal of Clinical Cell Immunology, Vol. 6 (3) (pii:334), pp. 1-18

Schneider, Ulrich, Schwenk, Hans-Ulrich, Bornkamm, Georg (1977): Characterization of EBV-Genome Negative "Null" and "T" Cell Lines Derived from Children with Acute Lymphoblastic Leukemia and Leukemic Transformed 
Non-Hodgkin Lymphoma, in: International Journal of Cancer, Vol. 19 (5), pp. 621-626

Seah, Yu Fen Samantha, Hu, Hongxing, Merten, Christoph A. (2018): Microfluidic single-cell technology in immunology and antibody screening, in: Molecular Aspects of Medicine, Vol. 59, pp. 47-61

Shah, Pranjul, Vedarethinam, Indumathi, Kwasny, Dorota, Andresen, Lars, Dimaki, Maris, Skov, Søren, Svendsen, Winnie, Edith (2011): Microfluidic bioreactors for culture of non-adherent cells, in: Sensors and Actuators B, Vol. 156 (15), pp. 1002-1008

Smith, Aaron J., Oertle, John, Warren, Dan, Prato, Dino (2016): Chimeric antigen receptor (CAR) T cell therapy for malignant cancers. Summary and perspective, in: Journal of Cellular Immunotherapy, Vol. 2 (2), pp. 59-68

Smith, Edvard, Holmdahl, Rikard, Kämpe, Olle, Kärre, Klas (2018): Scientific Background. Discovery of cancer therapy by inhibition of negative immune regulation, in: Nobelförsamlingen. The Nobel Assembly at Karolinska Institutet, pp. 1-15 (Annex)

Smith-Garvin, Jennifer E., Koretzky, Gary A., Jordan, Martha S. (2009): T Cell Activation, in: The Annual Review of Immunology, Vol. 27, pp. 591-619

Sommer, Greg J., Chang, Dustin S., Jain, Akshat, Langelier, Sean M., Park, Jihyang, Rhee, Minsoung, Wang, Fang, Zeitoun, Ramsey I., Burns, Mark A. (2009): Introduction to microfluidics, in: Wei-Cheng Tian, Erin Finehout (Eds.): Microfluidics for Biological Applications, Boston, MA: Springer Science \& Business Media, pp. 1-34

Stewart, Carleton C., Cramer, Stewart F., Steward, Palmer G. (1975): The Response of Human Peripheral Blood Lymphocytes to Phytohemagglutinin. Determination of Cell Numbers, in: Cellular Immunology, Vol. 16, pp. 237-250 Trickett, Annette, Kwan, Yiu Lam (2003): T cell stimulation and expansion using anti-CD3/CD28 beads, in: Journal of Immunological Methods, Vol. 275 (1-2), pp. 251-255 
Zhang, Chi, van Noort, Danny (2011): Cells in Microfluidics, in: Topics in Current Chemistry, Vol. 304, pp. 295-321

Zhao, Zijun, Chen, Yu, Ngiambudulu, Francisco M., Zhang, Yuanqing, Wu, Minhoa (2018): The application of CAR-T cell therapy in hematological malignancies. Advantages and challenges, in: Acta Pharmaceutica Sinica B, Vol. 8 (4), pp. 359-551

Zhong, Shi, Malecek, Karolina, Johnson, Laura A., Yu, Zhiya, Vega-Saenz de Miera, Eleazar, Darvishian, Farbod, McGary, Katelyn, Huang, Kevin, Boyer, Josh, Corse, Emily, Shao, Yongzhao, Rosenberg, Steven A., Restifo, Nicholas P., Osman, Iman, Krogsgaard, Michelle (2013): T-cell receptor affinity and avidity defines antitumor response and autoimmunity in T-cell immunotherapy, in: Proceedings of the National Academy of Science, Vol. 110 (17), pp. 6973-6978

Wang, Xiuyan, Rivère, Isabelle (2016): Clinical manufacturing of CAR T cells. Foundation of a promising therapy, in: Molecular Therapy - Oncolytics, Vol. 3, 16015, pp. 1-7

Willyard, Cassandra (2016): Cancer. An Evolving Threat, in: Nature, Vol. 532, pp. 166-168

\section{Author Information}

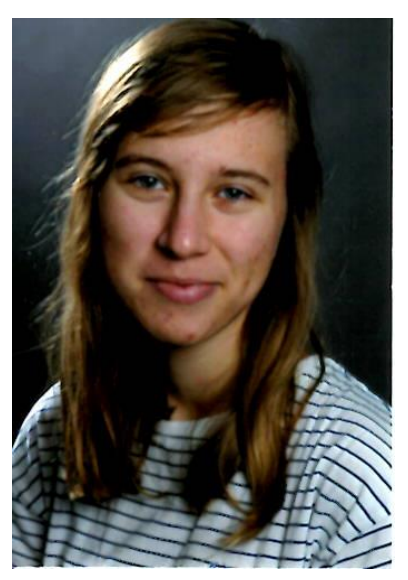

Julia Pinter is a medical engineer currently enrolled in the Master's program of Biomedical Engineering at the Hochschule Furtwangen University, Germany. Her scientific interest in microfluidic cell culture and immunotherapeutic approaches to cancer therapy originates from her internship in the Laboratory for Biochemistry of the University of Buenos Aires, Argentina. After receiving her Master's degree, she plans to do her PhD in this research field. 